\title{
p53, SKP2, and DKK3 as MYCN target genes and their potential therapeutic significance
}

\section{Lindi Chen and Deborah A. Tweddle*}

Newcastle Cancer Centre, Northern Institute for Cancer Research, Newcastle University, Newcastle, UK

Edited by:

Arturo Sala, Brunel University/UCL Institute of Child Health, UK

\section{Reviewed by:}

Paolo Salomoni, University College

London Cancer Institute, UK

Giuseppe Raschellà, ENEA, Italy

*Correspondence:

Deborah A. Tweddle, Newcastle

Cancer Centre, Northern Institute for

Cancer Research, Newcastle

University, Newcastle upon Tyne NE2

$4 H H, U K$.

e-mail: deborah.tweddle@ncl.ac.uk
Neuroblastoma is the most common extra-cranial solid tumor of childhood. Despite significant advances, it currently still remains one of the most difficult childhood cancers to cure, with less than $40 \%$ of patients with high-risk disease being long-term survivors. MYCN is a proto-oncogene implicated to be directly involved in neuroblastoma development. Amplification of MYCN is associated with rapid tumor progression and poor prognosis. Novel therapeutic strategies which can improve the survival rates whilst reducing the toxicity in these patients are therefore required. Here we discuss genes regulated by MYCN in neuroblastoma, with particular reference to $p 53, S K P 2$, and $D K K 3$ and strategies that may be employed to target them.

Keywords: neuroblastoma, MYCN, p53, SKP2, DKK3, MDM2-p53 antagonists

\section{INTRODUCTION}

Neuroblastoma, an embryonal malignancy of the developing neural crest, is the most common extra-cranial solid tumor of childhood. It accounts for $8-10 \%$ of all pediatric cancers and $15 \%$ of childhood cancer mortality (Park et al., 2010). Over 50\% of patients present with high-risk metastatic disease at the time of diagnosis and most will respond to intensive multi-modal therapy despite significant acute toxicities. However relapse with chemoresistant disease is common and the overall long-term survival of high-risk patients currently remains less than $40 \%$, with those that survive often having long-term toxicities. Thus there is a continuing need to identify novel, less toxic therapies that will ultimately improve the survival of this subset of patients. A typical feature of high-risk disease is $M Y C N$ amplification which occurs in $~ 25 \%$ of neuroblastoma, associating with rapid tumor progression and a poor prognosis (reviewed by Cohn and Tweddle, 2004). MYCN is a proto-oncogene directly involved in neuroblastoma tumorigenesis, evident by the spontaneous development of neuroblastoma in a MYCN dose-dependent manner in transgenic murine models (Weiss et al., 1997).

Direct inhibition of MYCN has not yet been clinically successful (Gustafson and Weiss, 2010), consequently there is a focus on developing therapeutic strategies directed at destabilizing MYCN protein, and at the downstream targets or pathways which mediate the oncogenic functions of MYCN, and drive the aggressive behavior and progression of MYCN amplified tumors. This review will focus on three selected MYCN target genes $p 53$, SKP2, and DKK3, which we have previously identified as being directly or indirectly regulated by MYCN (Bell et al., 2007a; Chen et al., 2010), and strategies that are now being or could be employed in the future to target them, particularly in $M Y C N$ amplified neuroblastoma.

\section{MYCN}

MYCN belongs to the MYC family of basic-helix-loop-helixleucine zipper (bHLH-LZ) transcription factors which also includes c-MYC, and MYCL. Deregulated expression of Myc family members have been implicated in the genesis of several human cancers. Consistent with this, studies have shown that MYC contributes to numerous aspects of tumorigenesis including unrestricted cellular growth and proliferation, angiogenesis, inhibition of differentiation, metastasis, genomic instability, and reduced cell adhesion (reviewed by Adhikary and Eilers, 2005).

The MYCN gene located at $2 \mathrm{p} 24$ encodes a $64 \mathrm{kDa}$ nuclear phosphoprotein, which contains a transcriptional activation domain at the $\mathrm{N}$-terminal, and a transcriptional regulation domain with a bHLH-LZ motif at the C-terminal (Schwab, 2000). In contrast to c-MYC, which is expressed in a wide variety of embryonic and adult tissues, MYCN expression is limited to the developing nervous system and selected other sites (Cohn and Ikegaki, 2000).

\section{TRANSACTIVATION AND REPRESSION OF TARGET GENES BY MYCN}

MYC proteins function as active heterodimers with MAX via their conserved bHLH-LZ domains to exert transcriptional activation via direct binding to E-Box motifs (CANNTG) within target gene promoters and the subsequent recruitment of multiple transcriptional coactivators. Heterodimerization with MAX is required for direct binding of MYC proteins to DNA. Myc family members have short half-lives and their expression levels are highly regulated. In contrast, MAX is stable and constitutively expressed, and normally present in stoichiometric excess to MYC, which suggests that the abundance of active heterodimers is dependent on the levels of MYC proteins (reviewed by Grandori et al., 2000).

In contrast to transactivation mediated by MYC, transcriptional repression is independent of E-Box binding and has been shown to involve recruitment of MYC proteins to target gene promoters by Miz-1 and disruption of the interaction between transcriptional complexes. MYC mediated transcriptional repression via Miz-1 has been shown for $p 15^{I N K 4 B}$ (Staller et al., 2001) and $p 21^{C I P 1}$ (Seoane et al., 2002). Other candidate proteins which have been 
proposed to recruit MYC to core promoters include TFII-I, NFY, YY-1, and SP1 (reviewed by Wanzel et al., 2003; Adhikary and Eilers, 2005).

\section{IDENTIFYING MYCN TARGET GENES}

The identification of MYCN target genes enables a greater understanding of MYCN driven neuroblastoma tumorigenesis and promotes the identification of potential targets for therapeutic intervention in the treatment of neuroblastoma. A vast number of c-MYC target genes have been identified and can be found at http://myccancergene.org/site/mycTargetDB.asp (Zeller et al., 2003), however less is known about the target genes of MYCN. It has been estimated that MYC is bound to $\sim 25,000$ sites within the human genome (reviewed by Adhikary and Eilers, 2005). Early studies found that several c-MYC target genes were expressed in some neuroblastoma cell lines with MYCN amplification, but not all, suggesting that other cell specific factors may be important (Ben-Yosef et al., 1998). More recent studies have reported significant overlap between c-MYC and MYCN-regulated gene sets (Laurenti et al., 2008; Westermann et al., 2008).

Target genes downstream of MYCN can be classified as direct or indirect. Direct target genes of MYCN can be defined as genes which possess a MYCN binding E-Box motif located within close proximity to the transcriptional start site of the gene and/or for which MYCN has been shown to directly bind to the gene promoter to drive transcription. This involves using methods such as electrophoretic mobility shift assay (EMSA), reporter gene assays, and/or more recently Chromatin Immunoprecipitation (ChIP) analysis, a technique which allows specific protein-DNA interactions to be isolated. Indirect target genes of MYCN are genes which are altered as a consequence of other genes or pathways that are directly regulated by MYCN (Bell et al., 2010).

There are several approaches used to identify target genes of transcription factors such as MYCN. The candidate gene approach involves selecting genes which are involved in the known biological functions of MYCN, such as cell proliferation. Furthermore due to the homology between the $M y c$ family members, the candidate gene approach is often used to determine whether previously known c-MYC target genes are also MYCN target genes (Bell et al., 2010). Alternatively, the inference approach is used and is based on identifying putative target genes by the presence of MYCN/MAX binding sites within their gene regulatory regions (Dang, 1999). Moreover, target genes may also be identified based on their differential expression in conditions with varying MYCN expression levels, such as MYCN regulatable expression systems or comparing MYCN amplified versus non-amplified cell lines and/or tumors. The latter is often performed using microarray based genome-wide approaches (reviewed by Bell et al., 2010).

More recently, with the development of ChIP and advances in technology, genome-wide in vivo approaches for identifying protein-DNA interactions have become available, including ChIPcloning, ChIP-chip, and the latest and increasingly popular, ChIPseq. These techniques enable the identification of direct target genes, and the specific in vivo binding sites within the genome without prior knowledge. Direct targets may be further confirmed using quantitative PCR based ChIP analysis (Wu et al., 2006). Interestingly, a ChIP-chip array study of MYCN/c-MYC target genes in neuroblastoma demonstrated that distinct MYCN/c-MYC target gene expression was associated with overall survival, and independent of well-established markers such as MYCN amplification, disease stage, and age at diagnosis (Westermann et al., 2008).

p53

p53 was discovered over three decades ago as one of the first tumor suppressors (Lane and Crawford, 1979; Linzer and Levine, 1979) and has since been shown to be the most frequently mutated gene in human cancer. p53 is involved in the regulation of several processes that contribute to its central role in maintaining genomic stability and tumor suppression, including cell cycle arrest, apoptosis, senescence, differentiation, autophagy, DNA repair, angiogenesis, cell migration, metabolism, and the immune response. The TP53 gene located at chromosome position 17p13.1 encodes a $53 \mathrm{kDa}$ nuclear phosphoprotein that consists of an N-terminal transactivation domain (TAD), a central sequence-specific DNA binding domain (DBD), a tetramerization domain, and a highly basic C-terminal regulatory domain. Nuclear export signals (NES) are located within both the $\mathrm{N}$ - and C-termini, and three lysinerich nuclear localization signals (NLS) are located within the C-terminal (reviewed by Bai and Zhu, 2006). Identified more recently, p63 and p73 are two homologs which share structural and functional similarity to p53 and belong to the p53 family (reviewed by Levrero et al., 2000).

\section{THE p53/MDM2/p14 ${ }^{\text {ARF }}$ PATHWAY}

Under normal cellular conditions, p53 is maintained at low levels mainly due to MDM2, an E3 ubiquitin ligase and the critical negative regulator of p53 (Honda et al., 1997). This is supported by the observed embryonic lethality of MDM2 knockout mice and their rescue by the concomitant deletion of p53 (Jones et al., 1995; Montes de Oca Luna et al., 1995). MDM2 is a direct transcriptional target of p53 and is induced in response to p53 activation thereby forming a tightly regulated negative feedback loop. MDM2 directly binds to the N-terminal TAD of p53 to inhibit p53 transcriptional activity (Momand et al., 1992), as well as promoting nuclear export and targeting p53 for ubiquitin mediated proteasome degradation (Honda et al., 1997; Tao and Levine, 1999a). p14 ${ }^{\mathrm{ARF}}$ is a tumor suppressor and the negative regulator of MDM2. Studies have shown that $\mathrm{p} 14^{\mathrm{ARF}}$ promotes $\mathrm{p} 53$ stability and activity by inhibiting MDM2-mediated degradation of p53 via direct interaction with MDM2 and inhibiting its E3 ligase activity (Honda and Yasuda, 1999), preventing MDM2 and p53 nuclear export (Tao and Levine, 1999b), sequestering MDM2 within the nucleolus (Weber et al., 1999), and also by promoting MDM2 degradation (Zhang et al., 1998). Activated p53 can subsequently downregulate the expression of p14 ${ }^{A R F}$ (Robertson and Jones, 1998; Stott et al., 1998). MDMX is a homolog of MDM2 and a negative regulator of p53. It has been shown to enhance MDM2-mediated ubiquitination and degradation of $\mathrm{p} 53$, and repress $\mathrm{p} 53$-mediated transcription (reviewed by Marine et al., 2007; Kruse and Gu, 2009). Interestingly, MDM2 can promote ubiquitination and degradation of MDMX, an effect which is stimulated by $\mathrm{p} 14^{\mathrm{ARF}}$ and which correlates with the ability of $\mathrm{p} 14^{\mathrm{ARF}}$ to bind MDM2 (Pan and Chen, 2003; Figure 1). 


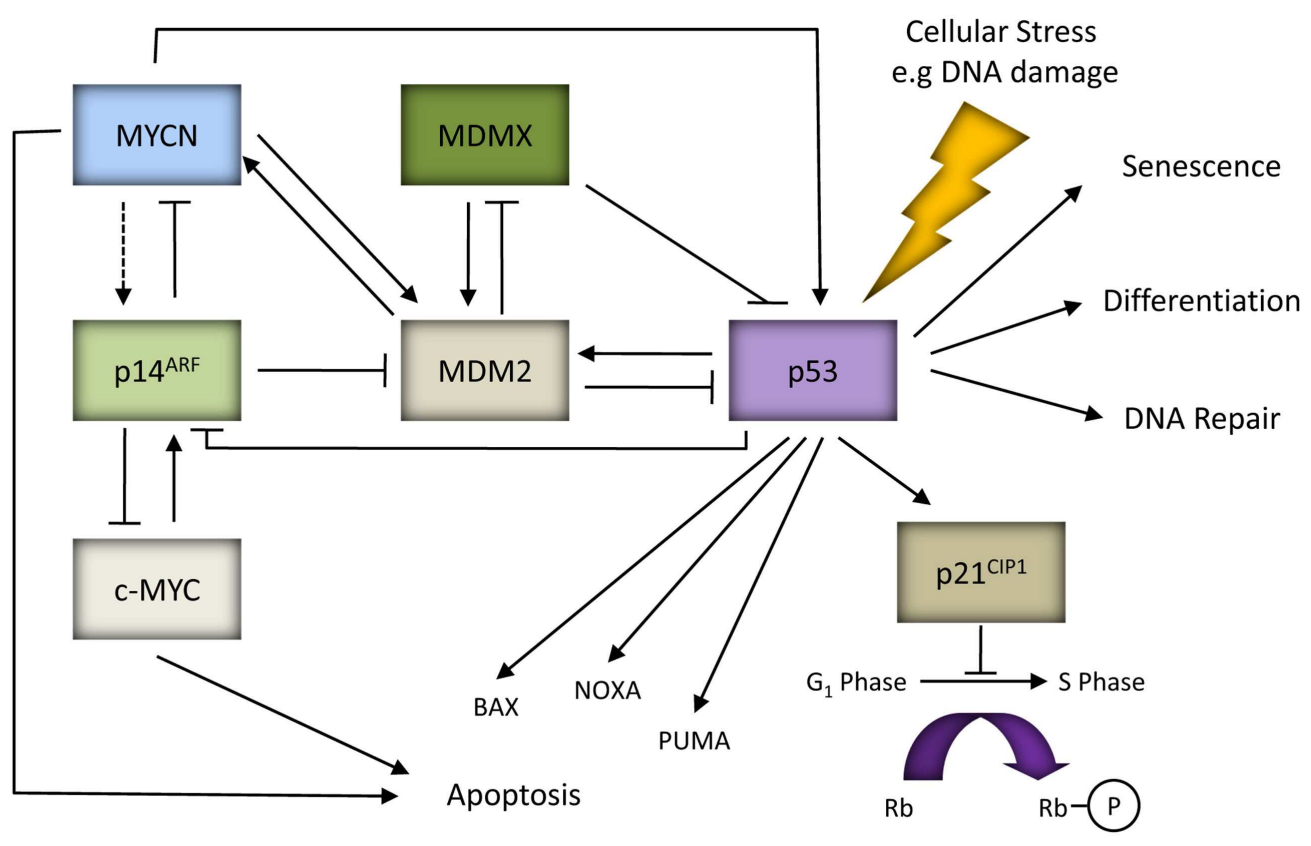

Cell Cycle Arrest

FIGURE 1 | MYC proteins and the p53/MDM2/p14 ARF pathway. In response to cellular stresses p53 can mediate the expression of genes involved in various cellular responses such as apoptosis (e.g., BAX, NOXA and PUMA), cell cycle arrest (e.g., p21 ${ }^{\mathrm{CIP} 1}$ ), differentiation, DNA repair or senescence. p53, MDM2 and p14 ${ }^{\mathrm{ARF}}$ form an autoregulatory feedback loop to tightly regulate $\mathrm{p} 53$ expression and activity. p14 ${ }^{\mathrm{ARF}}$ can be activated in

\section{ACTIVATION AND FUNCTION OF p53}

In response to a variety of intrinsic and extrinsic cellular stresses such as DNA damage, oncogenic activation, deprivation of growth factors/signals, ribonucleotide depletion, microtubule disruption, and hypoxia, there is stabilization, nuclear accumulation, and activation of $\mathrm{p} 53$. This is predominantly regulated by posttranslational modifications conferred on the p53 protein, such as phosphorylation, ubiquitylation, acetylation, and sumoylation (Bode and Dong, 2004). N-terminal modifications of p53 act to inhibit the p53-MDM2 interaction thereby preventing MDM2mediated inactivation and degradation of $\mathrm{p} 53$. In addition, modifications within the DBD and C-terminal of p53 have been shown to increase p53 sequence-specific DNA binding and relieve the inhibitory effect of the C-terminal regulatory domain on the core DBD of p53, respectively (reviewed by Appella and Anderson, 2001). Once activated, p53 initiates cellular responses via transcriptional regulation of a vast repertoire of downstream target genes encoding proteins and microRNAs (miRNAs), as well as transcriptional independent functions. The type of response can be dependent on several factors that are both extrinsic and intrinsic to the cell, such as cell type, cellular environment, oncogenic lesions present in the cell, and also stress type (Jimenez et al., 1999; Vousden and Lu, 2002).

p53 functions as an active tetramer to directly bind to a consensus p53 DNA binding sequence consisting of two adjacent 10 bp half-sites $5^{\prime}$-RRRCWWGYYY-3' $(R=\mathrm{A}$ or $\mathrm{G}, Y=\mathrm{C}$ or $\mathrm{T}$, response to aberrant oncogenic factors such as c-MYC, and possibly MYCN (as indicated by the dashed line). p14 ${ }^{\mathrm{ARF}}$ can also exhibit p53-independent tumor suppressor activity by directly binding and inhibiting the activity of C-MYC and MYCN. Both p53 and MDM2 are direct target genes of MYCN. MDM2 can regulate $M Y C N$ mRNA stability and translation, thereby forming a positive feedback loop.
$W=\mathrm{A}$ or $\mathrm{T})$, separated by $0-13 \mathrm{bp}$, located within the promoters of downstream target genes (el-Deiry et al., 1992). In contrast, most genes which are repressed by p53 tend to lack p53 DNA binding sites within their promoters (Mirza et al., 2003). To date several mechanisms for p53-mediated transcriptional repression have been identified (reviewed by Wang et al., 2010a; Bohlig and Rother, 2011). The total number of p53 target genes is unknown however it has been shown that 4852 genes within the human genome contain at least one consensus p53 DNA binding site. Furthermore, the identification of non-consensus p53 binding sites also contributes to the ever expanding repertoire of p53 target genes (reviewed by Menendez et al., 2009). p53 target genes have been previously reviewed (Mirza et al., 2003; Harms et al., 2004; Nakamura, 2004; Riley et al., 2008; Wang et al., 2010a).

In recent years, p53 has also been shown to regulate the transcriptional expression and maturation of miRNAs, a class of endogenously expressed small ( $\sim 18-25 \mathrm{nt}$ ) non-coding RNA molecules involved in post-transcriptional regulation of gene expression (Lujambio and Lowe, 2012). p53 has been found to upregulate the expression of the miR-34 cluster which is reported to mediate several tumor suppressive functions of p53 including senescence, cell cycle arrest, and apoptosis (Bommer et al., 2007; Chang et al., 2007; He et al., 2007; Raver-Shapira et al., 2007; Tarasov et al., 2007). Consistent with this, reduced levels of $m i R-34$ have been observed in both tumors and cell lines, including neuroblastoma (Bommer et al., 2007; Chang et al., 2007; Tarasov et al., 2007; 
Welch et al., 2007; Feinberg-Gorenshtein et al., 2009). Additionally, p53 has also been reported to induce the expression of $m i R-192$, $m i R-215, m i R-145$, and $m i R-107$, of which $m i R-145$ was shown to inhibit c-MYC expression (Braun et al., 2008; Georges et al., 2008; Sachdeva et al., 2009; Yamakuchi et al., 2010). Conversely, several miRNAs have been found to regulate the abundance and activity of $\mathrm{p} 53$, such as $m i R-380-5 p$, which is associated with poor outcome in MYCN amplified neuroblastoma (Swarbrick et al., 2010).

p53 is also able to exert functions via protein-protein interactions, and several proteins involved in cell cycle control, DNA repair, gene transcription, and apoptosis have been shown to bind to p53 (Moll et al., 2005; Braithwaite et al., 2006; Speidel et al., 2006). Although p53 is a nuclear protein, a fraction of $\mathrm{p} 53$ has been found within the cytoplasm, exhibiting non-nuclear transcriptional independent activities. Cytoplasmic p53 has been reported to directly interact with members of the BCL2 family including anti-apoptotic BCLxL and BCL2, and proapoptotic BAX and BAK which result in mitochondria membrane permeability, release of cytochrome C, and apoptosis (reviewed by Moll et al., 2005).

\section{p53 PATHWAY INACTIVATION AND CANCER}

The crucial role p53 plays in tumor suppression is emphasized by observations that the $\mathrm{p} 53$ pathway is abrogated in around half of all cancers due to an inactivating p53 mutation, and the rest have impaired upstream or downstream p53 pathways (Brown et al., 2009). This is further supported by the severe predisposition to cancers observed in individuals with Li-Fraumeni syndrome (Evans and Lozano, 1997). Additionally, p53 null mice are reported to develop a range of spontaneous tumors, most commonly T-cell lymphomas (Donehower, 1996).

The frequency of $p 53$ mutations varies from 10 to $70 \%$ across different cancers types, and are more common in solid tumors compared with hematological malignancies (Calin et al., 1999; Soussi et al., 2000). The majority are missense mutations resulting in single amino acid substitutions and map within the DBD of p53 (Brosh and Rotter, 2009). In tumors and cell lines, mutational inactivation predominantly leads to the accumulation of high levels of mutant p53 protein. Some p53 mutants have been shown to exert a dominant negative effect on wild-type (wt) p53 owing to the requirement for p53 to function as an active tetramer (Vousden and Lu, 2002). p53 mutations identified to date can be found within publically available p53 databases such as The International Agency for Research on Cancer (IARC) TP53 Mutation Database $^{1}$ and The $\mathrm{p} 53$ Website ${ }^{2}$. In addition to loss of tumor suppressive function and exerting dominant negative effects against wt p53, it has become increasingly evident that p53 mutants can exhibit new functions independent of wt p53 and can vary depending on the mutation. These new gain-of-function mutants have been reported to play a role in promoting tumorigenesis including increased metastasis and genomic instability, and resistance to anti-cancer therapies (reviewed by Xu, 2008; Brosh and Rotter, 2009; Oren and Rotter, 2010; Hanel and Moll, 2012). Studies using murine models have observed that mutant $p 53$ knock-in mice develop more aggressive and metastatic tumors in comparison to

\footnotetext{
${ }^{1}$ http://www-p53.iarc.fr/

${ }^{2}$ http://p53.free.fr/
}

p53 null mice, and that the different p53 mutants are associated with distinct tumor patterns (Lang et al., 2004; Olive et al., 2004; Lozano, 2007; Song et al., 2007; Oren and Rotter, 2010).

The prognostic and predictive significance of $p 53$ somatic mutations in human cancer have been extensively evaluated over the past 15 years however due to inconsistencies have failed to reach clinical practice to guide treatment. This has predominantly been attributed to the use of immunohistochemistry to detect p53 accumulation as a marker of $p 53$ mutational inactivation which is inaccurate as this detects both wt and mutant p53 in most cases. More recent studies which have used gene sequencing to determine $p 53$ status have obtained more consistent results. There is a general trend associating $p 53$ mutations with a poor prognosis and resistance to chemo- and radiotherapy. This has been shown for malignancies of the breast, head and neck, colorectum, and hematopoietic system (Brosh and Rotter, 2009; Olivier and Taniere, 2011).

In addition to $p 53$ mutations, amplification, and/or overexpression of MDM2 or MDMX, as well as $p 14^{A R F}$ mutation, deletion, or methylation can also lead to abrogation of the p53 pathway (reviewed by Brown et al., 2009). Similar to p53 null mice, mice deficient in $p 14^{A R F}$, or overexpressing MDM2 or MDMX also developed spontaneous tumors, albeit at a slower rate (Jones et al., 1998; Kamijo et al., 1999; Xiong et al., 2010). Abrogation of p53 function may also occur as the result of viral inactivation such as the human papillomavirus, or impaired upstream signaling and/or downstream mediators of p53 function, such as inactivation of $A T M$ or $C H K 2$, or genes involved in the apoptotic response, and/or cell cycle arrest. Although it is not clear why certain mechanisms of 553 pathway inactivation are favored in some tumors but not others, it is likely to be influenced by the various selective pressures acting upon the cancer (Junttila and Evan, 2009).

Interestingly in contrast to $p 53, p 63$, and $p 73$ are rarely mutated in human cancers and neither $p 63$ nor $p 73$ knockout mice exhibit an increased susceptibility to developing spontaneous tumors (Moll and Slade, 2004).

\section{p53 AND NEUROBLASTOMA \\ p53 accumulation and function in neuroblastoma}

In contrast to many other human cancers, $p 53$ mutations in neuroblastoma are rare, occurring in $\sim 3 \%$ of cases analyzed to date (Imamura et al., 1993; Komuro et al., 1993; Ohgaki et al., 1993; Vogan et al., 1993; Castresana et al., 1994; Hosoi et al., 1994; Kusafuka et al., 1997; Manhani et al., 1997; Omura-Minamisawa et al., 2001; Tweddle et al., 2001b; Carr-Wilkinson et al., 2010). Despite this, p53 has been reported to accumulate in neuroblastoma, which has been suggested to be due to the embryonic nature of these tumors, reflecting a failure of precursor cells to mature (Sidell and Koeffler, 1988; Davidoff et al., 1992). This is consistent with studies which have shown a decrease in p53 expression following retinoic acid induced in vitro differentiation of neuroblastoma cell lines (Sidell and Koeffler, 1988; Davidoff et al., 1992; Chen et al., 2007), and also during neuronal development/differentiation (Eizenberg et al., 1996; Ferreira and Kosik, 1996). In addition siRNA mediated inhibition of p53 in neuroblastoma cell lines led to morphological evidence of differentiation (Carr-Wilkinson et al., 2011). The presence of high levels of accumulated wt p53 
suggests that neuroblastoma circumvent the tumor suppressive properties of p53 by a mechanism independent of mutation. Early studies reported cytoplasmic sequestration of wt p53 as a nonmutational mechanism for p53 inactivation and accumulation in neuroblastoma (Moll et al., 1995, 1996). To date several mechanisms for cytoplasmic sequestration of p53 in neuroblastoma have been proposed, including masking of the p53 C-terminal nuclear localization signal (Ostermeyer et al., 1996), hyperactive nuclear export (Stommel et al., 1999), binding to the cytoplasmic anchor, Parc (Nikolaev and Gu, 2003; Nikolaev et al., 2003), aberrant hyperubiquitylation of p53 (Becker et al., 2007), and MDMX and MDM2-mediated cytoplasmic tethering (Ohtsubo et al., 2009). In contrast, a number of studies including our own have reported predominantly nuclear localization and/or functional p53 in neuroblastoma (Layfield et al., 1995; Hoehner et al., 1997; Danks et al., 1998; Isaacs et al., 1998; McKenzie et al., 1999; Smart et al., 1999; Keshelava et al., 2000, 2001; Tweddle et al., 2001a,b; Cui et al., 2002; Goldschneider et al., 2004; Chen et al., 2007, 2010; Xue et al., 2007; Kurata et al., 2008; Van Maerken et al., 2011; Gamble et al., 2012). The conflicting results over the localization and function of p53 are likely to be due to the different p53 antibodies and the criteria used to define functional p53. Interestingly, despite functional, transcriptionally active p53, we have previously reported a failure for MYCN amplified neuroblastoma cells to $\mathrm{G}_{1}$ arrest after DNA damage (Tweddle et al., 2001b; Bell et al., 2006) and have recently shown that the outcome of the p53-mediated response to DNA damage in neuroblastoma cell lines is determined by both morphological subtype (neuronal or substrate adherent) and MYCN expression (Carr-Wilkinson et al., 2011).

Inactivation of the p53 pathway and resistance to cytotoxic therapy Most neuroblastomas initially respond well to cytotoxic agents however the disease frequently relapses with acquired resistance to therapy thus posing a major problem in the treatment of patients with high-risk neuroblastoma. Consequently, gaining a greater understanding into the mechanisms behind resistance to cytotoxic therapies could lead to the development and use of novel therapies in progressing or relapsed disease (Tweddle et al., 2001a). An important mechanism for chemo- and radioresistance is inactivation of the p53 pathway (reviewed by Levine, 1997). The initial good response to chemotherapy may be partly due to the presence of functional p53 at diagnosis, and the development of resistance at relapse may be the result of acquired p53 inactivation at a later stage (reviewed by Tweddle et al., 2003). Consistent with this, of the few $p 53$ mutations which have been identified in neuroblastoma to date, the majority were in tumors from patients with progressive or relapsed disease and/or post-chemotherapy (Imamura et al., 1993; Komuro et al., 1993; Ohgaki et al., 1993; Vogan et al., 1993; Castresana et al., 1994; Hosoi et al., 1994; Kusafuka et al., 1997; Manhani et al., 1997; Omura-Minamisawa et al., 2001; Tweddle et al., 2001b; Carr-Wilkinson et al., 2010). Similarly, despite the frequency being slightly higher than those in tumors, p53 mutations in neuroblastoma cell lines are also rare, and the majority were also identified in cell lines established at relapse (Tweddle et al., 2003; Carr et al., 2006; Table 1).

Using a pair of neuroblastoma cell lines derived from the same patient, before and after cytotoxic therapy, we previously demonstrated that the cell line derived after therapy, at disease relapse, had mutant non-functional p53, and was more resistant to chemotherapy compared to the cell line derived at diagnosis before therapy, which had wt functional p53 (Tweddle et al., 2001a). Other studies have also correlated loss of p53 function with drug resistance in neuroblastoma cell lines, and found that transfection of wt p53 drug sensitive cell lines with E6 vectors led to chemoresistance (Keshelava et al., 2000, 2001). In line with these observations, we recently reported that the presence of a p53 mutation was independently prognostic for overall survival in neuroblastoma patients (Carr-Wilkinson et al., 2010).

In addition to $p 53$ mutations, MDM 2 amplification, and $p 14^{A R F}$ deletion or methylation have also been reported in neuroblastoma tumors and cell lines, most of which were from patients with progressive or relapsed disease and/or post-chemotherapy (Corvi et al., 1995; Omura-Minamisawa et al., 2001; Thompson et al., 2001; Gonzalez-Gomez et al., 2003; Su et al., 2004; Carr et al., 2006; Spitz et al., 2006; Caren et al., 2008; Carr-Wilkinson et al., 2010; Wolf et al., 2010). Interestingly, in our recent study of paired neuroblastoma tumors established at diagnosis and relapse which demonstrated a high frequency of $\mathrm{p} 53 / \mathrm{MDM} 2 / \mathrm{p} 14^{\mathrm{ARF}}$ pathway abnormalities in relapsed neuroblastoma, a higher frequency of abnormalities involving MDM2 amplification, and $p 14^{A R F}$ inactivation (35\%) compared to $p 53$ mutations (15\%) was observed. In all three cases with MDM2 amplification and 8/12 cases with a $p 14^{A R F}$ alteration, the abnormality was present in both the diagnostic and relapsed specimen, whereas in 5/6 cases where a $p 53$ mutation was detected it was present in the relapsed specimen alone. This therefore suggests that for MDM2 amplification and $p 14^{A R F}$ alterations their presence predisposes to relapse whereas p53 mutations are acquired at relapse (Carr-Wilkinson et al., 2010).

In recent years there has been increased interest in assessing whether polymorphisms can influence cancer risk and clinical outcome. A single-nucleotide polymorphism (SNP) in the MDM2 promoter $\left(\mathrm{SNP} 309_{\mathrm{T}}\right.$ to $\mathrm{G}$ ) leading to high levels of MDM2 expression has been found in some tumors and is associated with a poor prognostic outcome, including neuroblastoma (Cattelani et al., 2008; Perfumo et al., 2008). In p53, a SNP at codon 72 which leads to an Arg > Pro substitution has previously been identified, and the Arg72 variant has been shown to exhibit enhanced apoptotic capability compared with the Pro72 variant (Dumont et al., 2003). Very recently, analysis of the $p 53$ codon 72 Arg/Pro polymorphism identified the Pro/Pro phenotype as an independent marker of poor prognosis in neuroblastoma patients, and in vitro led to reduced levels of apoptosis in response to chemotherapy and irradiation (Cattelani et al., 2012).

\section{MYCN mediated upregulation of p53 as a mechanism for MYCN induced apoptosis in neuroblastoma}

Members of the $M y c$ family are known to play a paradoxical role in driving both cellular proliferation and inducing apoptosis, which is thought to provide a safeguard mechanism to prevent uncontrolled cellular proliferation and oncogenic transformation. This paradox is observed histologically by a high mitosis-karyorrhexis index, a combined index of both proliferation and apoptosis, in both human MYCN amplified neuroblastoma tumors (Shimada 
et al., 1995, 1999; Goto et al., 2001; Altungoz et al., 2007) and THMYCN transgenic mouse neuroblastoma tumors (Moore et al., 2008).

p53 has long been known to be a direct target gene of c-MYC, and mediate c-MYC induced apoptosis (Reisman et al., 1993; Hermeking and Eick, 1994; Roy et al., 1994; Zeller et al., 2003). Initial studies in neuroblastoma showed that MYCN amplified tumors expressed significantly higher levels of p53 mRNA in comparison with non-amplified tumors (Raschella et al., 1991; Berwanger et al., 2002; Westermann et al., 2008), and higher p53 protein expression in the presence of ectopic MYCN in cell lines (Cui et al., 2005; Bell et al., 2006; Sugihara et al., 2006). Using ChIP-chip arrays MYCN was reported to bind to an E-Box within the $p 53$ promoter, however this study did not include the functional upregulation of $p 53$ (Westermann et al., 2008). Most recently, in a study of p53 expression, accumulation, and function in neuroblastoma in relation to MYCN amplification and expression, we demonstrated that p53 protein expression correlated with MYCN protein expression in both neuroblastoma tumors and cell lines (Chen et al., 2010). Furthermore, we demonstrated that p53 was functional and exhibited greater transcriptional activity in the presence of MYCN leading to the increased expression of several p53 target genes. Finally, we showed that MYCN mediates transactivation of $p 53$ by interacting directly with the same E-Box motif (CATGTG) as previously reported for c-MYC (Reisman et al., 1993; Figure 1), and is likely to be an important and direct mechanism by which MYCN is able to sensitize cells to p53-mediated apoptosis (Chen et al., 2010). This is consistent with, and may help to explain why human MYCN amplified and TH-MYCN transgenic mouse neuroblastoma tumors have high levels of apoptosis, and MYCN amplified and Tet21N MYCN+ neuroblastoma cells undergo higher levels of apoptosis in response to chemotherapeutic agents (Fulda et al., 1999, 2000; Paffhausen et al., 2007; Chesler et al., 2008), irradiation (Bell et al., 2006), and MDM2-p53 antagonists (Gamble et al., 2012). Certainly, siRNA mediated inhibition of p53 led to reduced levels of apoptosis in $M Y C N$ amplified neuroblastoma cell lines (Chesler et al., 2008; Chen et al., 2010).

Further support for MYCN driven p53-dependent apoptosis being an important mechanism for tumor suppression in neuroblastoma comes from in vivo work using p53 or Mdm2 haploinsufficient models of neuroblastoma. MYCN driven tumor formation had higher penetrance and reduced latency in p53 haploinsufficient mice, and chemotherapy induced apoptosis was shown to be p53-dependent, in which apoptosis was significantly reduced in $\mathrm{TH}-\mathrm{MYCN} p 53+/-$ tumors compared with TH-MYCN p53+/+tumors (Chesler et al., 2008). In contrast, $M d m 2$ deficiency suppressed MYCN driven neuroblastoma tumorigenesis, as evident by an extended tumor latency and survival and reduced tumor incidence and growth in $\mathrm{TH}$ MYCN Mdm2+1-transgenic mice compared with TH-MYCN $M d m 2+1+$ mice. Additionally, TH-MYCN Mdm2+/-tumors commonly exhibited methylation of $p 19^{A R F}$. These observations thereby demonstrate the necessity of MYCN to overcome p53-mediated tumor suppression during neuroblastoma tumorigenesis either via direct inhibition of p53 by MDM2 or suppression of the $\mathrm{p} 14^{\mathrm{ARF}} / \mathrm{p} 53$ pathway (Chen et al., 2009).
The ability of MYCN to induce apoptosis, such as through direct upregulation of $\mathrm{p} 53$, may be a potential pathway for spontaneous regression. Certainly, a study analyzing MYCN/c-MYC target gene expression and outcome in neuroblastoma has previously suggested p53 as a strong candidate involved in spontaneous regression of 4 s tumors (Westermann et al., 2008).

MYCN and p53 are both expressed in the normal embryonic developing nervous system, during the phase of precursor cell expansion prior to the onset of differentiation. In the context of normal embryonic development, direct upregulation of p53 by MYCN may be an important mechanism to eliminate any rapidly proliferating neuroblasts exposed to potential teratogens, to prevent deregulated proliferation and aberrations during development.

In addition to direct transcriptional upregulation of $p 53, \mathrm{c}$ MYC has been previously reported to sensitize cells to increased apoptosis via induction of $\mathrm{p} 14^{\mathrm{ARF}}$ mediated upregulation of $\mathrm{p} 53$ expression, stability, and activity (Zindy et al., 1998). Due to the homology between c-MYC and MYCN, MYCN may also be able to stabilize $\mathrm{p} 53$ via $\mathrm{p} 14^{\mathrm{ARF}}$, however this remains to be proven experimentally (Figures 1 and 2 ).

\section{Mechanisms of p53 inactivation and evasion of p53-dependent apoptosis in MYCN amplified neuroblastoma}

Several lines of evidence from published literature lend support to the notion that during the process of neuroblastoma progression there is evasion of p53-mediated tumor suppression via inactivation of the $\mathrm{p} 53 / \mathrm{MDM} 2 / \mathrm{p} 14^{\mathrm{ARF}}$ pathway (reviewed by Van Maerken et al., 2009b) as well as a requirement for MYCN amplified neuroblastoma to circumvent MYCN driven apoptosis (reviewed by Hogarty, 2003). In vivo studies have demonstrated the importance of the p53 pathway in neuroblastoma (Chesler et al., 2008; Chen et al., 2009). Potential mechanisms whereby MYCN amplified tumors can overcome p53-mediated tumor suppression in neuroblastoma are discussed below.

\section{MYCN amplification and inactivation of the p53/MDM2/p14 ${ }^{A R F}$ pathway in neuroblastoma}

There is evidence from neuroblastoma cell line studies that MYCN amplified neuroblastoma cells may circumvent MYCN driven p53dependent apoptosis by selecting for cells with aberrations in the p53/MDM2/p14 ARF pathway. Analysis of neuroblastoma cell lines reported to date with aberrations in the $\mathrm{p} 53 / \mathrm{MDM} 2 / \mathrm{p} 14^{\mathrm{ARF}}$ pathway demonstrates that $31 / 40(78 \%)$ of these cell lines are $M Y C N$ amplified and predominantly established following previous cytotoxic therapy at relapse (Table 1), when abnormalities of the p53 pathway in neuroblastoma tumors have also been previously reported (reviewed by Tweddle et al., 2003; Carr-Wilkinson et al., 2010). In contrast, the proportion of neuroblastoma tumors with aberrations in the $\mathrm{p} 53 / \mathrm{MDM} 2 / \mathrm{p} 14^{\mathrm{ARF}}$ pathway which are $M Y C N$ amplified are lower than in cell lines (Corvi et al., 1995; GonzalezGomez et al., 2003; Su et al., 2004; Spitz et al., 2006; Caren et al., 2008; Carr-Wilkinson et al., 2010), therefore it is possible that these abnormalities are selected for during the in vitro establishment and/or maintenance of these cell lines. It is however important to note that MYCN amplification and/or overexpression is unlikely to be the only selection pressure for $\mathrm{p} 53$ inactivation as aberrations in 
Table 1 | MYCN status and aberrations in the p53/MDM2/p14ARF pathway in neuroblastoma cell lines.

\begin{tabular}{|c|c|c|c|c|c|c|c|c|}
\hline Cell Line & $\begin{array}{l}\text { MYCN } \\
\text { Status }\end{array}$ & $\begin{array}{l}\text { p53 } \\
\text { Mut }\end{array}$ & $\begin{array}{l}\text { p53 Mut } \\
\text { Codon }\end{array}$ & $\begin{array}{l}\text { MDM2 } \\
\text { Amp }\end{array}$ & $\begin{array}{l}\text { p14 } \\
\text { Deln }\end{array}$ & $\begin{array}{l}\text { p14 } \\
\text { Meth }\end{array}$ & $\begin{array}{l}\text { Diagnosis/ } \\
\text { Relapse }^{\S}\end{array}$ & Reference \\
\hline $\mathrm{ACN}$ & nMNA & Yes & 113 & & & & Relapse & Forbes et al. (2008) \\
\hline CHLA-119 & $\mathrm{MNA}^{1}$ & Yes & 342 & & & & Relapse & Keshelava et al. (2001) \\
\hline CHLA-172 & $\mathrm{nMNA}^{1}$ & Yes & 216 & & & & Relapse & Keshelava et al. (2001) \\
\hline CHLA-90 & nMNA & Yes & 286 & & & & Relapse & Keshelava et al. (2001) \\
\hline CLB-Pe & MNA & Yes & 176 & & & & Relapse & Mergui et al. (2008) \\
\hline IGRN91 & MNA & Yes & a & & & & Relapse & Goldschneider et al. (2004, 2006) \\
\hline IGR-NB8 & MNA & Yes & 326 & & & & Diagnosis & Goldschneider et al. (2006) \\
\hline KELLY/N-206 & MNA & Yes & 177 & & & & Unknown & Mergui et al. (2008), Van Maerken et al. (2011) \\
\hline KP-N-YS & MNA & Yes & 135 & & & & Diagnosis ${ }^{2}$ & Forbes et al. (2008) \\
\hline LAN-1 & MNA & Yes & 182 & & & & Relapse & Davidoff et al. (1992), Van Maerken et al. (2011) \\
\hline LAN-2 & MNA & Yes & 337 & & & & Diagnosis & Van Maerken et al. (2011) \\
\hline NB4 & MNA & Yes & 173 & & & & Diagnosis ${ }^{3}$ & Teitz et al. (2002) \\
\hline NB6 & MNA & Yes & 282 & & & & Relapse & Teitz et al. (2002) \\
\hline NB8 & MNA & Yes & $\mathrm{b}$ & & & & Diagnosis & Teitz et al. (2002), Van Maerken et al. (2011) \\
\hline NB12 & MNA & Yes & 173 & & & & Unknown & Teitz et al. (2002) \\
\hline NB13 & MNA & Yes & 173 & & & & Unknown & Teitz et al. (2002) \\
\hline NB14 & MNA & Yes & c & & & & Diagnosis & Teitz et al. (2002) \\
\hline NB15 & MNA & Yes & 248 & & & & Unknown & Teitz et al. (2002) \\
\hline NB20 & MNA & Yes & 248 & & & & Unknown & Teitz et al. (2002) \\
\hline NLF & MNA & Yes & 203 & & & & Diagnosis ${ }^{4}$ & Van Maerken et al. (2011) \\
\hline NMB & MNA & Yes & 245 & & & & Relapse & Goldman et al. (1996) \\
\hline SJNB-4 & MNA & Yes & 176 & & & & Relapse & McPake et al. (1998) \\
\hline SKNAS & nMNA & Yes & $d$ & & & & Relapse & $\begin{array}{l}\text { Goldschneider et al. (2006), Nakamura et al. } \\
\text { (2007), Van Maerken et al. (2011) }\end{array}$ \\
\hline SKNBE2C & MNA & Yes & 135 & & & & Relapse & $\begin{array}{l}\text { Kaghad et al. (1997), Keshelava et al. (2001), } \\
\text { Tweddle et al. (2001a,b) Van Maerken et al. (2011) }\end{array}$ \\
\hline SK-N-DZ & MNA & Yes & 110 & & & & Relapse $^{5}$ & Forbes et al. (2008) \\
\hline SK-N-FI & nMNA & Yes & 246 & & & & Relapse & Van Maerken et al. $(2006,2011)$ \\
\hline TGW & MNA & Yes & 282 & & & & Relapse & Sugiyama et al. (2003) \\
\hline NGP & MNA & & & Yes & & & Relapse & $\begin{array}{l}\text { Corvi et al. (1995), Tweddle et al. (2001b), Van } \\
\text { Maerken et al. (2011) }\end{array}$ \\
\hline NB1691 & MNA & & & Yes & & & Relapse & McKenzie et al. (1999) \\
\hline CHLA134 & MNA & & & Yes & & & Relapse & Keshelava et al. (2001) \\
\hline LS & MNA & & & Yes & & & Relapse & Corvi et al. (1995), Carr et al. (2006) \\
\hline TR-14 & MNA & & & Yes & & & Relapse & Carr et al. (2006), Van Maerken et al. (2011) \\
\hline LAN-6 & nMNA & & & & Yes & & Relapse & $\begin{array}{l}\text { Keshelava et al. (2001), Thompson et al. (2001), } \\
\text { Van Maerken et al. (2011) }\end{array}$ \\
\hline SHEP & nMNA & & & & Yes & & Relapse & $\begin{array}{l}\text { Tweddle et al. (2001b), Carr et al. (2006), Van } \\
\text { Maerken et al. (2011) }\end{array}$ \\
\hline CHLA-101 & MNA & & & & Yes $^{e}$ & & Relapse & Thompson et al. (2001) \\
\hline CHLA-174 & nMNA & & & & Yes & & Relapse & Thompson et al. (2001) \\
\hline CHLA-179 & MNA & & & & Yes & & Relapse & Thompson et al. (2001) \\
\hline STA-NB-3 & MNA & & & & Yes & & Relapse $^{6}$ & Van Maerken et al. (2011) \\
\hline GIMEN & nMNA & & & & & Yes & Relapse & Carr et al. (2006) \\
\hline PER-108 & MNA & & & & & Yes & Relapse & Carr et al. (2006) \\
\hline
\end{tabular}

Mut, mutation; Amp, amplification; Deln, deletion; Meth, methylation; MNA, MYCN amplified; nMNA, non-MYCN amplified.

${ }^{s}$ Any cell line established prior to chemo/radiotherapy was classified as established at diagnosis and any cell lines established post-treatment was classified as established at relapse.

${ }^{1}$ Personal communication with P. Reynolds, ${ }^{2}$ Personal communication with T. Sugimoto, ${ }^{3}$ Personal communication with S. Ragsdale, ${ }^{4}$ Personal communication with G. Brodeur, ${ }^{5}$ Personal communication with L. Helson, ${ }^{6}$ Personal communication with P. Ambros.

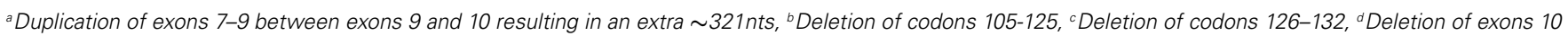
and 11 resulting in truncated product $\sim 369$ nts, ${ }^{e} 104$ bp deletion. 
the p53 pathway are also found in non-MYCN amplified tumors and cell lines (Table 1; Carr et al., 2006; Carr-Wilkinson et al., 2010).

MDM2-mediated MYCN driven tumorigenesis. MDM2 is a direct target gene of MYCN (Slack et al., 2005; Westermann et al., 2008) and non-syntenic co-amplification of MDM2 and MYCN has been reported in neuroblastoma (Corvi et al., 1995). Consistent with observations that $M d m 2$ haploinsufficiency inhibits c-MYC induced lymphomagenesis (Alt et al., 2003), MDM2 has been shown to be necessary for MYCN to overcome p53-mediated tumor suppression for MYCN directed centrosome amplification and genomic instability (Slack et al., 2007), and also during MYCN driven neuroblastoma tumorigenesis (Chen et al., 2009; Figure 2). The importance of MDM2 in neuroblastoma pathogenesis is further illustrated by studies which have observed that a SNP within the MDM2 promoter (SNP309 ${ }_{\mathrm{T}}$ to $\mathrm{G}$ ) that can lead to higher expression of MDM2 and greater inhibition of p53, is associated with poor survival in neuroblastoma, in particular stage 4 patients with MYCN amplification (Cattelani et al., 2008; Perfumo et al., 2008, 2009).

An additional mechanism whereby MYCN can overcome p53mediated apoptosis is through reduced expression of CHD5, a tumor suppressor gene (TSG) mapping to $1 \mathrm{p} 36.31$, which is a region commonly deleted in neuroblastoma and frequently correlated with MYCN amplification (Figure 2). CHD5 has been shown to control proliferation, apoptosis, and senescence by inducing $p 19^{A R F}$, the negative regulator of MDM2, and stabilizing p53 (Bagchi et al., 2007). Low levels of CHD5 expression have been found in neuroblastoma cell lines, as well as correlating with MYCN amplification and poor prognosis in neuroblastoma tumors (Thompson et al., 2003; Fujita et al., 2008; Koyama et al., 2012).

Furthermore, MYCN can also suppress p53 through Aurora Kinase A (AURKA), a serine/threonine kinase which plays a key role in mitosis and is expressed at high levels in $M Y C N$ amplified neuroblastoma (Figure 2). AURKA has been shown to directly phosphorylate p53 at Ser-215 and Ser-315 which abrogates p53 DNA binding and transactivation of target genes (Liu et al., 2004), and promotes MDM2-mediated destabilization and inhibition of p53 (Katayama et al., 2004). There is additional evidence to suggest that AURKA can also inhibit p53 via the AKT/MDM2 axis in gastric cancer cells, however this remains to be shown in neuroblastoma (Dar et al., 2008). Interestingly, AURKA has also been reported to stabilize MYCN, which would further promote MYCN driven tumorigenesis (Otto et al., 2009; Figure 2).

Very recently, MDM2 was reported to play a p53-independent role by interacting directly with $M Y C N$ mRNA and regulating its stabilization and translation, thereby forming a positive feedback loop, critical for MYCN amplified neuroblastoma tumor cell growth and survival (Gu et al., 2012; Figures 1 and 2).

Twist-1 and BMI-1 mediated inhibition of the p53 pathway. Twist- 1 which belongs to the bHLH transcription factor family, and BMI-1, a polycomb ring finger oncogene, are both overexpressed in several human cancers, and have been shown to be involved in epithelial-mesenchymal transition and cancer stemness which have clinical implications of cancer metastasis, drug resistance, and survival (Wu et al., 2012a). Twist-1 expression has been shown to be consistently overexpressed in MYCN amplified neuroblastoma tumors and cell lines, correlating with MYCN expression (Valsesia-Wittmann et al., 2004). Studies have

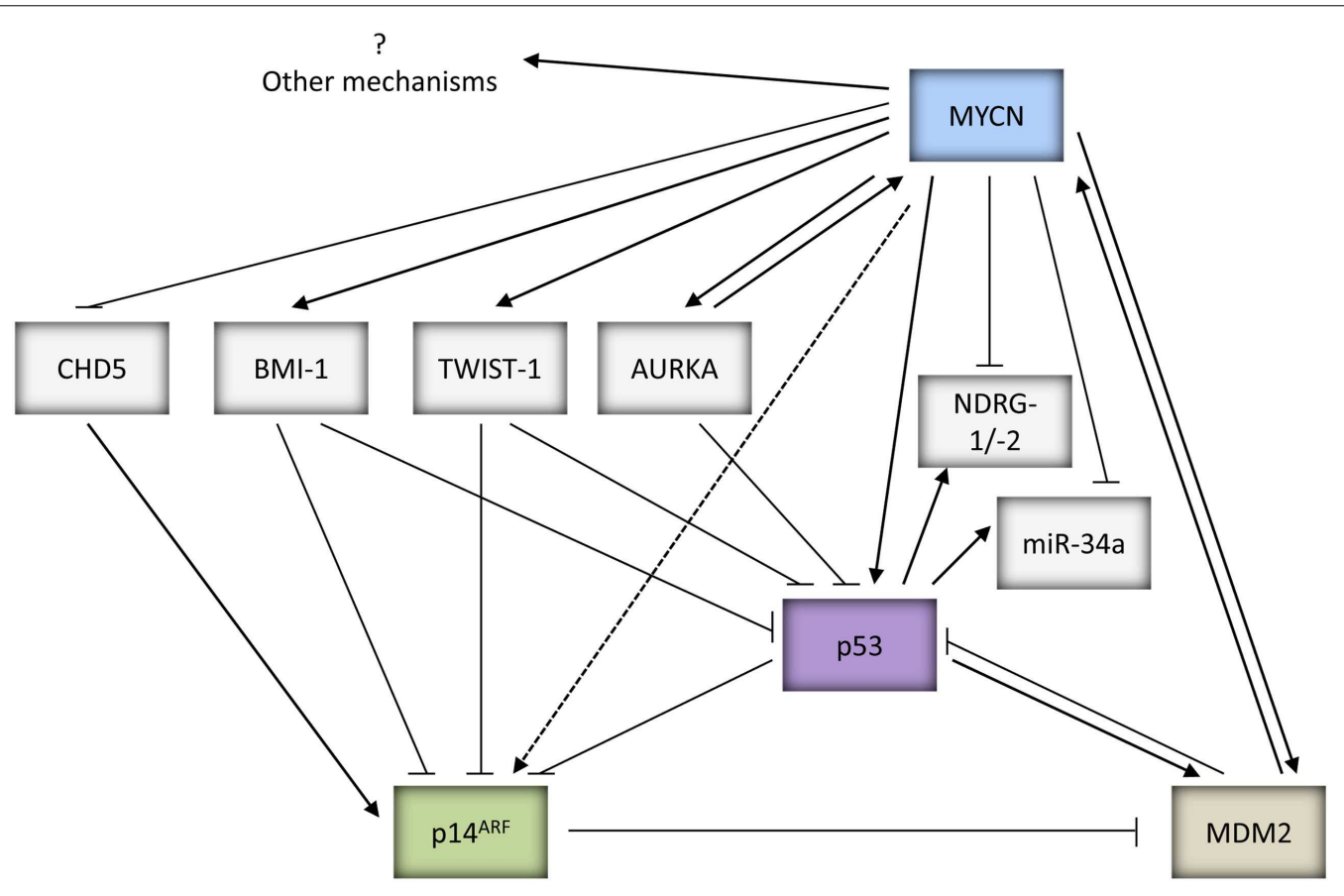

FIGURE 2 | Summary of the potential mechanisms by which MYCN can both positively and negatively regulate p53 activity and function. 
demonstrated the ability of Twist- 1 to inhibit p53 expression and activity via both transcriptional and post-translational mechanisms (Figure 2). Twist-1 has been shown to directly interact with HOXA5, a potent transactivator of p53 (Stasinopoulos et al., 2005). Additionally, it interferes with p53 stabilization and activity via inhibition of the $\mathrm{p} 53 / \mathrm{p} 14^{\mathrm{ARF}}$ pathway by reducing $p 14^{A R F}$ levels (Maestro et al., 1999), and inhibition of Ser-20 phosphorylation in response to DNA damage (Stasinopoulos et al., 2005). Furthermore, Twist-1 has been reported to repress p53-mediated gene transcription and stability via inhibition of p300-mediated acetylation of p53 (Hamamori et al., 1999). Moreover, it is found to directly interact with the DBD of p53, thereby inhibiting p53mediated transactivation of downstream target genes (Shiota et al., 2008). Finally, very recently Twist- 1 has also been reported to interact with the C-terminal regulatory domain of $\mathrm{p} 53$, which hinders post-translational modifications of p53 including Ser-392 phosphorylation, and promotes MDM2-mediated p53 degradation (Piccinin et al., 2012).

$B M I-1$ is a direct transcriptional target of c-MYC and MYCN and is overexpressed in $\sim 90 \%$ of neuroblastoma, correlating with MYCN expression (Ochiai et al., 2010; Huang et al., 2011b). It is reported to repress the CDKN2A $\left(p 16^{I N K 4 a} / p 14^{A R F}\right)$ locus which can lead to inactivation of the p53 pathway. In neuroblastoma, BMI-1 is shown to be essential for neuroblastoma tumorigenesis in vitro and in vivo, cooperating with $\mathrm{MYCN}$ via inhibition of MYCN driven apoptosis and downregulation of p53 expression (Cui et al., 2007; Huang et al., 2011b). Very recently, as an additional mechanism for BMI-1 mediated p53 inactivation, BMI-1 was found to directly bind to p53 in a complex with other Polycomb complex proteins in neuroblastoma cells leading to increased p53 ubiquitination and degradation (Calao et al., 2012; Figure 2).

Downregulation of NDRG1 and NDRG2 mediated p53dependent apoptosis. NDRG1 and NDRG2 were originally identified as a genes downregulated by MYCN (Shimono et al., 1999; Li and Kretzner, 2003; Zhang et al., 2006, 2008). The promoter of NDRG1 has been reported to possess a p53 binding site and leads to p53-mediated transactivation. NDRG1 was shown to be upregulated by $\mathrm{p} 53$ after DNA damage, and inhibition of NDRG1 expression by siRNA abolishes p53-dependent caspase activation and apoptosis. Furthermore, NDRG1 has been found to suppress metastatic cell growth (Stein et al., 2004). Similar results have been reported for NDRG2 (Liu et al., 2008a). Downregulation of NDRG1 and NDRG2 may therefore enable MYCN amplified and/or overexpressing neuroblastoma to evade p53 driven apoptosis (Figure 2).

MYCN and miRNAs. The $3^{\prime}$-UTR of MYCN has been identified as a direct target of $m i R-34 a$ (Wei et al., 2008), a miRNA which is directly upregulated by $\mathrm{p} 53$ and mediates several tumor suppressive functions of p53 (reviewed by Hermeking, 2007). Studies have shown that $m i R-34 a$ plays a role in inhibiting cellular proliferation and inducing apoptosis in neuroblastoma cells (Welch et al., 2007; Cole et al., 2008). Interestingly, $m i R-34 a$ is located at $1 \mathrm{p} 36.23$, a region showing frequent loss of heterozygosity $(\mathrm{LOH})$ in neuroblastoma and which is associated with MYCN amplification and aggressive disease progression (reviewed by Wei et al.,
2008). Consistent with this, lower expression levels of $m i R-34 a$ have been reported to correlate with $1 \mathrm{p} 36 \mathrm{LOH}$ in neuroblastoma (Welch et al., 2007; Cole et al., 2008; Feinberg-Gorenshtein et al., 2009; Figure 2). More recently, $m i R-380-5 p$, a miRNA which is reported to repress $\mathrm{p} 53$, has been shown to be expressed at high levels in neuroblastoma correlating with poor outcome in MYCN amplified tumors. Anti-miR-380-5p treatment restored p53 function in p53 wt neuroblastoma cell lines and inhibited the growth of orthotopically transplanted TH-MYCN tumors (Swarbrick et al., 2010).

\section{THERAPEUTIC STRATEGIES TO OVERCOME MECHANISMS OF p53 INACTIVATION IN NEUROBLASTOMA MDM2-p53 antagonists}

The importance of p53 in human cancer has led to vast efforts in the development of p53-based cancer therapeutics (reviewed by Lane et al., 2010). One such approach is the development of small molecule inhibitors (SMIs) which disrupt the interaction between $\mathrm{p} 53$ and its negative regulator MDM2 to reactivate wt $\mathrm{p} 53$, as a novel class of anti-cancer agents. This class includes cis-imidazolines (e.g., Nutlins), spiro-oxindoles (MI compounds), benzodiazepinediones, isoindolinones, isoquinolinones, and thiophenes (RITA; reviewed by (Yuan et al., 2011); (Hardcastle et al., 2011)). All of these act by targeting the p53 binding pocket of MDM2 to inhibit the MDM2-p53 interaction, except RITA which binds directly to p53. Compounds that bind to the RING domain of MDM2 and act in part by inhibiting the interaction of MDM2 with the proteasome have also been developed and include 5-deazaflavins and tryptamines (reviewed by Yuan et al., 2011).

Nutlins were the first potent and selective inhibitors of the MDM2-p53 interaction (Vassilev et al., 2004), in particular Nutlin3 has been extensively evaluated in vitro and in vivo in several types of human cancers and the cis-imidazoline RG7112 is currently in phase I clinical trials ${ }^{3}$ (NCT00559533 and NCT00623870). Overall, MDM2-p53 antagonists have been shown to activate the p53 pathway, inducing p53-dependent apoptosis and sensitizing tumor cells to cytotoxic and other molecular targeted therapies whilst inducing a reversible cell cycle arrest in normal cells (reviewed by (Van Maerken et al., 2009a); (Vassilev, 2004; Shangary et al., 2008; Korotchkina et al., 2009; Cheok et al., 2011)). In recent years, there has been increased interest in the use of MDM2-p53 antagonists in a cyclotherapeutic setting to protect normal cells from the harmful effects of chemotherapy (reviewed by Cheok et al., 2011; van Leeuwen, 2012) and also in the identification of natural MDM2 inhibitors (Qin et al., 2012). It is worth mentioning here that despite structural similarities between MDM2 and MDMX, MDM2-p53 antagonists are largely ineffective against MDMX, and in some cases overexpression of MDMX has been reported to confer resistance to MDM2 antagonists (reviewed by Wade and Wahl, 2009).

Evaluation of Nutlin-3 and other MDM2-p53 antagonists in preclinical models of neuroblastoma have reported potent antitumor effects such as induction of growth arrest, senescence, differentiation and apoptosis, and inhibition of tumor cell proliferation and metastasis (Barbieri et al., 2006; Van Maerken et al.,

${ }^{3}$ http://www.clinicaltrials.gov 
2006, 2009a, 2011; Hardcastle et al., 2011; Patterson et al., 2011; Gamble et al., 2012). In addition, Nutlin-3 has been shown to sensitize neuroblastoma cells to chemotherapy induced apoptosis (Barbieri et al., 2006; Michaelis et al., 2009; Peirce and Findley, 2009a; Patterson et al., 2011). Furthermore, in line with observations that $\mathrm{p} 53$ is a direct target gene of MYCN and mediates MYCN induced apoptosis, we recently reported that MYCN sensitizes neuroblastoma cells to both Nutlin-3 and MI63 (Gamble et al., 2012). Moreover, there is also evidence that the MDM2 and $p 14^{A R F}$ status of p53 wt neuroblastoma cells can affect the response to MDM2p53 antagonists and warrants further investigation (Van Maerken et al., 2011; Gamble et al., 2012).

Some studies to date have reported several p53-independent functions of Nutlin-3, including disruption of the MDM2-p73 interaction, which leads to enhanced p73 activity, suppression of tumor cell growth, and induction of apoptosis in p53 deficient neuroblastoma cells (Lau et al., 2008). Additionally, Nutlin-3 has also been shown to sensitize p53 deficient chemoresistant neuroblastoma cells to chemotherapy induced apoptosis via upregulation of TAp73 and E2F1 (Ambrosini et al., 2007; Peirce and Findley, 2009b), and inhibition of P-glycoprotein (Michaelis et al., 2009).

The low incidence of $p 53$ mutations in pediatric cancers, in particular neuroblastoma, compared with adult malignancies support the use of MDM2-p53 antagonists as a novel therapeutic strategy in the treatment of neuroblastoma. This is further strengthened by reports that the MDM2 SNP309 ${ }_{\mathrm{T} \text { to } \mathrm{G}}$ is associated with poor outcome, and that several mechanisms by which $M Y C N$ amplified neuroblastoma can overcome p53-mediated apoptosis are dependent on MDM2. Moreover, observations that inactivation of the p53/MDM2/p14 ${ }^{\mathrm{ARF}}$ pathway in relapsed neuroblastoma is predominantly due to lesions upstream of p53 combined with the reported therapeutic efficacy of Nutlin-3 in p53 wt multi-drugresistant preclinical models of neuroblastoma with metastatic burden (Van Maerken et al., 2009a), highly support reactivation of p53 by inhibiting MDM2 as an attractive treatment option for metastatic relapsed neuroblastoma. MDM2-p53 antagonists are currently undergoing phase I clinical evaluation in adults and are anticipated to enter pediatric clinical trials in the near future, including neuroblastoma. There is however recent evidence in neuroblastoma cell lines suggesting that continuous exposure to Nutlin-3 can induce de novo p53 mutations, resulting in cells exhibiting Nutlin-3 and multi-drug resistance. Consequently these results suggest that patients treated with MDM2-p53 antagonists should be closely monitored for the development of $p 53$ mutations and/or that MDM2-p53 antagonists should be given in combination with other agents to try to prevent the development of p53 mutations (Michaelis et al., 2011).

\section{Aurora kinase inhibitors}

The Aurora kinase family which includes Aurora A, B, and C, have attracted much attention over recent years as potential novel anti-cancer targets. In particular, AURKA has been shown to have oncogenic properties and is amplified and/or overexpressed in a range of human cancers (Maris, 2009). In neuroblastoma AURKA has been found to be expressed at high levels in MYCN amplified tumors and required for the growth of MYCN amplified cells (Berwanger et al., 2002; Otto et al., 2009). Studies have shown that it suppresses p53 transcriptional activity as well as promoting increased MDM2-mediated p53 degradation (Katayama et al., 2004; Liu et al., 2004). Additionally, via direct interaction but in a kinase independent manner, AURKA has been reported to stabilize MYCN by preventing its ubiquitin mediated degradation (Maris, 2009; Otto et al., 2009). These observations support the therapeutic potential of using AURKA inhibitors to simultaneously restore p53 activity and destabilize MYCN in neuroblastoma. Consistent with this, inhibition of AURKA expression in neuroblastoma cells has been shown to lead to growth inhibition, increased p53 expression, and decreased MYCN expression (Otto et al., 2009). Preclinical evaluations of a second generation AURKA inhibitor MLN8237 in pediatric cancers including neuroblastoma have been promising (Maris et al., 2010; Carol et al., 2011). Additionally, Aurora kinase inhibitor CCT137690 has also shown preclinical efficacy, downregulating MYCN, upregulating p53, and inhibiting neuroblastoma tumor growth in vitro and in vivo. Furthermore, consistent with the observation that AURKA is required for growth of MYCN amplified neuroblastoma, cells expressing high levels of MYCN were more sensitive to CCT137690 in comparison to cells expressing low or no MYCN (Faisal et al., 2011). Several AURKA inhibitors are currently undergoing clinical evaluations for use as a single agent or in combination with existing chemotherapeutics in various phase I-II trials for different human cancers including neuroblastoma (Cheung et al., 2011). Interestingly, the concomitant inhibition of the MDM2-p53 interaction and Aurora kinases has been shown to act synergistically to induce apoptosis in leukemia cells (Kojima et al., 2008), and should be assessed in neuroblastoma.

\section{Twist-1 and BMI-1 inhibitors}

Twist- 1 and BMI- 1 are involved in inactivation of the $\mathrm{p} 53$ pathway and are overexpressed in several cancers including neuroblastoma, often correlating with aggressive disease, and poor prognosis (reviewed by Wu et al., 2012a). Strategies which can inhibit Twist1 and/or BMI-1 activity or expression and lead to restoration of the $\mathrm{p} 53$ pathway and tumor suppression are therefore therapeutically promising. In support of this, studies in neuroblastoma have observed that MYCN functionally cooperates with Twist-1 or BMI-1 to induce neuroblastoma tumorigenesis, where overexpression of Twist-1 or BMI-1 is necessary for tumor growth both in vitro and in vivo (Valsesia-Wittmann et al., 2004; Cui et al., 2007; Huang et al., 2011b). To date no specific inhibitor of Twist1 has been identified, however PTC Therapeutics Inc., has very recently announced the development of PTC596, a first in its class, potent, oral, and selective inhibitor of BMI-1 protein expression. The inhibitor acts by altering the post-translational modification of BMI-1 which results in reduced levels of the protein and subsequently the reduced action of epigenetic complexes dependent on BMI- $1^{4}$. In addition, histone deacetylase (HDAC) inhibitors and the drug artemisinin have also been shown to reduce expression levels of BMI-1 (Cao et al., 2011). Furthermore, as Twist-1 and BMI-1 both act through negative regulation of $\mathrm{p} 14^{\mathrm{ARF}}$ to inactivate the p53 pathway, this could also be overcome by the use

\footnotetext{
${ }^{4}$ http://www.ptcbio.com/ptc596
} 
of MDM2-p53 antagonists. A study to evaluate the therapeutic efficacy of PTC596 in neuroblastoma is warranted.

\section{miRNA mimics and antagomirs}

It has become increasingly evident that miRNAs play a role in tumorigenesis and thus are potential targets for cancer therapy. The widespread deregulation of miRNAs in neuroblastoma is reported to be due to $M Y C N$ amplification and chromosomal imbalances (Bray et al., 2009). Several miRNAs have been suggested to have prognostic significance and therapeutic potential in neuroblastoma including $m i R-34 a$ and $m i R-380-5 p$ (reviewed by Verissimo et al., 2011). The restoration of $m i R-34 a$ and inhibition of $m i R-380-5 p$ have been shown to reactivate the $\mathrm{p} 53$ pathway and inhibit MYCN expression, as well as inhibiting tumor growth in cell lines and orthotopic murine models of neuroblastoma (Wei et al., 2008; Swarbrick et al., 2010; Tivnan et al., 2012). Advances in miRNA cancer therapy toward clinical use are being made. MiR34 mimics developed by Mirna Therapuetics Inc., are anticipated to enter clinical trials in early 2013 (Bader, 2012). Miravirsen, a miRNA-targeted drug inhibiting $m i R-122$, was the first of its class to enter clinical trials and is currently in phase II trials for the treatment of patients with Hepatitis C virus (Hu et al., 2012).

\section{Other strategies}

Similar to $\mathrm{miR}-34 a, C H D 5$ is also located at $1 \mathrm{p} 36$, and is frequently deleted and/or methylated in several human cancers including neuroblastoma. 1p deletion and epigenetic silencing of CHD5 have been suggested to account for the low expression observed in both neuroblastoma tumors and cell lines, as homozygous deletions or mutations were reported to be infrequent (Fujita et al., 2008; Koyama et al., 2012). The promising therapeutic implications of restoring CHD5 expression in neuroblastoma has previously been shown by the reduced clonogenicity and xenograft tumor growth of neuroblastoma cell lines stably transfected with CHD5 cDNA (Fujita et al., 2008). Very recently, genistein has been reported to demethylate the CHD5 promoter, enhance the expression of CHD5 and p53, and inhibit neuroblastoma growth in vivo (Li et al., 2012b).

Originally identified as genes downregulated by MYCN, NDRG1, and NDRG2 have subsequently been shown to be necessary for p53-mediated apoptosis. NDRG1 has been shown to be upregulated in response to differentiation and suppress metastasis, and there is growing interest in using NDRG1 as a biomarker of disease progression (reviewed by Ellen et al., 2008). Very recently, NDRG1 has been shown to upregulate NEDD4L, PTEN, and SMAD4 and inhibit the PI3K and Ras signaling pathways, thereby implicating its involvement in regulating key oncogenic pathways (Kovacevic et al., 2012). The exact role of NDRG1 and family members in cancers including neuroblastoma remain to be fully elucidated, however the iron chelator Dp44mT which exhibits anti-cancer properties has been reported to upregulate the expression of NDRG1 (Chen et al., 2012).

\section{SKP2}

S-phase kinase-associated protein 2 (SKP2) is an F-Box protein and the variable substrate recognition component of the E3 ubiquitin ligase $\mathrm{SCF}^{\mathrm{SKP} 2}$ complex. The invariable core components of
SCF complexes are SKP1, CUL1, and RBX1 (Skowyra et al., 1997; Deshaies, 1999; Nakayama and Nakayama, 2005). SKP2 was originally discovered as a protein associated with Cyclin A-CDK2, and subsequently shown to play a key role in promoting cell cycle progression, in particular at the $\mathrm{G}_{1} / \mathrm{S}$ transition (Zhang et al., 1995). More recently, studies have also identified the involvement of SKP2 in several processes closely linked to tumorigenesis such as cell survival, apoptosis, migration, and metastasis (reviewed by Chan et al., 2010b).

SKP2 protein is approximately $45 \mathrm{kDa}$, consisting of an $\mathrm{N}$ terminal F-Box domain which mediates the interaction between SKP2 and SKP1, thereby tethering SKP2 to the SCF complex, and C-terminal leucine-rich repeats (LRR) which enable SKP2 to directly bind to target substrates (Bai et al., 1996; Skowyra et al., 1997; Schulman et al., 2000; Zheng et al., 2002). Since its discovery, SKP2 has been found to target numerous proteins for ubiquitination and subsequent degradation via the $26 \mathrm{~S}$ proteasome pathway, including CDK inhibitors p21 ${ }^{\mathrm{CIP} 1}$ (Yu et al., 1998; Bornstein et al., 2003), p27 KIP1 (Carrano et al., 1999; Sutterluty et al., 1999; Tsvetkov et al., 1999), and p57 KIP2 (Kamura et al., 2003), Rb family member p130 (Tedesco et al., 2002), apoptosis regulator FOXO1, tumor suppressors BRCA2 (Moro et al., 2006), RASSF1A (Song et al., 2008), and TOB1 (Hiramatsu et al., 2006), Cyclins D (Yu et al., 1998) and E (Yeh et al., 2001), as well as oncogenes c-MYC (Kim et al., 2003; von der Lehr et al., 2003) and MYB (Charrasse et al., 2000). The binding and recognition of the substrate by SKP2 is dependent on prior phosphorylation of the target substrate, and in some cases also requires the activity of a co-factor protein, CKS1 (Cyclin-kinase-subunit 1; Ganoth et al., 2001; Spruck et al., 2001; Frescas and Pagano, 2008).

\section{REGULATION OF SKP2 EXPRESSION, STABILITY, AND ACTIVITY}

Consistent with its role as a cell cycle regulator, expression levels of SKP2 oscillate during the cell cycle, and are regulated by both transcriptional and post-transcriptional mechanisms (Bashir and Pagano, 2004). Levels of SKP2 are low in $G_{0} / G_{1}$ and late $M /$ early $G_{1}$, increase during $G_{1} / S$ transition and reach a maximum in S phase (Wirbelauer et al., 2000; Bashir et al., 2004; Wei et al., 2004). Studies to date have revealed that several transcription factors act directly via the SKP2 promoter to upregulate SKP2 gene expression, such as E2F1 (Zhang and Wang, 2006), NFKB (Schneider et al., 2006), SP1 (Appleman et al., 2006), CBF1 (Sarmento et al., 2005), GABP (Imaki et al., 2003), FOXM1 (Wang et al., 2005), c-MYC (Bretones et al., 2011), STAT3 (Huang et al., 2012), and NOR1 (Gizard et al., 2011). In addition, Foxp3 (Zuo et al., 2007), FOXO3A (Wu et al., 2012b) and STAT1 (Wang et al., 2010c) have been identified to transcriptionally repress SKP2 expression.

The identification of SKP2 as a direct target gene of E2F (Zhang and Wang, 2006) is of particular importance as Yung et al. (2007) subsequently described the SKP2 autoinduction loop comprising pRB-E2F, SKP2, p27 ${ }^{\mathrm{KIP} 1}$, and Cyclin E-CDK2, in which SKP2 expression initiates proteolysis of $\mathrm{p} 27^{\mathrm{KIP} 1}$, activation of Cyclin ECDK2 which feeds back to sustain $\mathrm{pRB}$ inactivation, E2F release, and further induction of the SKP2 gene. Therefore, once activated, this autoinduction loop ensures mitogen independent cell cycle progression through the restriction point. 
In addition to transcriptional regulation, SKP2 is also subject to regulation via protein stability. The E3 ubiquitin ligase $\mathrm{APC}^{\mathrm{Cdh} 1}$ complex mediates the ubiquitination and subsequent degradation of SKP2, primarily in early $\mathrm{G}_{1}$ (Bashir et al., 2004; Wei et al., 2004). The interaction between Cdh1 and SKP2 is essential for APC ${ }^{\mathrm{Cdh} 1}$ complex mediated degradation of SKP2. In support of this, several kinases including CDK2, AKT, and Pim-1 have been shown to phosphorylate SKP2 at residues Ser64 and Ser-72 and/or Thr-417, thereby inhibiting the Cdh1-SKP2 interaction and protecting SKP2 from APC ${ }^{\mathrm{Cdh} 1}$ mediated ubiquitination and degradation. Furthermore, Pim-1 has also been shown to phosphorylate Cdh1, impairing its association with CDC27 and inhibiting APC ${ }^{\text {Cdh1 }}$ activity, thereby protecting SKP2 from degradation (reviewed by Chan et al., 2010b). In contrast, studies have shown that $\mathrm{pRb}$ interacts with Cdh1 and promotes SKP2 degradation (Binne et al., 2007), and TGF $\beta$ signaling induces nuclear translocation of SKP2 which facilitates its ubiquitylation by $\mathrm{APC}^{\mathrm{Cdh} 1}$ and subsequent degradation ( $\mathrm{Hu}$ et al., 2011).

Finally, the formation of the $\mathrm{SCF}^{\mathrm{SKP} 2}$ complex is critical for ligase activity. Studies have demonstrated that PI3K/AKT signaling pathway and Cyclin D positively regulate $\mathrm{SCF}^{\mathrm{SKP} 2}$ complex formation and ligase activity, potentially through neddylation of CUL1 (reviewed by Chan et al., 2010b).

\section{SKP2 AS AN ONCOPROTEIN}

Numerous studies to date have provided evidence showing the oncogenic potential of SKP2, and its cross-talk with multiple signaling pathways involved in carcinogenesis such as PI3K/AKT, mTOR, ERK, NFKB, Ras/MAPK, and IGF (Wang et al., 2012c). Overexpression of SKP2 can drive quiescent cells to enter the cell cycle (Sutterluty et al., 1999), and promote adhesion-independent growth of cancer cells (Carrano and Pagano, 2001; Signoretti et al., 2002). Downregulation or inhibition of SKP2 expression leads to growth arrest and/or apoptosis, as well as reduced cell migration, invasion, and metastasis (Koga et al., 2003; Yokoi et al., 2003; Jiang et al., 2005; Lee and McCormick, 2005; Shibahara et al., 2005; Katagiri et al., 2006; Kitagawa et al., 2008; Xiao et al., 2009; Chan et al., 2010a; Bretones et al., 2011). In transgenic mouse models, SKP2 cooperates with N-Ras to drive lymphomagenesis (Latres et al., 2001), and tissue targeted expression of SKP2 results in hyperplasia, dysplasia, and low-grade carcinoma of the prostate gland (Shim et al., 2003). Knockdown of SKP2 significantly reduced tumor formation and metastasis of breast cancer xenografts (Chan et al., 2010a). Furthermore, work in SKP2 knockout mice demonstrated that SKP2 is necessary for tumor formation induced by PTEN, p19ARF, or $R b$ deficiency (Lin et al., 2010; Wang et al., 2010b).

SKP2 overexpression at the mRNA and/or protein level have been detected in a number of human tumors and cell lines including prostate, breast, pancreatic, gastric, colorectal, ovarian, melanoma, lymphoma, and leukemia (reviewed by Nakayama and Nakayama, 2006; Frescas and Pagano, 2008; Hershko, 2008). In addition, amplification of SKP2 at chromosome $5 \mathrm{p} 13$ has been reported (Yokoi et al., 2004; Saigusa et al., 2005; Wang et al., 2009; Rose et al., 2011; Li et al., 2012a), and tends to be observed in metastatic tumors whereas overexpression of SKP2 is reported in early cancers (Hershko, 2008). Overall, elevated SKP2 expression has been shown to correlate with a poor prognostic outcome, tumor size, dedifferentiation, advanced grade, and metastasis (reviewed by Wang et al., 2012c). It is worth mentioning that in some cases the latter has been correlated with cytoplasmic and not nuclear SKP2 expression. In the vast majority of cases, SKP2 overexpression inversely correlates with $\mathrm{p} 27^{\mathrm{KIP} 1}$ expression (Nakayama and Nakayama, 2006; Frescas and Pagano, 2008), which is consistent $\mathrm{p} 27^{\mathrm{KIP} 1}$ being a key target of SKP2 and to be rarely mutated in cancer (Chu et al., 2008). Finally, in recent years, SKP2 overexpression has been shown to mediate resistance to TRAIL induced apoptosis (Schuler et al., 2011), and radio- and chemoresistance of human cancer cells (Ishii et al., 2004; Davidovich et al., 2008; Chan et al., 2012; Totary-Jain et al., 2012; Wang et al., 2012b).

\section{SKP2 mediated attenuation of p53 function}

Recent key publications have identified that SKP2 and an alternatively spliced variant of SKP2, SKP2B can attenuate p53 function through independent mechanisms (Figure 3). Initially, Kitagawa et al. (2008) identified that SKP2 is able to suppress p53-mediated apoptosis by inhibiting the p53 transcriptional co-activator, p300. This function was shown to be independent of the F-Box motif of SKP2 and hence SCF ${ }^{\text {SKP2 }}$ complex function. SKP2 was found to bind to the $\mathrm{CH} 1$ and $\mathrm{CH} 3$ domain of p300, thought to be p53 binding sites, thereby antagonizing the p53-p300 interaction, suppressing p300-mediated acetylation of p53 and the transactivation ability of p53. In addition, secondary to the latter, SKP2 was also observed to promote the degradation of p300. As proof-ofconcept, the study demonstrated that inhibition of SKP2 combined with DNA damaging agents or Nutlin-3, led to greater induction of apoptosis (Kitagawa et al., 2008). More recently, SKP2B was demonstrated to attenuate $\mathrm{p} 53$ function via a mechanism independent of $\mathrm{p} 300$. SKP2B is shown to bind to and mediate the degradation of Prohibitin, a potential TSG which binds to and stimulates p53 transcriptional activity. Taken together, these observations suggest that amplification of the SKP2 locus would represent a powerful mechanism to attenuate p53 function in cancer (Chander et al., 2010; Figure 3).

Interestingly, a very recent study has reported an additional mechanism for the SKP2-p300 interaction, whereby p300 is able to reciprocally regulate SKP2 function (Figure 3). p300-mediated acetylation of SKP2 at Lys-68 and Lys-71 within its NLS region was shown to promote SKP2 stabilization and cytoplasmic retention, thereby influencing its oncogenic potential. In part the latter was reported to be achieved through cytoplasmic SKP2 mediated increased cellular migration via ubiquitination and destruction of E-cadherin (Inuzuka et al., 2012).

\section{THE ROLE OF SKP2 IN NEUROBLASTOMA}

In line with observations that SKP2 drives cellular proliferation, CAMP induces proliferation of neuroblastoma cells by upregulating SKP2 (Cho et al., 2007), while growth arrest and differentiation of neuroblastoma cell lines induced by retinoic acid, BMP2, and the HDAC inhibitor Helminthosporium carbonum toxin is accompanied by a decrease in SKP2 levels (Nakamura et al., 2003a,b; Cuende et al., 2008; Deubzer et al., 2008a). This decrease has been attributed to retinoic acid induced downregulation of Rae1 which 


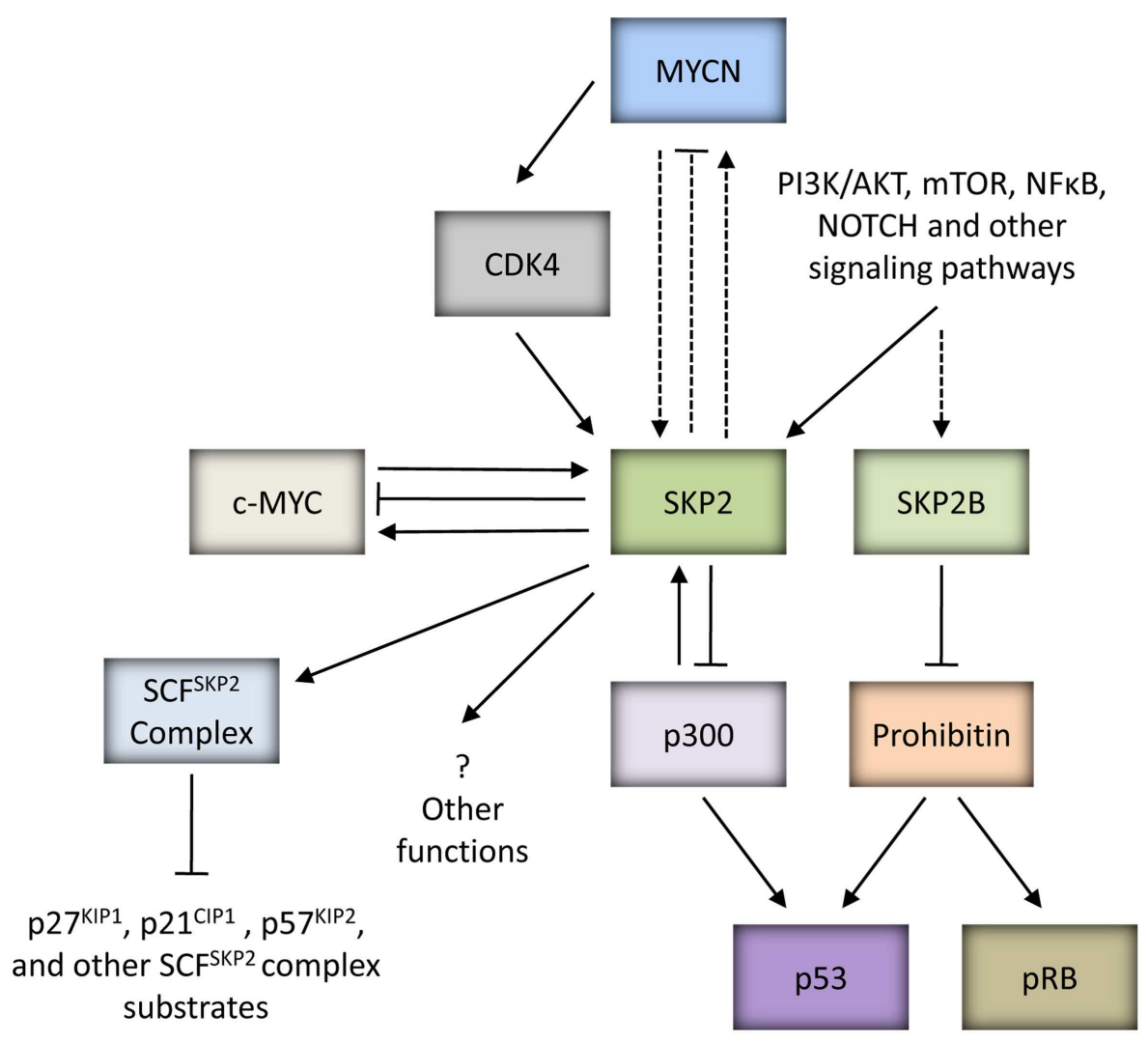

FIGURE 3 | MYC proteins and SKP2. SKP2 is an oncoprotein which can be upregulated by MYC proteins to drive tumorigenesis. SKP2 is a direct target gene of c-MYC, and can regulate the stability of c-MYC and be a co-factor for c-MYC mediated transcriptional activation of target genes. Due to the homology between $\mathrm{c}-\mathrm{MYC}$ and MYCN, it is possible that SKP2 is also a direct target gene of MYCN and plays a similar role in regulating MYCN stability and transactivation of MYCN target genes (as indicated by the dashed lines). In neuroblastoma, MYCN can indirectly upregulate SKP2 via CDK4. In addition to upregulation by oncogenic MYC proteins, several signaling pathways closely linked to carcinogenesis such as PI3K/AKT and mTOR have been shown to influence SKP2 expression, stability and SCF ${ }^{\text {SKP2 }}$ ligase activity. SKP2 is a component of the SCF ${ }^{\text {KKP2 }}$ complex which mediates the degradation of several substrates including CDK inhibitors p21 $1^{\mathrm{CIP} 1}, \mathrm{p} 27^{\mathrm{KIP} 1}$, and p57 $7^{\mathrm{KIP} 2}$. Independently of SCF complex formation, SKP2 can bind to p300 and attenuate p53 function. Interestingly, p300 is able to reciprocally regulate SKP2 activity. SKP2B, an alternatively spliced variant of SKP2, can perturb both p53 and pRB pathways via degradation of Prohibitin. It is possible that SKP2 has other functions which may promote tumorigenesis. leads to increased $\mathrm{APC}^{\mathrm{Cdh} 1}$ mediated degradation of SKP2, or HDAC inhibitor induced activation of the Rb pathway (Cuende et al., 2008; Deubzer et al., 2008b).

Several studies including our own have found higher expression of SKP2 in the presence of ectopic MYCN, and in MYCN amplified cell lines and tumors (Sugihara et al., 2006; Bell et al., 2007a; Westermann et al., 2007; Chen et al., 2010; Muth et al., 2010; Table 2), suggesting that deregulated SKP2 expression is driven by MYCN to promote neuroblastoma. The exact role of SKP2 in neuroblastoma pathogenesis is currently unclear. It is possible that high expression of SKP2 simply collaborates with MYCN to drive uncontrolled proliferation through increased degradation of CDK inhibitors. Alternatively, as $M y c$ family members are known to drive both proliferation and apoptosis, MYCN may upregulate SKP2 to inhibit apoptosis and tip the balance in favor of proliferation. In particular, as p53 has previously been shown to be a direct target gene of MYCN, and a mechanism for MYCN mediated apoptosis in neuroblastoma, it is plausible that MYCN directly upregulates SKP2 to attenuate p53-mediated apoptosis (Kitagawa et al., 2008; Chen et al., 2010), as has previously been reported for c-MYC (Bretones et al., 2011; Figure 3).

The precise mechanism of MYCN mediated upregulation of SKP2 remains unclear, as SKP2 is a direct target gene of E2F (Zhang and Wang, 2006), E2F is a direct target of c-MYC (Fernandez et al., 2003) and higher E2F expression levels are observed in the presence of MYCN (Mac et al., 2000; Woo et al., 2008). In neuroblastoma tumors, SKP2 expression has been shown to tightly correlate with E2F1 expression, and both genes are expressed at significantly higher levels in MYCN amplified tumors (Westermann et al., 2007; Muth et al., 2010). Interestingly, although SKP2 expression levels were found to be highest in MYCN amplified tumors, this did not correlate with MYCN expression in MYCN single-copy tumors (Westermann et al., 2007). Similarly, Bell et al. (2007a) reported that although SKP2 mRNA levels decreased after MYCN siRNA and after removal of MYCN expression in Tet21N cells, SKP2 protein levels did not correlate with MYCN protein levels or MYCN amplification in a panel of neuroblastoma cell lines. It has been 
Table 2 | Summary of studies which have shown increased SKP2 expression in the presence of MYCN and/or MYCN amplification in neuroblastoma.

\begin{tabular}{|c|c|c|c|c|}
\hline Study & Tumors & Cell Lines & Methods & Evidence \\
\hline Bell et al. (2007a) & - & IMR32, SKNBE2C, Tet21N² & MYCN siRNA, microarray ${ }^{3}$, qRT-PCR & $\mathrm{Si}, \mathrm{E}$ \\
\hline & $\begin{array}{l}\text { Microarray/qRT-PCR/lHC } \\
\text { tissue array/WB }\end{array}$ & - & Microarray, qRT-PCR, WB, IHC & $\mathrm{T}$ \\
\hline
\end{tabular}

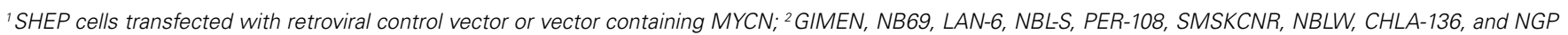

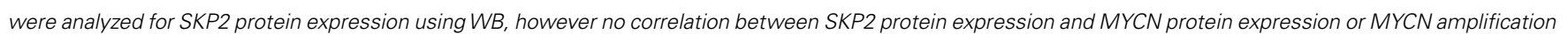

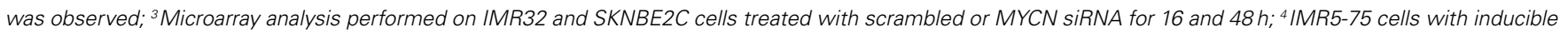
stably transfected short hairpin RNAs against MYCN.

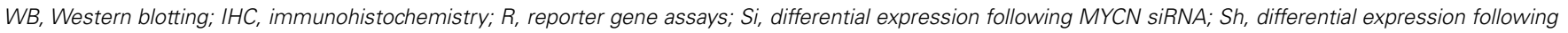
MYCN shRNA; E, differential expression/correlation in ectopic MYCN expression systems; T, correlation in tumors with MYCN amplification.

suggested that deregulated MYCN expression in MYCN amplified neuroblastoma indirectly upregulates SKP2 via the induction of CDK4 (Figure 3), thereby reducing the abundance of repressive pRB-E2F1 complexes bound to the SKP2 promoter and providing an entry point into the SKP2 autoinduction loop (Muth et al., 2010). Whether SKP2 is a direct transcriptional target of MYCN remains to be determined. However, as c-MYC and MYCN are known to share some common target genes, and C-MYC has recently been shown to directly bind to two high affinity E-Box motifs (CATGCG and CACGCG) mapping to -756 and $-389 \mathrm{bp}$ upstream of the transcriptional start site within the SKP2 promoter and drive transcription (Bretones et al., 2011), it is therefore possible that MYCN may also directly regulate SKP2 expression (Figure 3).

Whether or not SKP2 is a direct target gene of MYCN, the prognostic significance of SKP2 overexpression in neuroblastoma has been demonstrated in primary tumor samples. High SKP2 expression was found to characterize aggressive high-risk disease independent of both MYCN status and stage. Furthermore, high SKP2 expression was observed to correlate with low p $27^{\mathrm{KIP} 1}$ expression levels (Westermann et al., 2007), consistent with studies in other cancer types (reviewed by Nakayama and Nakayama, 2006; Frescas and Pagano, 2008; Hershko, 2008). Interestingly, the prognostic value of low $\mathrm{p} 27^{\mathrm{KIP} 1}$ expression in neuroblastoma, independent of MYCN status had previously been demonstrated (Bergmann et al., 2001).

SKP2 has previously been shown to regulate the stability of cMYC and to be a co-factor for c-MYC mediated transcriptional activation of target genes (Kim et al., 2003; von der Lehr et al., 2003), however it is currently remains unclear whether it plays a similar role in regulating MYCN stability and transactivation of MYCN target genes (Figure 3).

Taken together, SKP2 has prognostic significance in neuroblastoma and could be a promising novel therapeutic target, however further studies investigating the role of SKP2 in neuroblastoma are required. Consequently, together with in vitro experiments, crossing SKP2 knockout mice with murine models of neuroblastoma, such as the transgenic TH-MYCN mouse, the role of SKP2 in driving neuroblastoma could be elucidated.

\section{THERAPEUTIC STRATEGIES TARGETING SKP2}

Over the past decade, SKP2 has emerged as a novel and attractive pharmacological target in cancer therapeutics. This is supported by the involvement of SKP2 in proliferation, apoptosis, differentiation, migration, and metastasis, as well as its cross-talk with multiple signaling pathways closely linked to carcinogenesis. In addition, the prognostic significance and overexpression of SKP2 in a variety of human cancers, combined with observations that SKP2 knockout mice are both viable and fertile (Nakayama et al., 2000), further strengthens its appeal. Furthermore, with the discovery of the role of SKP2 and SKP2B in attenuating p53mediated apoptosis and transcriptional activity, and that SKP2 deficiency triggers a potent ARF-p53-independent cellular senescence in the presence of oncogenic conditions (such as inactivation of TSGs/overexpression of proto-oncogenes), has implicated the wide applicability of targeting SKP2 as a strategy to reactivate p53 and as pro-senescence therapy (Kitagawa et al., 2008; Chander et al., 2010; Lin et al., 2010). Finally, the availability of crystallographic maps of the structure of SKP2 and SCF ${ }^{\mathrm{SKP} 2}$ complex components and their interaction with substrates, together with biochemical data provides the opportunity to develop novel SKP2 inhibitors (Frescas and Pagano, 2008).

Inhibitors targeting the ubiquitin proteasome system (UPS) have been developed and used with success in preclinical and/or clinical studies thereby highlighting these inhibitors as a new class of cancer therapeutics (Kisselev et al., 2012). Bortezomib (Vel$\left.\mathrm{cade}^{\mathrm{TM}}\right)$ is the first clinically approved proteasome inhibitor, and has been reported to induce $\mathrm{p} 27^{\mathrm{KIP} 1}$ expression through degradation of SKP2 (Uddin et al., 2008, 2009). Of interest, although not directly linked to SKP2, bortezomib is shown to induce apoptosis and inhibit cell growth, migration, angiogenesis, and metastasis both in vitro and in murine models of chemosensitive and chemoresistant neuroblastoma (Brignole et al., 2006; Michaelis et al., 2006; Hamner et al., 2007; Valentiner et al., 2009). Despite 
the overall success of bortezomib, severe side-effects have been reported in patients, and may be attributable to the broad ranging functions and targets of the UPS (Chen et al., 2011). Therefore the development of specific inhibitors directly targeting SKP2 is likely to have enhanced efficacy and reduced toxicity.

To date, no specific inhibitor of SKP2 has been identified however three SMIs have been shown to downregulate SKP2 activity, and exhibit anti-tumor effects in preclinical studies. Using highthroughput screening, Cpd A and SMIP004 were identified (Chen et al., 2008; Rico-Bautista et al., 2010). CpdA, interferes with the SKP1/SKP2 interaction, thereby directly preventing SCF ${ }^{\text {SKP2 }}$ complex formation and ligase activity that results in the accumulation of several SCF ${ }^{\mathrm{SKP} 2}$ substrates including $\mathrm{p} 27^{\mathrm{KIP} 1}$ and $\mathrm{p} 21^{\mathrm{CIP} 1}$. It has been shown to induce cell cycle arrest and apoptosis, exhibiting preferential activity against neoplastic cells, as well as overcoming chemoresistance to dexamethasone, doxorubicin, melphalan, and bortezomib (Chen et al., 2008). Similarly, SMIP0004 was identified and shown to inhibit cell growth and induce apoptosis, and exhibit cancer cell specificity. It was found not only to downregulate SKP2 and induce dose-dependent stabilization of $\mathrm{p} 27^{\mathrm{KIP} 1}$ and $\mathrm{p} 21^{\mathrm{CIP} 1}$, but also to inhibit cellular CDK2 activity (Rico-Bautista et al., 2010). Finally, MLN4924 is a compound which targets NEDD8activating enzyme, consequently affecting CUL1 neddylation and impairing SCF ${ }^{\mathrm{SKP} 2}$ complex formation and ligase activity. Preclinically, MLN4924 exhibits potent cytotoxicity against a panel of human cancer cell lines, and suppresses tumor growth in mouse xenograft models (Soucy et al., 2009; Lin et al., 2010). Furthermore, in contrast to bortezomib, MLN4924 did not significantly affect bulk protein turnover (Soucy et al., 2009). MLN4924 was recently evaluated by the Pediatric Preclinical Testing Program (PPTP), exhibiting potent activity in vitro and inhibiting tumor growth against a subset of the PPTP solid tumor and ALL xenografts. Specifically in the neuroblastoma panel, MLN4924 had a median relative $\mathrm{IC}_{50}$ of $278 \mathrm{nM}$, and induced intermediate activity (EFS $\mathrm{T} / \mathrm{C}$ values $>2$ ) in $1 / 4$ xenografts (Smith et al., 2012). In addition to the above SMIs, several natural compounds have also been shown to downregulate SKP2 activity, including retinoic acid, silibinin, curcumin, quercetin, lycopene, epigallocatechin-3-gallate (Nakamura et al., 2003a; Roy et al., 2007; Cuende et al., 2008; Huang et al., 2011a). Retinoic acid is of particular relevance to neuroblastoma, as Isotretinoin (13-cis RA) is routinely used in the treatment of high-risk disease following high-dose chemotherapy and stem cell rescue, in a setting of minimal residual disease (Wagner and Danks, 2009).

Several signaling pathways have been shown to influence SKP2 expression, stability, and $\mathrm{SCF}^{\mathrm{SKP} 2}$ ligase activity, therefore an alternative strategy would be to use inhibitors that target components of these pathways such as PI3K/AKT, mTOR, ERK, IGF, Notch, and $I K K / N F K B$, and some of which are currently in clinical trials. In support of this, PI3K inhibitor LY294002 and Rapamycin have been shown to decrease SKP2 expression (Motti et al., 2005; Shapira et al., 2006). Of interest, it is worth mentioning that LY294002 has also been shown to destabilize MYCN in neuroblastoma (Chesler et al., 2006). Targeting the expression or stability of SKP2 is an appealing option due to the oncogenic functions of SKP2 which are independent of SCF ${ }^{\mathrm{SKP} 2}$ ligase formation and activity (Ji et al., 2006; Kitagawa et al., 2008; Chan et al., 2010a).

\section{DKK3}

The Wnt signaling pathway is involved in embryogenesis, playing a key role in both early and late cell-fate decisions, and also in adult tissue homeostasis. Deregulated activation of this pathway has been implicated in several malignancies (Klaus and Birchmeier, 2008). DKK3 is a member of the Dickkopf family of secreted Wnt antagonists, which also includes DKK1, $-2,-4$ and DKKL1. $D K K$ family members encode glycoproteins which all share an $\mathrm{N}$ terminal signal peptide, and with the exception of DKKL1, also share two cysteine-rich domains termed Cys1 and Cys2 that are separated by a non-conserved linker region of variable length. DKK 3 has a molecular weight of $38 \mathrm{kDa}$, and Cys 1 and Cys 2 are separated by a linker region of 13 amino acids (reviewed by Veeck and Dahl, 2012).

DKK1, -2 and -4 , are well-established antagonists of the canonical Wnt/ $\beta$-catenin pathway through direct high affinity binding to Wnt co-receptors lipoprotein receptor-related protein 5 and 6 (LRP5/6), and also DKK receptors Kremen 1 and 2 (KRM1/2; reviewed by (Niehrs, 2006)). The co-binding of DKK proteins to KRM1/2 receptors potentiates the ability of DKK proteins to inhibit Wnt signaling, through the formation of a ternary complex that leads to endocytosis and degradation of LRP receptors (Mao et al., 2002; Mao and Niehrs, 2003). In contrast, the role of DKK3 as a Wnt inhibitor is less clear. In some studies, DKK3 is not shown to bind to LRP5/ 6 at the cell surface membrane, and whether it binds to KRM1/2 remains controversial (Mao et al., 2002; Nakamura and Hackam, 2010). In contrast, others have however confirmed DKK3 as an inhibitor of the canonical pathway (Yue et al., 2008; Lee et al., 2009; Dellinger et al., 2012).

\section{DKK3 AS A TUMOR SUPPRESSOR}

Several lines of evidence exist to suggest that DKK3 acts as a tumor suppressor. Originally identified as a novel TSG by Tsuji et al. (2000) using an in vitro transformation model of normal human fibroblasts, reduced DKK3 expression was subsequently observed in cell lines and tumors of several different cancer types including liver, lung, prostate, breast, osteosarcoma, and leukemia (Tsuji et al., 2000; Nozaki et al., 2001; Hsieh et al., 2004; Kurose et al., 2004; Roman-Gomez et al., 2004; Abarzua et al., 2005; Tanimoto et al., 2007; Mizobuchi et al., 2008; Veeck et al., 2008; Yue et al., 2008; Yu et al., 2009; Dellinger et al., 2012). Studies into the mechanisms behind reduced DKK3 expression have revealed histone modification in cancers such as renal cell carcinoma (Ueno et al., 2011), and hypermethylation of the DKK3 promoter in a vast number of human cancers including lung, bladder, breast, and leukemia (reviewed by Veeck and Dahl, 2012). Additionally, loss of heterozygousity and homozygous deletions of the DKK3 gene at 11p15 have also been reported (Tsuji et al., 2001; Bashyam et al., 2005). In some cases, reduced DKK3 expression and/or DKK3 promoter methylation has been shown to be associated with poor prognostic clinicopathologic characteristics and outcome (Roman-Gomez et al., 2004; Yue et al., 2008; Veeck et al., 2009; Yu et al., 2009; Yang et al., 2010; Dellinger et al., 2012; Wang et al., 2012a).

Overexpression of DKK3 has been shown to mediate potent anti-tumor effects including reduced cell proliferation, anchorageindependent growth, and invasion and metastasis, and induced cancer cell specific apoptosis both in vitro and in murine tumor 
models (Tsuji et al., 2001; Abarzua et al., 2005; Edamura et al., 2007; Tanimoto et al., 2007; Koppen et al., 2008; Mizobuchi et al., 2008; Kawasaki et al., 2009; Gu et al., 2011; Than et al., 2011; Ueno et al., 2011; Dellinger et al., 2012; Yang et al., 2012). The precise mechanisms by which DKK3 inhibits tumorigenesis are not completely understood. Studies using a replication incompetent adenoviral vector incorporating the human DKK3 cDNA (Ad-REIC/DKK3) have demonstrated that DKK3 induced apoptosis is mediated via ER stress triggered activation of JNK with subsequent reduction in anti-apoptotic BCL2, mitochondrial translocation of BAX, cytochrome $\mathrm{C}$ release, and activated caspase cleavage (Abarzua et al., 2005, 2007; Tanimoto et al., 2007; Kashiwakura et al., 2008; Kobayashi et al., 2008; Kawasaki et al., 2009). Ad-REIC/DKK3 has also been shown to induce an indirect host-mediated antitumor effect via the induction of IL-7 (Sakaguchi et al., 2009). It is however important to mention that mechanisms which mediate resistance to DKK3 induced apoptosis have been identified, such as the overexpression of heat shock protein 70/72, an ER-residing chaperone BiP/GRP78 BiP/GRP78 and BCL2 (Veeck and Dahl, 2012). Interestingly, despite the vast body of evidence suggesting a fundamental role for DKK3 in cancer development, DKK3 knockout mice were both viable and fertile and were not observed to be more susceptible to cancer development (Barrantes Idel et al., 2006).

\section{THE ROLE OF DKK3 IN NEUROBLASTOMA}

DKK3 is secreted in neuroblastoma cell lines, and in primary tumors is found to be expressed in the endothelium (Koppen et al., 2008; Haug et al., 2011). An initial study of DKK3 and neuroblastic tumors observed that $D K K 3$ expression was a marker of tumor differentiation, where the highest expression was observed in the most differentiated ganglioneuromas, and the lowest expression in the least differentiated neuroblastoma. Specifically in neuroblastoma tumors, low DKK3 expression correlated significantly with poor prognosis, however this was not independent of $M Y C N$ amplification (Koppen et al., 2008). In a more recent study of 101 neuroblastic tumors including 88 neuroblastoma tumors, both high $D K K 3$ and $D K K 2$ expression correlated with good prognosis (Revet et al., 2010).

Several studies to date including our own have observed an inverse relationship between DKK3 expression and MYCN amplification and/or expression in both cell lines and primary tumors, thereby suggesting that downregulation of DKK3 is necessary for progression of MYCN amplified neuroblastoma (Table 3; Bell et al., 2007a; Koppen et al., 2008; Chen et al., 2010; Haug et al., 2011; De Brouwer et al., 2012; Figure 4). Consistent with this, overexpression of DKK3 inhibited the proliferation of $M Y C N$ amplified neuroblastoma cell lines in vitro (Koppen et al., 2008).

To determine the mechanism responsible for low DKK3 expression in MYCN amplified tumors, studies have observed that irrespective of MYCN status, reduced DKK3 expression in neuroblastoma was not due to promoter hypermethylation (Haug et al., 2011). Through ChIP analysis, MYCN was reported to downregulate $D K K 3$ expression through a mechanism independent of direct transcriptional repression (Koppen et al., 2008). Indeed, in support of this, two recent independent studies have shown that MYCN regulates the expression and secretion of DKK3 in neuroblastoma cells through direct upregulation of the oncogenic $m i R-17-92$ cluster (e.g., $m i R-92 a,-92 b$, and $-19 b$ ) which target the $3^{\prime}$ UTR of $D K K 3$ (Haug et al., 2011; De Brouwer et al., 2012; Figure 4). Analysis of primary tumors demonstrated a positive correlation between MYCN expression and miR-17-92 cluster expression, consistent with previous studies (Schulte et al., 2008), and an inverse correlation between miR-17-92 cluster expression and DKK3 expression (Haug et al., 2011; De Brouwer et al., 2012). In line with higher DKK3 expression in ganglioneuroma and ganglioneuroblastoma, these tumors had lower levels of $m i R-92 a$ compared with neuroblastoma (Haug et al., 2011).

The precise mechanism by which DKK3 suppresses neuroblastoma tumorigenesis is unclear however this does not appear to be through inhibition of the canonical Wnt/ $\beta$-catenin signaling pathway (Koppen et al., 2008). It is possible that DKK3 may act by inhibiting non-canonical Wnt signaling pathways such as the Planar cell polarity (PCP)-pathway, or the $\mathrm{Wnt} / \mathrm{Ca}^{2+}$ pathway.

Table 3 | Summary of studies which have observed an inverse relationship between DKK3 expression and MYCN expression and/or MYCN amplification in neuroblastoma.

\begin{tabular}{|c|c|c|c|c|}
\hline Study & Tumors & Cell Lines & Methods & Evidence \\
\hline Koppen et al. (2008) & $\begin{array}{l}13 \text { Ganglioneuroma, } 14 \\
\text { ganglioneuroblastoma, } \\
82 \text { neuroblastoma }\end{array}$ & $\begin{array}{l}14 \text { MNA and } 8 \text { MYCN single-copy NB cell } \\
\text { lines², Tet } 21 N \text {, SKNAS-NMYCER }\end{array}$ & Microarray ${ }^{3}$, Northern blot & $\mathrm{T}, \mathrm{C}, \mathrm{E}$ \\
\hline Chen et al. (2010) & - & Tet21N & Microarray & $E$ \\
\hline Haug et al. (2011) & 25 Neuroblastoma & SKNBE2C, Kelly, Tet21N & IHC, shMYCN, qRT-PCR & T, Sh, E \\
\hline
\end{tabular}

${ }^{1}$ Microarray analysis performed on IMR32 and SKNBE2C cells treated with scrambled or MYCN siRNA for 16 and $48 \mathrm{~h}$; ${ }^{2}$ see publication for full list of cell lines used; ${ }^{3}$ performed on 12/22 neuroblastoma cell lines.

MNA; MYCN amplified; NB, neuroblastoma; IHC, immunohistochemistry; Si, differential expression following MYCN siRNA; Sh, differential expression following MYCN shRNA; E, differential expression/correlation in ectopic MYCN expression systems; T, differential expression/correlation in tumors with MYCN amplification; $C$, differential expression/correlation in cell lines with/without MYCN amplification. 


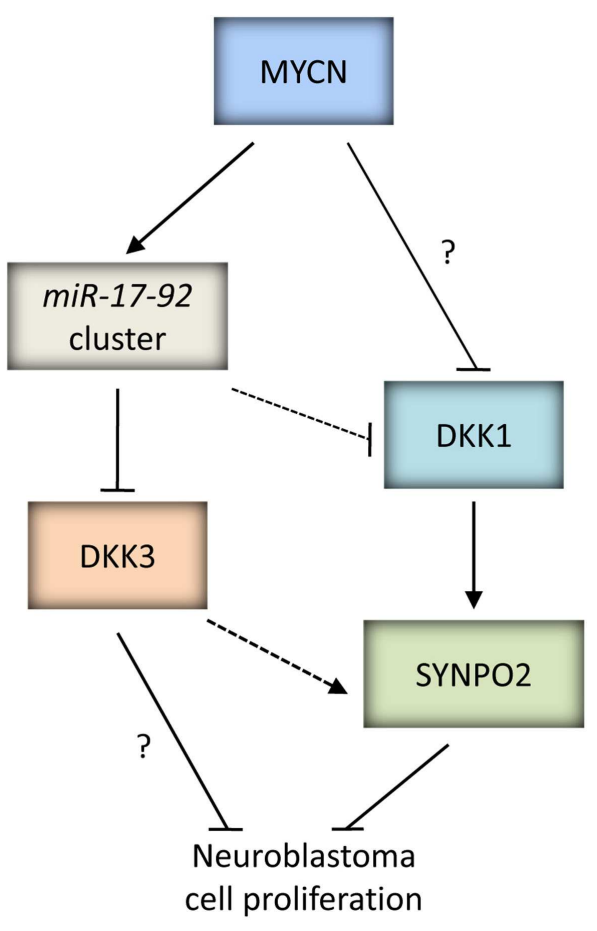

FIGURE 4 | MYCN mediated downregulation of DKK proteins in neuroblastoma. DKK1 and DKK3 can inhibit the proliferation of neuroblastoma cells, therefore downregulation of DKK proteins by MYCN will favor neuroblastoma tumorigenesis. MYCN mediated downregulation of DKK3 can occur via upregulation of the oncogenic miR-17-92 cluster, and due to the homology between $D K K$ family members, this may also be a potential mechanism for MYCN mediated downregulation of DKK1 (as indicated by the dashed line). DKK1 inhibits the proliferation of neuroblastoma cells via upregulation of SYNPO2, and although the mechanism for DKK3 remains unclear, due to the homology between DKK family members this may also occur via SYNPO2 (as indicated by the dashed line).

Interestingly, these non-canonical Wnt pathways have previously been shown to control neural crest migration (De Calisto et al., 2005).

Similar to DKK3, DKK1 is also reported to be secreted in neuroblastoma cell lines, and downregulated indirectly by MYCN (Koppen et al., 2007). Lower expression was observed in the presence of ectopic MYCN and in MYCN amplified tumors (Bell et al., 2007b; Koppen et al., 2007; Chen et al., 2010). Overexpression of DKK1 inhibited the proliferation of neuroblastoma cell lines through upregulation of synaptopodin-2 (SYNPO2), a protein previously reported to suppress tumor growth, and not by inhibition of canonical Wnt/ $\beta$-catenin signaling (Koppen et al., 2007; Figure 4).

The above findings suggest that DKK proteins may play a role in neuroblastoma pathogenesis, therefore it would be interesting to assess tumor formation in TH-MYCN transgenic mice deficient in $D K K 3$ or $D K K 1$. Certainly, the Wnt pathway is involved in early formation of the neural crest and the subsequent development, migration, and terminal differentiation of neural crest cells (Barembaum and Bronner-Fraser, 2005; Ille and Sommer, 2005), and $\mathrm{Wnt} / \beta$-catenin signaling has been shown to directly induce MYCN expression (Kuwahara et al., 2010). Additionally, embryonal malignancies of childhood such as neuroblastoma have been suggested to be disorders of normal development (reviewed by Grimmer and Weiss, 2006; Johnsen et al., 2009), therefore it is not surprising that deregulated Wnt pathway signaling may be involved in neuroblastoma development.

To date, studies into Wnt signaling in neuroblastoma have shown that siRNA mediated inhibition of the Wnt $1 / \beta$-catenin pathway leads to apoptosis of SHSY5Y cells (Zhang et al., 2009), and deregulated canonical and non-canonical Wnt signaling in chemoresistant and high-risk disease (Blanc et al., 2005; Liu et al., 2008b; Flahaut et al., 2009). Additionally, the expression of FZD6 is reported to predict poor survival in neuroblastoma patients, and marks rare and highly tumorigenic neuroblastoma stem cells (Cantilena et al., 2011). Furthermore, microarray analysis of Tet21N MYCN+ and MYCN- cells identified that in addition to $D K K 1$ and $D K K 3$, there was deregulated expression of several components of the Wnt pathway in the presence of MYCN. These included downregulation of additional Wnt signaling antagonists SFRP1 and APC together with the upregulated expression of positive regulators FRAT2, CSNK2A1, and RUVBL1 (Chen, 2009; Chen et al., 2010). Interestingly, in an independent study, SFRP1 was observed to correlate with good prognosis in neuroblastic tumors (Revet et al., 2010). CSNK2A1 and RUVBL1 have been reported to play multiple roles in driving malignant transformation (Duncan and Litchfield, 2008; Huber et al., 2008), and RUVBL1 expression was identified to be associated with poor overall survival in neuroblastoma patients (Westermann et al., 2008). Finally, several upstream components of the Wnt pathway have been reported to be highly expressed in neuroblastic tumors and cell lines (Revet et al., 2010). Taken together, these findings provide support to suggest that the Wnt pathway may be important in neuroblastoma pathogenesis although the precise role remains unclear and will require further investigation.

\section{THERAPEUTIC STRATEGIES TO RE-ESTABLISH DKK3}

Developmental pathways are becoming important targets for cancer therapy, and inhibitors targeting Wnt, Notch, and Hedgehog have reached clinical evaluation (see footnote 3 ). The low expression of DKK3 in several human cancers combined with its cancer specific apoptosis inducing effects suggest that re-establishing DKK3 holds promise as a novel targeted cancer therapy. The use of demethylating agents to re-express $D K K 3$ in cancers where promoter hypermethylation leads to gene silencing have been shown in studies using cell lines of several cancers including gastric, prostate, lung, and leukemia (reviewed by Veeck and Dahl, 2012). Demethylating agents azacitidine and decitabine have been approved in the treatment of myelodysplastic syndromes (Cataldo et al., 2009; Santos et al., 2010), however this method is not gene specific and could alter the epigenetic patterns of the entire genome. In neuroblastoma, demethylating agents are unlikely to be of therapeutic use, as low DKK3 expression was not shown to be due to promoter methylation (Haug et al., 2011). An alternative strategy involves DKK3 targeted gene therapy. The vast majority of work to date has been carried out Ad-REIC/DKK3 (Abarzua et al., 2005), however the use of a biodegradable cationic 
polymer based vector has also been reported (Veeck and Dahl, 2012). Ad-REIC/DKK3 has been used with success in preclinical studies demonstrating robust anti-tumor effects including induction of cancer cell specific apoptosis and inhibition of metastatic disease (Abarzua et al., 2005; Edamura et al., 2007; Kawasaki et al., 2009; Sakaguchi et al., 2009; Than et al., 2011), and is currently in clinical trials for use in prostate cancer (see footnote 3; NCT01197209). In addition, DKK3 also appears to play a role in chemoresistance, and Ad-REIC/DKK3 mediated downregulation of MDR-1 expression through JNK activation sensitized previously chemoresistant tumor cells to chemotherapy, which supports the applicability of using Ad-REIC/DKK3 in combination with convention chemotherapies in the treatment of drug-resistant cancers (Kawasaki et al., 2009; Hirata et al., 2012). Preclinical studies to evaluate the effect of Ad-REIC/DKK3 in neuroblastoma are yet to be conducted.

Alternative strategies more specific to neuroblastoma may involve the direct targeting of the oncogenic miR-17-92 cluster to re-establish $D K K 3$ expression in $M Y C N$ amplified neuroblastoma, or the use of agents which directly affect $M Y C N$ expression in neuroblastoma cells such as the BET inhibitor, JQ1 (Mertz et al., 2011). Certainly, targeting miRNAs as a new class of therapeutics has been gaining increased interest in recent years, and Miravirsen, which inhibits miR-122 is currently in phase II trials for the treatment of patients with Hepatitis C virus (Hu et al., 2012).

\section{CONCLUSIONS AND PERSPECTIVES}

In recent years, the involvement of the p53/MDM2/p14 ${ }^{\mathrm{ARF}}$ pathway in neuroblastoma has become increasingly evident and targeting this pathway through small molecule inhibitors of the MDM2p53 interaction in neuroblastoma which remains predominantly wt even at relapse, is an attractive therapeutic option. Currently newer more potent MDM2-p53 antagonists are undergoing

\section{REFERENCES}

Abarzua, F., Sakaguchi, M., Takaishi, M., Nasu, Y., Kurose, K., Ebara, S., et al. (2005). Adenovirus-mediated overexpression of REIC/Dkk-3 selectively induces apoptosis in human prostate cancer cells through activation of c-Jun-NH2-kinase. Cancer Res. 65, 9617-9622.

Abarzua, F., Sakaguchi, M., Tanimoto, R., Sonegawa, H., Li, D. W., Edamura, K., et al. (2007). Heat shock proteins play a crucial role in tumor-specific apoptosis by REIC/Dkk-3. Int. J. Mol. Med. 20, 37-43.

Adhikary, S., and Eilers, M. (2005). Transcriptional regulation and transformation by Myc proteins. Nat. Rev. Mol. Cell Biol. 6, 635-645.

Alt, J. R., Greiner, T. C., Cleveland, J. L., and Eischen, C. M. (2003). Mdm2 haplo-insufficiency profoundly inhibits Myc-induced commercial development, which will be tested in suitable preclinical models of neuroblastoma leading to their evaluation in early phase clinical trials and hopefully eventually into standard neuroblastoma therapy.

The precise involvement of SKP2 and DKK3 in neuroblastoma will require further investigation and these targets are currently much less developed in terms of their therapeutic potential. Nevertheless their involvement in other cancers as well as neuroblastoma makes them a priority for commercial and academic drug development programs.

It is envisaged that the therapeutic strategies which have been proposed in this review are most likely to be effective in combination with existing treatment regimens or other targeted agents and not alone. The increased understanding of neuroblastoma tumorigenesis and mechanisms of therapy resistance and relapse, advances in the development of murine models which more closely resemble high-risk metastatic and/or relapsed disease, and the drive towards targeted/personalized therapies, will hopefully provide increased opportunities to test out some of the paradigms mentioned in this review. When testing therapies directed against all these targets it will be important to do so both in MYCN amplified and non-amplified settings to fully evaluate their dependence on MYCN.

This is an exciting time for neuroblastoma drug development and with many new targeted agents in the pipeline undergoing preclinical evaluation and early phase clinical trials it surely will not be long before one reaches frontline therapy and improves the outcome, whilst hopefully reducing long-term toxicity in patients with high-risk disease.

\section{ACKNOWLEDGMENTS}

Work carried out by Dr L. Chen in the laboratory of Professor D. A. Tweddle is currently funded by SPARKS (Sport Aiding Medical Research for Kids) and the Dubois Cancer Fund. costimulation mediates transcription of SKP2 and CKS1, the substrate recognition components of SCFSkp2 ubiquitin ligase that leads p27kip1 to degradation. Cell Cycle 5, 2123-2129.

Bader, A. G. (2012). miR-34 - a microRNA replacement therapy is headed to the clinic. Front. Gene. 3:120. doi:10.3389/fgene.2012. 00120

Bagchi, A., Papazoglu, C., Wu, Y., Capurso, D., Brodt, M., Francis, D., et al. (2007). CHD5 is a tumor suppressor at human 1p36. Cell 128, 459-475.

Bai, C., Sen, P., Hofmann, K., Ma, L., Goebl, M., Harper, J. W., et al. (1996). SKP1 connects cell cycle regulators to the ubiquitin proteolysis machinery through a novel motif, the F-box. Cell 86, 263-274.

Bai, L., and Zhu, W. (2006). p53: structure, function and therapeutic applications. J. Cancer Mol. 2, 141-153.
Barbieri, E., Mehta, P., Chen, Z. Zhang, L., Slack, A., Berg, S., et al. (2006). MDM2 inhibition sensitizes neuroblastoma to chemotherapy-induced apoptotic cell death. Mol. Cancer Ther. 5, 2358-2365.

Barembaum, M., and Bronner-Fraser, M. (2005). Early steps in neural crest specification. Semin. Cell Dev. Biol. 16, 642-646.

Barrantes Idel, B., Montero-Pedrazuela, A., Guadano-Ferraz, A., Obregon, M J., Martinez De Mena, R., GailusDurner, V., et al. (2006). Generation and characterization of dickkopf3 mutant mice. Mol. Cell. Biol. 26, 2317-2326.

Bashir, T., Dorrello, N. V., Amador, V., Guardavaccaro, D., and Pagano, M. (2004). Control of the SCF(Skp2-Cks1) ubiquitin ligase by the $\mathrm{APC} / \mathrm{C}(\mathrm{Cdh} 1)$ ubiquitin ligase. Nature 428, 190-193. 
Bashir, T., and Pagano, M. (2004). Don't skip the G1 phase: how APC/CCdh1 keeps SCFSKP2 in check. Cell Cycle 3, 850-852.

Bashyam, M. D., Bair, R., Kim, Y. H., Wang, P., Hernandez-Boussard, T., Karikari, C. A., et al. (2005). Array-based comparative genomic hybridization identifies localized DNA amplifications and homozygous deletions in pancreatic cancer. Neoplasia 7, 556-562.

Becker, K., Marchenko, N. D., Maurice, M., and Moll, U. M. (2007). Hyperubiquitylation of wild-type p53 contributes to cytoplasmic sequestration in neuroblastoma. Cell Death Differ. 14, 1350-1360.

Bell, E., Chen, L., Liu, T., Marshall, G. M., Lunec, J., and Tweddle, D. A. (2010). MYCN oncoprotein targets and their therapeutic potential. Cancer Lett. 293, 144-157.

Bell, E., Lunec, J., and Tweddle, D. A. (2007a). Cell cycle regulation targets of MYCN identified by gene expression microarrays. Cell Cycle 6, 1249-1256.

Bell, E., University of Newcastle Upon Tyne. School of Clinical and Laboratory Sciences., and University of Newcastle Upon Tyne. (2007b). The Role of MYCN in 553 Activation and the Downstream Response to p53 After DNA Damage in Neuroblastoma. Newcastle upon Tyne: University of Newcastle upon Tyne.

Bell, E., Premkumar, R., Carr, J., Lu, X., Lovat, P. E., Kees, U. R., et al. (2006). The role of MYCN in the failure of MYCN amplified neuroblastoma cell lines to G1 arrest after DNA damage. Cell Cycle 5, 2639-2647.

Ben-Yosef, T., Yanuka, O., Halle, D., and Benvenisty, N. (1998). Involvement of Myc targets in c-myc and N-myc induced human tumors. Oncogene 17, 165-171.

Bergmann, E., Wanzel, M., Weber, A., Shin, I., Christiansen, H., and Eilers, M. (2001). Expression of $\mathrm{P} 27(\mathrm{KIP} 1)$ is prognostic and independent of MYCN amplification in human neuroblastoma. Int. J. Cancer 95, 176-183.

Berwanger, B., Hartmann, O., Bergmann, E., Bernard, S., Nielsen, D., Krause, M., et al. (2002). Loss of a FYN-regulated differentiation and growth arrest pathway in advanced stage neuroblastoma. Cancer Cell 2, 377-386.

Binne, U. K., Classon, M. K., Dick, F. A., Wei, W., Rape, M., Kaelin, W. G. Jr., et al. (2007). Retinoblastoma protein and anaphase-promoting complex physically interact and functionally cooperate during cell-cycle exit. Nat. Cell Biol. 9, 225-232.

Blanc, E., Roux, G. L., Benard, J., and Raguenez, G. (2005). Low expression of Wnt-5a gene is associated with high-risk neuroblastoma. Oncogene 24, 1277-1283.

Bode, A. M., and Dong, Z. (2004). Posttranslational modification of p53 in tumorigenesis. Nat. Rev. Cancer 4, 793-805.

Bohlig, L., and Rother, K. (2011). One function - multiple mechanisms: the manifold activities of p53 as a transcriptional repressor. J. Biomed. Biotechnol. 2011, 464916.

Bommer, G. T., Gerin, I., Feng, Y., Kaczorowski, A. J., Kuick, R., Love, R. E., et al. (2007). p53-Mediated activation of miRNA34 candidate tumor-suppressor genes. Curr. Biol. 17, 1298-1307.

Bornstein, G., Bloom, J., Sitry-Shevah, D., Nakayama, K., Pagano, M., and Hershko, A. (2003). Role of the SCFSkp2 ubiquitin ligase in the degradation of $\mathrm{p} 21 \mathrm{Cip} 1$ in S phase. J. Biol. Chem. 278, 25752-25757.

Braithwaite, A. W., Del Sal, G., and Lu, X. (2006). Some p53-binding proteins that can function as arbiters of life and death. Cell Death Differ. 13, 984-993.

Braun, C. J., Zhang, X., Savelyeva, I., Wolff, S., Moll, U. M., Schepeler, T., et al. (2008). p53-Responsive micrornas 192 and 215 are capable of inducing cell cycle arrest. Cancer Res. 68, 10094-10104.

Bray, I., Bryan, K., Prenter, S., Buckley, P. G., Foley, N. H., Murphy, D. M., et al. (2009). Widespread dysregulation of MiRNAs by MYCN amplification and chromosomal imbalances in neuroblastoma: association of miRNA expression with survival. PLoS ONE 4, e7850. doi:10.1371/journal.pone.0007850

Bretones, G., Acosta, J. C., Caraballo, J. M., Ferrandiz, N., Gomez-Casares, M. T., Albajar, M., et al. (2011). SKP2 oncogene is a direct MYC target gene and MYC down-regulates p27(KIP1) through SKP2 in human leukemia cells. J. Biol. Chem. 286, 9815-9825.

Brignole, C., Marimpietri, D., Pastorino, F., Nico, B., Di Paolo, D., Cioni, M., et al. (2006). Effect of bortezomib on human neuroblastoma cell growth, apoptosis, and angiogenesis. J. Natl. Cancer Inst. 98, 1142-1157.

Brosh, R., and Rotter, V. (2009). When mutants gain new powers: news from the mutant p53 field. Nat. Rev. Cancer 9, 701-713.

Brown, C. J., Lain, S., Verma, C. S., Fersht, A. R., and Lane, D. P. (2009).
Awakening guardian angels: drugging the p53 pathway. Nat. Rev. Cancer 9, 862-873.

Calao, M., Sekyere, E. O., Cui, H. J., Cheung, B. B., Thomas, W. D., Keating, J., et al. (2012). Direct effects of Bmil on 553 protein stability inactivates oncoprotein stress responses in embryonal cancer precursor cells at tumor initiation. Oncogene. doi: 10.1038/onc. 2012.368

Calin, G., Ivan, M., and Stefanescu, D. (1999). The difference between p53 mutation frequency in haematological and non-haematological malignancies: possible explanations. Med. Hypotheses 53, 326-328.

Cantilena, S., Pastorino, F., Pezzolo, A., Chayka, O., Pistoia, V., Ponzoni, M., et al. (2011). Frizzled receptor 6 marks rare, highly tumourigenic stem-like cells in mouse and human neuroblastomas. Oncotarget 2, 976-983.

Cao, L., Bombard, J., Cintron, K. Sheedy, J., Weetall, M. L., and Davis, T. W. (2011). BMI1 as a novel target for drug discovery in cancer. J. Cell. Biochem. 112, 2729-2741.

Caren, H., Erichsen, J., Olsson, L., Enerback, C., Sjoberg, R. M., Abrahamsson, J., et al. (2008). High-resolution array copy number analyses for detection of deletion, gain, amplification and copy-neutral LOH in primary neuroblastoma tumors: four cases of homozygous deletions of the CDKN2A gene. BMC Genomics 9, 353. doi:10.1186/1471-2164-9-353

Carol, H., Boehm, I., Reynolds, C. P., Kang, M. H., Maris, J. M., Morton, C. L., et al. (2011). Efficacy and pharmacokinetic/pharmacodynamic evaluation of the aurora kinase A inhibitor MLN8237 against preclinical models of pediatric cancer. Cancer Chemother. Pharmacol. 68, 1291-1304.

Carr, J., Bell, E., Pearson, A. D., Kees, U. R., Beris, H., Lunec, J., et al. (2006). Increased frequency of aberrations in the p53/MDM2/p14(ARF) pathway in neuroblastoma cell lines established at relapse. Cancer Res. 66 2138-2145.

Carrano, A. C., Eytan, E., Hershko, A., and Pagano, M. (1999). SKP2 is required for ubiquitin-mediated degradation of the CDK inhibitor p27. Nat. Cell Biol. 1, 193-199.

Carrano, A. C., and Pagano, M. (2001). Role of the F-box protein Skp2 in adhesion-dependent cell cycle progression. J. Cell Biol. 153, 1381-1390. Carr-Wilkinson, J., Griffiths, R., Elston, R., Gamble, L. D., Goranov, B., Redfern, C. P., et al. (2011). Outcome of the p53-mediated DNA damage response in neuroblastoma is determined by morphological subtype and MYCN expression. Cell Cycle 10, 3778-3787.

Carr-Wilkinson, J., O’Toole, K., Wood, K. M., Challen, C. C., Baker, A. G., Board, J. R., et al. (2010). High frequency of $\mathrm{p} 53 / \mathrm{MDM} 2 / \mathrm{p} 14 \mathrm{ARF}$ pathway abnormalities in relapsed neuroblastoma. Clin. Cancer Res. 16, 1108-1118.

Castresana, J. S., Bello, M. J., Rey, J. A., Nebreda, P., Queizan, A. Garcia-Miguel, P., et al. (1994). No TP53 mutations in neuroblastomas detected by PCR-SSCP analysis. Genes Chromosomes Cancer 10, 136-138.

Cataldo, V. D., Cortes, J., and QuintasCardama, A. (2009). Azacitidine for the treatment of myelodysplastic syndrome. Expert Rev. Anticancer Ther. 9, 875-884.

Cattelani, S., Defferrari, R., Marsilio, S., Bussolari, R., Candini, O., Corradini, F., et al. (2008). Impact of a single nucleotide polymorphism in the MDM2 gene on neuroblastoma development and aggressiveness: results of a pilot study on 239 patients. Clin. Cancer Res. 14, 3248-3253.

Cattelani, S., Ferrari-Amorotti, G., Galavotti, S., Defferrari, R., Tanno, B., Cialfi, S., et al. (2012). The p53 Codon 72 Pro/Pro genotype identifies poor-prognosis neuroblastoma patients: correlation with reduced apoptosis and enhanced senescence by the p53-72P Isoform. Neoplasia 14, 634-643.

Chan, C. H., Lee, S. W., Li, C. F., Wang, J., Yang, W. L., Wu, C. Y., et al. (2010a). Deciphering the transcriptional complex critical for RhoA gene expression and cancer metastasis. Nat. Cell Biol. 12, 457-467.

Chan, C. H., Lee, S. W., Wang, J., and Lin, H. K. (2010b). Regulation of Skp2 expression and activity and its role in cancer progression. ScientificWorldJournal 10, 1001-1015.

Chan, C. H., Li, C. F., Yang, W. L., Gao, Y., Lee, S. W., Feng, Z., et al. (2012). The Skp2-SCF E3 ligase regulates Akt ubiquitination, glycolysis, herceptin sensitivity, and tumorigenesis. Cell 149, 1098-1111.

Chander, H., Halpern, M., ResnickSilverman, L., Manfredi, J. J., and Germain, D. (2010). Skp2B attenuates 553 function by inhibiting prohibitin. EMBO Rep. 11, 220-225.

Chang, T.-C., Wentzel, E. A., Kent, O. A., Ramachandran, K., Mullendore, M., Lee Kwang, H., et al. (2007). Transactivation of miR-34a by $\mathrm{p} 53$ Broadly influences gene expression 
and promotes apoptosis. Mol. Cell 26, 745-752.

Charrasse, S., Carena, I., Brondani, V., Klempnauer, K. H., and Ferrari, S. (2000). Degradation of BMyb by ubiquitin-mediated proteolysis: involvement of the Cdc34SCF(p45Skp2) pathway. Oncogene 19, 2986-2995.

Chen, D., Frezza, M., Schmitt, S., Kanwar, J., and Dou, Q. P. (2011). Bortezomib as the first proteasome inhibitor anticancer drug: current status and future perspectives. Curr. Cancer Drug Targets 11, 239-253.

Chen, L. (2009). An Investigation of the Relationship Between p53 Function, Differentiation and MYCN in Neuroblastoma. Newcastle upon Tyne: University of Newcastle upon Tyne.

Chen, L., Iraci, N., Gherardi, S., Gamble, L. D., Wood, K. M., Perini, G., et al. (2010). p53 Is a direct transcriptional target of MYCN in neuroblastoma. Cancer Res. 70, 1377-1388.

Chen, L., Malcolm, A. J., Wood, K. M., Cole, M., Variend, S., Cullinane, C., et al. (2007). p53 is nuclear and functional in both undifferentiated and differentiated neuroblastoma. Cell Cycle 6, 2685-2696.

Chen, Q., Xie, W., Kuhn, D. J., Voorhees, P. M., Lopez-Girona, A., Mendy, D., et al. (2008). Targeting the p27 E3 ligase SCF(Skp2) results in p27- and Skp2-mediated cell-cycle arrest and activation of autophagy. Blood 111, 4690-4699.

Chen, Z., Lin, Y., Barbieri, E., Burlingame, S., Hicks, J., Ludwig, A., et al. (2009). Mdm2 deficiency suppresses MYCN-driven neuroblastoma tumorigenesis in vivo. Neoplasia 11, 753-762.

Chen, Z., Zhang, D., Yue, F., Zheng, M., Kovacevic, Z., and Richardson, D. R. (2012). The iron chelators Dp44mT and DFO inhibit TGF-beta-induced epithelial-mesenchymal transition via up-regulation of N-Myc downstream-regulated gene 1 (NDRG1). J. Biol. Chem. 287, 17016-17028.

Cheok, C. F., Verma, C. S., Baselga, J., and Lane, D. P. (2011). Translating p53 into the clinic. Nat. Rev. Clin. Oncol. 8, 25-37.

Chesler, L., Goldenberg, D. D., Collins, R., Grimmer, M., Kim, G. E., Tihan, T., et al. (2008). Chemotherapyinduced apoptosis in a transgenic model of neuroblastoma proceeds through p53 induction. Neoplasia 10, 1268-1274.

Chesler, L., Schlieve, C., Goldenberg, D. D., Kenney, A., Kim, G., McMillan, A., et al. (2006).
Inhibition of phosphatidylinositol 3-kinase destabilizes Mycn protein and blocks malignant progression in neuroblastoma. Cancer Res. 66, 8139-8146.

Cheung, C. H., Coumar, M. S., Chang, J. Y., and Hsieh, H. P. (2011). Aurora kinase inhibitor patents and agents in clinical testing: an update (200910). Expert Opin. Ther. Pat. 21, 857-884.

Cho, C. H., Seo, M., Lee, Y. I., Kim, S. Y., Youn, H. D., and Juhnn, Y. S. (2007). Dibutyryl cAMP stimulates the proliferation of SH-SY5Y human neuroblastoma cells by upregulating Skp2 protein. J. Cancer Res. Clin. Oncol. 133, 135-144.

Chu, I. M., Hengst, L., and Slingerland, J. M. (2008). The Cdk inhibitor p27 in human cancer: prognostic potential and relevance to anticancer therapy. Nat. Rev. Cancer 8, 253-267.

Cohn, S. L., and Ikegaki, N. (2000). "Expression of MYCN mRNA and Protein," in Neuroblastoma, eds G. M. Brodeur, T. Sawada, Y. Tsuchida, and P. A. Voûte (Amsterdam: Elsevier Science B.V.), 137-146.

Cohn, S. L., and Tweddle, D. A. (2004). MYCN amplification remains prognostically strong 20 years after its "clinical debut." Eur. J. Cancer 40, 2639-2642.

Cole, K. A., Attiyeh, E. F., Mosse, Y. P., Laquaglia, M. J., Diskin, S. J., Brodeur, G. M., et al. (2008). A Functional Screen Identifies miR-34a as a candidate neuroblastoma tumor suppressor gene. Mol. Cancer Res. 6, 735-742.

Corvi, R., Savelyeva, L., Breit, S., Wenzel, A., Handgretinger, R., Barak, J., et al. (1995). Non-syntenic amplification of MDM2 and MYCN in human neuroblastoma. Oncogene 10, 1081-1086.

Cuende, J., Moreno, S., Bolanos, J. P., and Almeida, A. (2008). Retinoic acid downregulates Rael leading to APC(Cdh1) activation and neuroblastoma SH-SY5Y differentiation. Oncogene 27, 3339-3344.

Cui, H., Hu, B., Li, T., Ma, J., Alam, G., Gunning, W. T., et al. (2007). Bmi-1 is essential for the tumorigenicity of neuroblastoma cells. Am. J. Pathol. 170, 1370-1378.

Cui, H., Li, T., and Ding, H. F. (2005). Linking of N-Myc to death receptor machinery in neuroblastoma cells. J. Biol. Chem. 280, 9474-9481.

Cui, H., Schroering, A., and Ding, H. F. (2002). p53 mediates DNA damaging drug-induced apoptosis through a caspase-9-dependent pathway in SH-SY5Y neuroblastoma cells. Mol. Cancer Ther. 1, 679-686.
Dang, C. V. (1999). c-Myc target genes involved in cell growth, apoptosis, and metabolism. Mol. Cell. Biol. 19, $1-11$.

Danks, M. K., Whipple, D. O., Mcpake, C. R., Lu, D., and Harris, L. C. (1998). Differences in epitope accessibility of p53 monoclonal antibodies suggest at least three conformations or states of protein binding of $\mathrm{p} 53$ protein in human tumor cell lines. Cell Death Differ. 5, 678-686.

Dar, A. A., Zaika, A., Piazuelo, M. B., Correa, P., Koyama, T., Belkhiri, A., et al. (2008). Frequent overexpression of aurora kinase A in upper gastrointestinal adenocarcinomas correlates with potent antiapoptotic functions. Cancer 112, 1688-1698.

Davidoff, A. M., Pence, J. C., Shorter, N. A., Iglehart, J. D., and Marks, J. R. (1992). Expression of p53 in human neuroblastoma- and neuroepithelioma-derived cell lines. Oncogene 7, 127-133.

Davidovich, S., Ben-Izhak, O., Shapira, M., Futerman, B., and Hershko, D. D. (2008). Over-expression of Skp2 is associated with resistance to preoperative doxorubicin-based chemotherapy in primary breast cancer. Breast Cancer Res. 10, R63.

De Brouwer, S., Mestdagh, P., Lambertz, I., Pattyn, F., De Paepe, A., Westermann, F., et al. (2012). Dickkopf-3 is regulated by the MYCN-induced miR-17-92 cluster in neuroblastoma. Int. J. Cancer 130, 2591-2598.

De Calisto, J., Araya, C., Marchant, L., Riaz, C. F., and Mayor, R. (2005). Essential role of non-canonical Wnt signalling in neural crest migration. Development 132, 2587-2597.

Dellinger, T. H., Planutis, K., Jandial D. D., Eskander, R. N., Martinez, M. E., Zi, X., et al. (2012). Expression of the Wnt antagonist Dickkopf3 is associated with prognostic clinicopathologic characteristics and impairs proliferation and invasion in endometrial cancer. Gynecol. Oncol. 126, 259-267.

Deshaies, R. J. (1999). SCF and cullin/ring H2-based ubiquitin ligases. Annu. Rev. Cell Dev. Biol. 15, 435-467.

Deubzer, H. E., Ehemann, V., Kulozik, A. E., Westermann, F., Savelyeva, L., Kopp-Schneider, A., et al. (2008a). Anti-neuroblastoma activity of Helminthosporium carbonum (HC)-toxin is superior to that of other differentiating compounds in vitro. Cancer Lett. 264, 21-28.

Deubzer, H. E., Ehemann, V., Westermann, F., Heinrich, R., Mechtersheimer, G., Kulozik, A. E., et al. (2008b). Histone deacetylase inhibitor helminthosporium carbonum (HC)-toxin suppresses the malignant phenotype of neuroblastoma cells. Int. J. Cancer 122, 1891-1900.

Donehower, L. A. (1996). The p53deficient mouse: a model for basic and applied cancer studies. Semin. Cancer Biol. 7, 269-278.

Dumont, P., Leu, J. I., Della Pietra, A. C. III, George, D. L., and Murphy, M. (2003). The codon 72 polymorphic variants of p53 have markedly different apoptotic potential. Nat. Genet. 33, 357-365.

Duncan, J. S., and Litchfield, D. W. (2008). Too much of a good thing: the role of protein kinase CK2 in tumorigenesis and prospects for therapeutic inhibition of CK2 Biochim. Biophys. Acta 1784, 33-47.

Edamura, K., Nasu, Y., Takaishi, M., Kobayashi, T., Abarzua, F., Sakaguchi, M., et al. (2007) Adenovirus-mediated REIC/Dkk-3 gene transfer inhibits tumor growth and metastasis in an orthotopic prostate cancer model. Cancer Gene Ther. 14, 765-772.

Eizenberg, O., Faber-Elman, A., Gottlieb, E., Oren, M., Rotter, V., and Schwartz, M. (1996). p53 plays a regulatory role in differentiation and apoptosis of central nervous systemassociated cells. Mol. Cell. Biol. 16, 5178-5185.

el-Deiry, W. S., Kern, S. E., Pietenpol, J. A., Kinzler, K. W., and Vogelstein, B. (1992). Definition of a consensus binding site for p53. Nat. Genet. 1, 45-49.

Ellen, T. P., Ke, Q., Zhang, P., and Costa, M. (2008). NDRG1, a growth and cancer related gene: regulation of gene expression and function in nor$\mathrm{mal}$ and disease states. Carcinogenesis 29, 2-8.

Evans, S. C., and Lozano, G. (1997). The Li-Fraumeni syndrome: an inherited susceptibility to cancer. Mol. Med. Today 3, 390-395.

Faisal, A., Vaughan, L., Bavetsias, V., Sun, C., Atrash, B., Avery, S., et al. (2011). The aurora kinase inhibitor CCT137690 downregulates MYCN and sensitizes MYCNamplified neuroblastoma in vivo. Mol. Cancer Ther. 10, 2115-2123.

Feinberg-Gorenshtein, G., Avigad, S., Jeison, M., Halevy-Berco, G., Mardoukh, J., Luria, D., et al. (2009). Reduced levels of miR-34a in neuroblastoma are not caused by mutations in the TP53 binding site. Genes Chromosomes Cancer 48, 539-543.

Fernandez, P. C., Frank, S. R., Wang, L., Schroeder, M., Liu, S., Greene, J., et al. (2003). Genomic targets of the 
human c-Myc protein. Genes Dev. 17, 1115-1129.

Ferreira, A., and Kosik, K. S. (1996). Accelerated neuronal differentiation induced by 553 suppression. J. Cell. Sci. 109 (Pt 6), 1509-1516.

Flahaut, M., Meier, R., Coulon, A., Nardou, K. A., Niggli, F. K., Martinet, D., et al. (2009). The Wnt receptor FZD1 mediates chemoresistance in neuroblastoma through activation of the Wnt/betacatenin pathway. Oncogene 28, 2245-2256.

Forbes, S. A., Bhamra, G., Bamford, S., Dawson, E., Kok, C., Clements, J., et al. (2008). The catalogue of somatic mutations in cancer (COSMIC). Curr. Protoc. Hum. Genet. 10, Unit 1011.

Frescas, D., and Pagano, M. (2008). Deregulated proteolysis by the F-box proteins SKP2 and beta-TrCP: tipping the scales of cancer. Nat. Rev. Cancer 8, 438-449.

Fujita, T., Igarashi, J., Okawa, E. R., Gotoh, T., Manne, J., Kolla, V., et al. (2008). CHD5, a tumor suppressor gene deleted from $1 \mathrm{p} 36.31$ in neuroblastomas. J. Natl. Cancer Inst. 100, 940-949.

Fulda, S., Lutz, W., Schwab, M., and Debatin, K. M. (1999). MycN sensitizes neuroblastoma cells for druginduced apoptosis. Oncogene 18, 1479-1486.

Fulda, S., Lutz, W., Schwab, M., and Debatin, K. M. (2000). MycN sensitizes neuroblastoma cells for drugtriggered apoptosis. Med. Pediatr. Oncol. 35, 582-584.

Gamble, L. D., Kees, U. R., Tweddle, D. A., and Lunec, J. (2012). MYCN sensitizes neuroblastoma to the MDM2p53 antagonists Nutlin-3 and MI-63. Oncogene 31, 752-763.

Ganoth, D., Bornstein, G., Ko, T. K., Larsen, B., Tyers, M., Pagano, M., et al. (2001). The cell-cycle regulatory protein $\mathrm{Cks} 1$ is required for SCF(Skp2)-mediated ubiquitinylation of p27. Nat. Cell Biol. 3, 321-324.

Georges, S. A., Biery, M. C., Kim, S. Y., Schelter, J. M., Guo, J., Chang, A. N., et al. (2008). Coordinated regulation of cell cycle transcripts by $\mathrm{p} 53$-Inducible microRNAs, miR192 and miR-215. Cancer Res. 68, 10105-10112.

Gizard, F., Zhao, Y., Findeisen, H. M., Qing, H., Cohn, D., Heywood, E. B., et al. (2011). Transcriptional regulation of $\mathrm{S}$ phase kinase-associated protein 2 by NR4A orphan nuclear receptor NOR1 in vascular smooth muscle cells. J. Biol. Chem. 286, 35485-35493.
Goldman, S. C., Chen, C. Y., Lansing, T. J., Gilmer, T. M., and Kastan, M. B. (1996). The p53 signal transduction pathway is intact in human neuroblastoma despite cytoplasmic localization. Am. J. Pathol. 148, 1381-1385.

Goldschneider, D., Blanc, E., Raguenez, G., Barrois, M., Legrand, A., Le Roux, G., et al. (2004). Differential response of p53 target genes to p73 overexpression in SH-SY5Y neuroblastoma cell line. J. Cell. Sci. 117, 293-301.

Goldschneider, D., Horvilleur, E., Plassa, L.-F., Guillaud-Bataille, M., Million, K., Wittmer-Dupret, E., et al. (2006). Expression of C-terminal deleted p53 isoforms in neuroblastoma. Nucleic Acids Res. 34, 5603-5612.

Gonzalez-Gomez, P., Bello, M. J., Lomas, J., Arjona, D., Alonso, M. E., Aminoso, C., et al. (2003). Aberrant methylation of multiple genes in neuroblastic tumours. Relationship with MYCN amplification and allelic status at 1p. Eur. J. Cancer 39, 1478-1485.

Goto, S., Umehara, S., Gerbing, R. B., Stram, D. O., Brodeur, G. M., Seeger, R. C., et al. (2001). Histopathology (international neuroblastoma pathology classification) and MYCN status in patients with peripheral neuroblastic tumors: a report from the children's cancer group. Cancer 92, 2699-2708.

Grandori, C., Cowley, S. M., James, L. P., and Eisenman, R. N. (2000). The Myc/Max/Mad network and the transcriptional control of cell behavior. Annu. Rev. Cell Dev. Biol. 16, 653-699.

Grimmer, M. R., and Weiss, W. A. (2006). Childhood tumors of the nervous system as disorders of normal development. Curr. Opin. Pediatr. 18, 634-638.

Gu, L., Zhang, H., He, J., Li, J., Huang, M., and Zhou, M. (2012). MDM2 regulates MYCN mRNA stabilization and translation in human neuroblastoma cells. Oncogene 31, 1342-1353.

Gu, Y. M., Ma, Y. H., Zhao, W. G., and Chen, J. (2011). Dickkopf3 overexpression inhibits pancreatic cancer cell growth in vitro. World J. Gastroenterol. 17, 3810-3817.

Gustafson, W. C., and Weiss, W. A. (2010). Myc proteins as therapeutic targets. Oncogene 29, 1249-1259.

Hamamori, Y., Sartorelli, V., Ogryzko, V., Puri, P. L., Wu, H. Y., Wang, J. Y., et al. (1999). Regulation of histone acetyltransferases p300 and PCAF by the bHLH protein twist and adenoviral oncoprotein E1A. Cell 96, 405-413.

Hamner, J. B., Dickson, P. V., Sims, T. L. Zhou, J., Spence, Y., Ng, C. Y., et al. (2007). Bortezomib inhibits angiogenesis and reduces tumor burden in a murine model of neuroblastoma. Surgery 142, 185-191.

Hanel, W., and Moll, U. M. (2012). Links between mutant p53 and genomic instability. J. Cell. Biochem. 113, 433-439.

Hardcastle, I. R., Liu, J., Valeur, E., Watson, A., Ahmed, S. U., Blackburn, T. J., et al. (2011). Isoindolinone inhibitors of the murine double minute 2 (MDM2)p53 protein-protein interaction: structure-activity studies leading to improved potency. J. Med. Chem. 54, 1233-1243.

Harms, K., Nozell, S., and Chen, X. (2004). The common and distinct target genes of the p53 family transcription factors. Cell. Mol. Life Sci. 61, 822-842.

Haug, B. H., Henriksen, J. R., Buechner, J., Geerts, D., Tomte, E., Kogner, P., et al. (2011). MYCN-regulated miRNA-92 inhibits secretion of the tumor suppressor DICKKOPF-3 (DKK3) in neuroblastoma. Carcinogenesis 32, 1005-1012.

He, L., He, X., Lim, L. P., De Stanchina, E., Xuan, Z., Liang, Y., et al. (2007). A microRNA component of the p53 tumour suppressor network. Nature 447, 1130-1134.

Hermeking, H. (2007). p53 enters the microRNA world. Cancer Cell 12, 414-418.

Hermeking, H., and Eick, D. (1994). Mediation of c-Myc-induced apoptosis by p53. Science 265, 2091-2093.

Hershko, D. D. (2008). Oncogenic properties and prognostic implications of the ubiquitin ligase Skp2 in cancer. Cancer 112, 1415-1424.

Hiramatsu, Y., Kitagawa, K., Suzuki, T., Uchida, C., Hattori, T., Kikuchi, H., et al. (2006). Degradation of Tob1 mediated by SCFSkp2dependent ubiquitination. Cancer Res. 66, 8477-8483.

Hirata, T., Watanabe, M., Kaku, H., Kobayashi, Y., Yamada, H., Sakaguchi, M., et al. (2012). REIC/Dkk3 -encoding adenoviral vector as a potentially effective therapeutic agent for bladder cancer. Int. J. Oncol. 41, 559-564.

Hoehner, J. C., Gestblom, C., Olsen, L., and Pahlman, S. (1997). Spatial association of apoptosis-related gene expression and cellular death in clinical neuroblastoma. $\mathrm{Br}$. J. Cancer 75, 1185-1194.
Hogarty, M. D. (2003). The requirement for evasion of programmed cell death in neuroblastomas with MYCN amplification. Cancer Lett. 197, 173-179.

Honda, R., Tanaka, H., and Yasuda, H. (1997). Oncoprotein MDM2 is a ubiquitin ligase E3 for tumor suppressor p53. FEBS Lett. 420, 25-27.

Honda, R., and Yasuda, H. (1999). Association of $\mathrm{p} 19$ (ARF) with $\mathrm{Mdm} 2$ inhibits ubiquitin ligase activity of $\mathrm{Mdm} 2$ for tumor suppressor p53. EMBO J. 18, 22-27.

Hosoi, G., Hara, J., Okamura, T., Osugi, Y., Ishihara, S., Fukuzawa, M., et al. (1994). Low frequency of the p53 gene mutations in neuroblastoma. Cancer 73, 3087-3093.

Hsieh, S. Y., Hsieh, P. S., Chiu, C. T., and Chen, W. Y. (2004). Dickkopf3/REIC functions as a suppressor gene of tumor growth. Oncogene 23, 9183-9189.

Hu, D., Liu, W., Wu, G., and Wan, Y. (2011). Nuclear translocation of Skp2 facilitates its destruction in response to TGFbeta signaling. Cell Cycle 10, 285-292.

Hu, J., Xu, Y., Hao, J., Wang, S., Li, C., and Meng, S. (2012). MiR-122 in hepatic function and liver diseases. Protein Cell 3, 364-371.

Huang, H., Zhao, W., and Yang, D. (2012). Stat3 induces oncogenic Skp2 expression in human cervical carcinoma cells. Biochem. Biophys. Res. Commun. 418, 186-190.

Huang, H. C., Lin, C. L., and Lin, J. K. (2011a). 1,2,3,4,6-penta-O-galloylbeta-D-glucose, quercetin, curcumin and lycopene induce cell-cycle arrest in MDA-MB-231 and BT474 cells through downregulation of $\mathrm{Skp} 2$ protein. J. Agric. Food Chem. 59, 6765-6775.

Huang, R., Cheung, N. K., Vider, J., Cheung, I. Y., Gerald, W. L., Tickoo, S. K., et al. (2011b). MYCN and MYC regulate tumor proliferation and tumorigenesis directly through BMI1 in human neuroblastomas. FASEB J. 25, 4138-4149.

Huber, O., Menard, L., Haurie, V., Nicou, A., Taras, D., and Rosenbaum, J. (2008). Pontin and reptin, two related ATPases with multiple roles in cancer. Cancer Res. 68, 6873-6876.

Ille, F., and Sommer, L. (2005). Wnt signaling: multiple functions in neural development. Cell. Mol. Life Sci. 62, 1100-1108.

Imaki, H., Nakayama, K., Delehouzee, S., Handa, H., Kitagawa, M., Kamura, T., et al. (2003). Cell cycle-dependent regulation of the Skp2 promoter by GA-binding protein. Cancer Res. 63, 4607-4613. 
Imamura, J., Bartram, C. R., Berthold, F., Harms, D., Nakamura, H., and Koeffler, H. P. (1993). Mutation of the p53 gene in neuroblastoma and its relationship with $\mathrm{N}$-myc amplification. Cancer Res. 53, 4053-4058.

Inuzuka, H., Gao, D., Finley, L. W., Yang, W., Wan, L., Fukushima, H., et al. (2012). Acetylation-dependent regulation of skp2 function. Cell 150, 179-193.

Isaacs, J. S., Hardman, R., Carman, T. A., Barrett, J. C., and Weissman, B. E. (1998). Differential subcellular p53 localization and function in $\mathrm{N}$ - and S-type neuroblastoma cell lines. Cell Growth Differ. 9, 545-555.

Ishii, T., Matsuse, T., Masuda, M., and Teramoto, S. (2004). The effects of S-phase kinase-associated protein 2 (SKP2) on cell cycle status, viability, and chemoresistance in A549 lung adenocarcinoma cells. Exp. Lung Res. 30, 687-703.

Ji, P., Goldin, L., Ren, H., Sun, D., Guardavaccaro, D., Pagano, M., et al. (2006). Skp2 contains a novel cyclin A binding domain that directly protects cyclin A from inhibition by p27Kip1. J. Biol. Chem. 281, 24058-24069.

Jiang, F., Caraway, N. P., Li, R., and Katz, R. L. (2005). RNA silencing of S-phase kinase-interacting protein 2 inhibits proliferation and centrosome amplification in lung cancer cells. Oncogene 24, 3409-3418.

Jimenez, G. S., Khan, S. H., Stommel, J. M., and Wahl, G. M. (1999). p53 regulation by post-translational modification and nuclear retention in response to diverse stresses. Oncogene 18, 7656-7665.

Johnsen, J. I., Kogner, P., Albihn, A., and Henriksson, M. A. (2009). Embryonal neural tumours and cell death. Apoptosis 14, 424-438.

Jones, S. N., Hancock, A. R., Vogel, H., Donehower, L. A., and Bradley, A. (1998). Overexpression of Mdm2 in mice reveals a p53-independent role for $\mathrm{Mdm} 2$ in tumorigenesis. Proc. Natl. Acad. Sci. U.S.A. 95, 15608-15612.

Jones, S. N., Roe, A. E., Donehower, L. A., and Bradley, A. (1995). Rescue of embryonic lethality in Mdm2deficient mice by absence of p53. Nature 378, 206-208.

Junttila, M. R., and Evan, G. I. (2009). p53 - a Jack of all trades but master of none. Nat. Rev. Cancer 9, 821-829.

Kaghad, M., Bonnet, H., Yang, A., Creancier, L., Biscan, J. C., Valent, A., et al. (1997). Monoallelically expressed gene related to $\mathrm{p} 53$ at $1 \mathrm{p} 36$, a region frequently deleted in neuroblastoma and other human cancers. Cell 90, 809-819.

Kamijo, T., Bodner, S., Van De Kamp, E., Randle, D. H., and Sherr, C. J. (1999). Tumor spectrum in ARF-deficient mice. Cancer Res. 59, 2217-2222.

Kamura, T., Hara, T., Kotoshiba, S., Yada, M., Ishida, N., Imaki, H., et al. (2003). Degradation of p57Kip2 mediated by SCFSkp2-dependent ubiquitylation. Proc. Natl. Acad. Sci. U.S.A. 100, 10231-10236.

Kashiwakura, Y., Ochiai, K., Watanabe, M., Abarzua, F., Sakaguchi, M., Takaoka, M., et al. (2008). Down-regulation of inhibition of differentiation-1 via activation of activating transcription factor 3 and Smad regulates REIC/Dickkopf-3induced apoptosis. Cancer Res. 68, 8333-8341.

Katagiri, Y., Hozumi, Y., and Kondo, S. (2006). Knockdown of Skp2 by siRNA inhibits melanoma cell growth in vitro and in vivo. J. Dermatol. Sci. 42, 215-224.

Katayama, H., Sasai, K., Kawai, H., Yuan, Z. M., Bondaruk, J., Suzuki, F., et al. (2004). Phosphorylation by aurora kinase A induces Mdm2mediated destabilization and inhibition of p53. Nat. Genet. 36, 55-62.

Kawasaki, K., Watanabe, M., Sakaguchi, M., Ogasawara, Y., Ochiai, K., Nasu, Y., et al. (2009). REIC/Dkk3 overexpression downregulates Pglycoprotein in multidrug-resistant MCF7/ADR cells and induces apoptosis in breast cancer. Cancer Gene Ther. 16, 65-72.

Keshelava, N., Zuo, J. J., Chen, P., Waidyaratne, S. N., Luna, M. C., Gomer, C. J., et al. (2001). Loss of p53 function confers high-level multidrug resistance in neuroblastoma cell lines. Cancer Res. 61, 6185-6193.

Keshelava, N., Zuo, J. J., Waidyaratne, N. S., Triche, T. J., and Reynolds, C. P. (2000). p53 mutations and loss of p53 function confer multidrug resistance in neuroblastoma. Med. Pediatr. Oncol. 35, 563-568.

Kim, S. Y., Herbst, A., Tworkowski, K. A., Salghetti, S. E., and Tansey, W. P. (2003). Skp2 regulates Myc protein stability and activity. Mol. Cell 11, 1177-1188.

Kisselev, A. F., Van Der Linden, W. A., and Overkleeft, H. S. (2012). Proteasome inhibitors: an expanding army attacking a unique target. Chem. Biol. 19, 99-115.

Kitagawa, M., Lee, S. H., and Mccormick, F. (2008). Skp2 suppresses p53-dependent apoptosis by inhibiting p300. Mol. Cell 29, 217-231.
Klaus, A., and Birchmeier, W. (2008). Wnt signalling and its impact on development and cancer. Nat. Rev. Cancer 8, 387-398.

Kobayashi, T., Sakaguchi, M., Tanimoto, R., Abarzua, F., Takaishi, M., Kaku, H., et al. (2008). Mechanistic analysis of resistance to REIC/Dkk-3induced apoptosis in human bladder cancer cells. Acta Med. Okayama 62 393-401.

Koga, H., Harada, M., Ohtsubo, M., Shishido, S., Kumemura, H., Hanada, S., et al. (2003) Troglitazone induces p27Kip1associated cell-cycle arrest through down-regulating Skp2 in human hepatoma cells. Hepatology 37, 1086-1096.

Kojima, K., Konopleva, M., Tsao, T., Nakakuma, H., and Andreeff, M. (2008). Concomitant inhibition of Mdm2-p53 interaction and Aurora kinases activates the p53dependent postmitotic checkpoints and synergistically induces p53mediated mitochondrial apoptosis along with reduced endoreduplication in acute myelogenous leukemia. Blood 112, 2886-2895.

Komuro, H., Hayashi, Y., Kawamura, M. Hayashi, K., Kaneko, Y., Kamoshita S., et al. (1993). Mutations of the p53 gene are involved in Ewing's sarcomas but not in neuroblastomas. Cancer Res. 53, 5284-5288.

Koppen, A., Ait-Aissa, R., Hopman, S., Koster, J., Haneveld, F., Versteeg, R., et al. (2007). Dickkopf1 is down-regulated by MYCN and inhibits neuroblastoma cell proliferation. Cancer Lett. 256, 218-228.

Koppen, A., Ait-Aissa, R., Koster, J. Ora, I., Bras, J., Van Sluis, P. G. et al. (2008). Dickkopf-3 expression is a marker for neuroblastic tumor maturation and is downregulated by MYCN. Int. J. Cancer 122, 1455-1464.

Korotchkina, L. G., Demidenko, Z. N., Gudkov, A. V., and Blagosklonny, M. V. (2009). Cellular quiescence caused by the $\mathrm{Mdm} 2$ inhibitor nutlin-3A. Cell Cycle 8, 3777-3781.

Kovacevic, Z., Chikhani, S., Lui, G. Y., Sivagurunathan, S., and Richardson, D. R. (2012). The Iron-Regulated metastasis suppressor NDRG1 targets NEDD4L, PTEN, and SMAD4 and Inhibits the PI3K and Ras signaling pathways. Antioxid Redox Signal.

Koyama, H., Zhuang, T., Light, J. E., Kolla, V., Higashi, M., McGrady, P. W., et al. (2012). Mechanisms of CHD5 Inactivation in neuroblastomas. Clin. Cancer Res. 18, 1588-1597.
Kruse, J. P., and Gu, W. (2009). Modes of p53 regulation. Cell 137, 609-622.

Kurata, K., Yanagisawa, R., Ohira, M., Kitagawa, M., Nakagawara, A., and Kamijo, T. (2008). Stress via p53 pathway causes apoptosis by mitochondrial Noxa upregulation in doxorubicin-treated neuroblastoma cells. Oncogene 27, 741-754.

Kurose, K., Sakaguchi, M., Nasu, Y., Ebara, S., Kaku, H., Kariyama, R., et al. (2004). Decreased expression of REIC/Dkk-3 in human renal clear cell carcinoma. J. Urol. 171, 1314-1318.

Kusafuka, T., Fukuzawa, M., Oue, T., Komoto, Y., Yoneda, A., and Okada, A. (1997). Mutation analysis of p53 gene in childhood malignant solid tumors. J. Pediatr. Surg. 32, 1175-1180.

Kuwahara, A., Hirabayashi, Y., Knoepfler, P. S., Taketo, M. M. Sakai, J., Kodama, T., et al. (2010). Wnt signaling and its downstream target N-myc regulate basal progenitors in the developing neocortex. Development 137, 1035-1044.

Lane, D. P., Cheok, C. F., and Lain, S. (2010). p53-based cancer therapy. Cold Spring Harb. Perspect. Biol. 2, a001222.

Lane, D. P., and Crawford, L. V. (1979). T antigen is bound to a host protein in SV40-transformed cells. Nature 278, 261-263.

Lang, G. A., Iwakuma, T., Suh, Y. A., Liu, G., Rao, V. A., Parant, J. M., et al. (2004). Gain of function of a p53 hot spot mutation in a mouse model of Li-Fraumeni syndrome. Cell 119, 861-872.

Latres, E., Chiarle, R., Schulman, B. A., Pavletich, N. P., Pellicer, A., Inghirami, G., et al. (2001). Role of the F-box protein Skp2 in lymphomagenesis. Proc. Natl. Acad. Sci. U.S.A. 98, 2515-2520.

Lau, L. M., Nugent, J. K., Zhao, X., and Irwin, M. S. (2008). HDM2 antagonist Nutlin-3 disrupts p73-HDM2 binding and enhances $\mathrm{p} 73$ function. Oncogene 27, 997-1003.

Laurenti, E., Varnum-Finney, B., Wilson, A., Ferrero, I., Blanco-Bose, W. E., Ehninger, A., et al. (2008). Hematopoietic stem cell function and survival depend on $\mathrm{c}-\mathrm{Myc}$ and N-Myc activity. Cell Stem Cell 3, 611-624.

Layfield, L. J., Thompson, J. K., Dodge, R. K., and Kerns, B. J. (1995). Prognostic indicators for neuroblastoma: stage, grade, DNA ploidy, MIB-1proliferation index, p53, HER-2/neu and EGFr - a survival study. J. Surg. Oncol. 59, 21-27. 
Lee, E. J., Jo, M., Rho, S. B., Park, K., Yoo, Y. N., Park, J., et al. (2009). Dkk3, downregulated in cervical cancer, functions as a negative regulator of beta-catenin. Int. J. Cancer 124, 287-297.

Lee, S. H., and McCormick, F. (2005). Downregulation of Skp2 and p27/Kip1 synergistically induces apoptosis in T98G glioblastoma cells. J. Mol. Med. 83, 296-307.

Levine, A. J. (1997). p53, the cellular gatekeeper for growth and division. Cell 88, 323-331.

Levrero, M., De Laurenzi, V., Costanzo, A., Gong, J., Wang, J. Y., and Melino, G. (2000). The p53/p63/p73 family of transcription factors: overlapping and distinct functions. J. Cell. Sci. 113, 1661-1670.

Li, C. F., Wang, J. M., Kang, H. Y., Huang, C. K., Wang, J. W., Fang, F. M., et al. (2012a). Characterization of gene amplification-driven SKP2 overexpression in myxofibrosarcoma: potential implications in tumor progression and therapeutics. Clin. Cancer Res. 18, 1598-1610.

Li, H., Xu, W., Huang, Y., Huang, X., $\mathrm{Xu}, \mathrm{L}$., and Lv, Z. (2012b). Genistein demethylates the promoter of CHD5 and inhibits neuroblastoma growth in vivo. Int. J. Mol. Med. 30, 1081-1086.

Li, J., and Kretzner, L. (2003). The growth-inhibitory Ndrgl gene is a Myc negative target in human neuroblastomas and other cell types with overexpressed N- or c-myc. Mol. Cell. Biochem. 250, 91-105.

Lin, H. K., Chen, Z., Wang, G., Nardella, C., Lee, S. W., Chan, C. H., et al. (2010). Skp2 targeting suppresses tumorigenesis by Arf-p53-independent cellular senescence. Nature 464, 374-379.

Linzer, D. I., and Levine, A. J. (1979). Characterization of a $54 \mathrm{~K}$ dalton cellular SV40 tumor antigen present in SV40-transformed cells and uninfected embryonal carcinoma cells. Cell 17, 43-52.

Liu, N., Wang, L., Li, X., Yang, Q., Liu, X., Zhang, J., et al. (2008a). $\mathrm{N}-\mathrm{Myc}$ downstream-regulated gene 2 is involved in p53-mediated apoptosis. Nucleic Acids Res. 36, 5335-5349.

Liu, X., Mazanek, P., Dam, V., Wang, Q., Zhao, H., Guo, R., et al. (2008b). Deregulated Wnt/betacatenin program in high-risk neuroblastomas without MYCN amplification. Oncogene 27, 1478-1488.

Liu, Q., Kaneko, S., Yang, L., Feldman, R. I., Nicosia, S. V., Chen, J., et al. (2004). Aurora-A abrogation of p53 DNA binding and transactivation activity by phosphorylation of serine 215. J. Biol. Chem. 279, 52175-52182.

Lozano, G. (2007). The oncogenic roles of p53 mutants in mouse models. Curr. Opin. Genet. Dev. 17, 66-70.

Lujambio, A., and Lowe, S. W. (2012) The microcosmos of cancer. Nature 482, 347-355.

Mac, S. M., D'Cunha, C. A., and Farnham, P. J. (2000). Direct recruitment of N-myc to target gene promoters. Mol. Carcinog. 29, 76-86.

Maestro, R., Dei Tos, A. P., Hamamori, Y., Krasnokutsky, S., Sartorelli, V., Kedes, L., et al. (1999). Twist is a potential oncogene that inhibits apoptosis. Genes Dev. 13, 2207-2217.

Manhani, R., Cristofani, L. M., Odone Filho, V., and Bendit, I. (1997). Concomitant p53 mutation and MYCN amplification in neuroblastoma. Med. Pediatr. Oncol. 29, 206-207.

Mao, B., and Niehrs, C. (2003). Kremen2 modulates Dickkopf2 activity during Wnt/LRP6 signaling. Gene 302, 179-183.

Mao, B., Wu, W., Davidson, G., Marhold, J., Li, M., Mechler, B. M., et al. (2002). Kremen proteins are Dickkopf receptors that regulate Wnt/beta-catenin signalling. Nature 417, 664-667.

Marine, J. C., Dyer, M. A., and Jochemsen, A. G. (2007). MDMX: from bench to bedside. J. Cell. Sci. 120, 371-378.

Maris, J. M. (2009). Unholy matrimony: aurora $\mathrm{A}$ and $\mathrm{N}-\mathrm{Myc}$ as malignant partners in neuroblastoma. Cancer Cell 15, 5-6.

Maris, J. M., Morton, C. L., Gorlick, R., Kolb, E. A., Lock, R., Carol, H., et al. (2010). Initial testing of the aurora kinase A inhibitor MLN8237 by the pediatric preclinical testing program (PPTP). Pediatr. Blood Cancer 55, 26-34.

McKenzie, P. P., Guichard, S. M., Middlemas, D. S., Ashmun, R. A., Danks, M. K., and Harris, L. C. (1999). Wildtype p53 can induce p 21 and apoptosis in neuroblastoma cells but the DNA damage-induced G1 checkpoint function is attenuated. Clin. Cancer Res. 5, 4199-4207.

McPake, C. R., Tillman, D. M., Poquette, C. A., George, E. O., Houghton, J. A., and Harris, L. C. (1998). Bax is an important determinant of chemosensitivity in pediatric tumor cell lines independent of $\mathrm{Bcl}-2$ expression and p53 status. Oncol. Res. 10, 235-244.

Menendez, D., Inga, A., and Resnick, M. A. (2009). The expanding universe of p53 targets. Nat. Rev. Cancer 9, 724-737.

Mergui, X., Leteurtre, F., Lipinski, M., Benard, J., and Amor-Gueret, M. (2008). Two distinctly altered cellular responses to DNA double-strand breaks in human neuroblastoma. Biochimie 90, 1656-1666.

Mertz, J. A., Conery, A. R., Bryant, B. M., Sandy, P., Balasubramanian, S., Mele, D. A., et al. (2011). Targeting MYC dependence in cancer by inhibiting BET bromodomains. Proc. Natl. Acad. Sci. U.S.A. 108, 16669-16674.

Michaelis, M., Fichtner, I., Behrens, D. Haider, W., Rothweiler, F., Mack, A., et al. (2006). Anti-cancer effects of bortezomib against chemoresistant neuroblastoma cell lines in vitro and in vivo. Int. J. Oncol. 28, 439-446.

Michaelis, M., Rothweiler, F., Barth S., Cinatl, J., Van Rikxoort, M., Loschmann, N., et al. (2011). Adaptation of cancer cells from different entities to the MDM2 inhibitor nutlin-3 results in the emergence of p53-mutated multi-drug-resistant cancer cells. Cell Death Dis. 2, e243.

Michaelis, M., Rothweiler, F., Klassert, D., Von Deimling, A., Weber, K. Fehse, B., et al. (2009). Reversal of P-glycoprotein-mediated multidrug resistance by the murine double minute 2 antagonist nutlin-3. Cancer Res. 69, 416-421.

Mirza, A., Wu, Q., Wang, L., Mcclanahan, T., Bishop, W. R., Gheyas, F., et al. (2003). Global transcriptional program of p53 target genes during the process of apoptosis and cell cycle progression. Oncogene 22 3645-3654.

Mizobuchi, Y., Matsuzaki, K. Kuwayama, K., Kitazato, K., Mure, H., Kageji, T., et al. (2008). REIC/Dkk-3 induces cell death in human malignant glioma. Neuro oncol. 10, 244-253.

Moll, U. M., Laquaglia, M., Benard, J., and Riou, G. (1995). Wild-type p53 protein undergoes cytoplasmic sequestration in undifferentiated neuroblastomas but not in differentiated tumors. Proc. Natl. Acad. Sci. U.S.A. 92, 4407-4411.

Moll, U. M., Ostermeyer, A. G., Haladay, R., Winkfield, B., Frazier, M. and Zambetti, G. (1996). Cytoplasmic sequestration of wild-type p53 protein impairs the G1 checkpoint after DNA damage. Mol. Cell. Biol. 16, 1126-1137.

Moll, U. M., and Slade, N. (2004). p63 and p73: roles in development and tumor formation. Mol. Cancer Res. 2, 371-386.
Moll, U. M., Wolff, S., Speidel, D., and Deppert, W. (2005). Transcriptionindependent pro-apoptotic functions of p53. Curr. Opin. Cell Biol. 17, 631-636.

Momand, J., Zambetti, G. P., Olson, D. C., George, D., and Levine, A. J. (1992). The mdm-2 oncogene product forms a complex with the p53 protein and inhibits p53mediated transactivation. Cell 69, 1237-1245.

Montes de Oca Luna, R., Wagner, D. S., and Lozano, G. (1995). Rescue of early embryonic lethality in $\mathrm{mdm} 2$ deficient mice by deletion of p53. Nature 378, 203-206.

Moore, H. C., Wood, K. M., Jackson, M. S., Lastowska, M. A., Hall, D., Imrie, H., et al. (2008). Histological profile of tumours from MYCN transgenic mice. J. Clin. Pathol. 61, 1098-1103.

Moro, L., Arbini, A. A., Marra, E. and Greco, M. (2006). Up-regulation of Skp2 after prostate cancer cell adhesion to basement membranes results in BRCA2 degradation and cell proliferation. J. Biol. Chem. 281, 22100-22107.

Motti, M. L., Califano, D., Troncone, G., De Marco, C., Migliaccio, I., Palmieri, E., et al. (2005). Complex regulation of the cyclin-dependent kinase inhibitor p27kip1 in thyroid cancer cells by the PI3K/AKT pathway: regulation of p27kipl expression and localization. Am. J. Pathol. 166, 737-749.

Muth, D., Ghazaryan, S., Eckerle, I., Beckett, E., Pohler, C., Batzler, J., et al. (2010). Transcriptional repression of SKP2 is impaired in MYCNamplified neuroblastoma. Cancer Res. 70, 3791-3802.

Nakamura, M., Matsuo, T., Stauffer, J., Neckers, L., and Thiele, C. J. (2003a). Retinoic acid decreases targeting of p27 for degradation via an N-mycdependent decrease in p27 phosphorylation and an $\mathrm{N}$-myc-independent decrease in Skp2. Cell Death Differ. 10, 230-239.

Nakamura, Y., Ozaki, T., Koseki, H., Nakagawara, A., and Sakiyama, S. (2003b). Accumulation of p27 KIP1 is associated with BMP2-induced growth arrest and neuronal differentiation of human neuroblastomaderived cell lines. Biochem. Biophys. Res. Commun. 307, 206-213.

Nakamura, R. E., and Hackam, A. S. (2010). Analysis of Dickkopf3 interactions with Wnt signaling receptors. Growth Factors 28, 232-242.

Nakamura, Y. (2004). Isolation of p53target genes and their functional analysis. Cancer Sci. 95, 7-11. 
Nakamura, Y., Ozaki, T., Niizuma, H., Ohira, M., Kamijo, T., and Nakagawara, A. (2007). Functional characterization of a new p53 mutant generated by homozygous deletion in a neuroblastoma cell line. Biochem. Biophys. Res. Commun. 354, 892-898.

Nakayama, K., Nagahama, H., Minamishima, Y. A., Matsumoto, M., Nakamichi, I., Kitagawa, K., et al. (2000). Targeted disruption of Skp2 results in accumulation of cyclin E and p27(Kip1), polyploidy and centrosome overduplication. EMBO J. 19, 2069-2081.

Nakayama, K. I., and Nakayama, K. (2005). Regulation of the cell cycle by SCF-type ubiquitin ligases. Semin. Cell Dev. Biol. 16, 323-333.

Nakayama, K. I., and Nakayama, K. (2006). Ubiquitin ligases: cell-cycle control and cancer. Nat. Rev. Cancer 6, 369-381.

Niehrs, C. (2006). Function and biological roles of the Dickkopf family of Wnt modulators. Oncogene 25, 7469-7481.

Nikolaev, A. Y., and Gu, W. (2003). PARC: a potential target for cancer therapy. Cell Cycle 2, 169-171.

Nikolaev, A. Y., Li, M., Puskas, N., Qin, J., and Gu, W. (2003). Parc: a cytoplasmic anchor for p53. Cell 112, 29-40.

Nozaki, I., Tsuji, T., Iijima, O., Ohmura, Y., Andou, A., Miyazaki, M., et al. (2001). Reduced expression of REIC/Dkk-3 gene in non-small cell lung cancer. Int. J. Oncol. 19, 117-121.

Ochiai, H., Takenobu, H., Nakagawa, A., Yamaguchi, Y., Kimura, M., Ohira, M., et al. (2010). Bmil is a MYCN target gene that regulates tumorigenesis through repression of KIF1Bbeta and TSLC1 in neuroblastoma. Oncogene 29, 2681-2690.

Ohgaki, H., Eibl, R. H., Schwab, M., Reichel, M. B., Mariani, L., Gehring, M., et al. (1993). Mutations of the p53 tumor suppressor gene in neoplasms of the human nervous system. Mol. Carcinog. 8, 74-80.

Ohtsubo, C., Shiokawa, D., Kodama, M., Gaiddon, C., Nakagama, H., Jochemsen, A. G., et al. (2009). Cytoplasmic tethering is involved in synergistic inhibition of p53 by Mdmx and Mdm2. Cancer Sci. 100, 1291-1299.

Olive, K. P., Tuveson, D. A., Ruhe, Z. C., Yin, B., Willis, N. A., Bronson, R. T., et al. (2004). Mutant p53 gain of function in two mouse models of Li-Fraumeni syndrome. Cell 119, $847-860$.
Olivier, M., and Taniere, P. (2011). Somatic mutations in cancer prognosis and prediction: lessons from TP53 and EGFR genes. Curr. Opin. Oncol. 23, 88-92.

Omura-Minamisawa, M., Diccianni, M. B., Chang, R. C., Batova, A., Bridgeman, L. J., Schiff, J., et al. (2001) p16/p14(ARF) cell cycle regulatory pathways in primary neuroblastoma: p16 expression is associated with advanced stage disease. Clin. Cancer Res. 7, 3481-3490.

Oren, M., and Rotter, V. (2010). Mutant p53 gain-of-function in cancer. Cold Spring Harb. Perspect. Biol. 2, a001107.

Ostermeyer, A. G., Runko, E., Winkfield, B., Ahn, B., and Moll, U. M. (1996). Cytoplasmically sequestered wild-type $\mathrm{p} 53$ protein in neuroblastoma is relocated to the nucleus by a C-terminal peptide. Proc. Natl. Acad. Sci. U.S.A. 93, 15190-15194.

Otto, T., Horn, S., Brockmann, M., Eilers, U., Schuttrumpf, L., Popov, N., et al. (2009). Stabilization of N-Myc is a critical function of Aurora A in human neuroblastoma. Cancer Cell $15,67-78$.

Paffhausen, T., Schwab, M., and Westermann, F. (2007). Targeted MYCN expression affects cytotoxic potential of chemotherapeutic drugs in neuroblastoma cells. Cancer Lett. 250, 17-24.

Pan, Y., and Chen, J. (2003). MDM2 promotes ubiquitination and degradation of MDMX. Mol. Cell. Biol.23, 5113-5121.

Park, J. R., Eggert, A., and Caron, H. (2010). Neuroblastoma: biology, prognosis, and treatment. Hematol. Oncol. Clin. North Am. 24, 65-86.

Patterson, D. M., Gao, D., Trahan, D. N., Johnson, B. A., Ludwig, A., Barbieri, E., et al. (2011). Effect of MDM2 and vascular endothelial growth factor inhibition on tumor angiogenesis and metastasis in neuroblastoma. Angiogenesis 14, 255-266.

Peirce, S. K., and Findley, H. W. (2009a). High level MycN expression in nonMYCN amplified neuroblastoma is induced by the combination treatment nutlin-3 and doxorubicin and enhances chemosensitivity. Oncol. Rep. 22, 1443-1449.

Peirce, S. K., and Findley, H. W. (2009b). The MDM2 antagonist nutlin-3 sensitizes p53-null neuroblastoma cells to doxorubicin via E2F1 and TAp73. Int. J. Oncol. 34, 1395-1402.

Perfumo, C., Parodi, S., Mazzocco, K., Defferrari, R., Inga, A., Haupt, R., et al. (2008). Impact of MDM2 SNP309 genotype on progression and survival of stage 4 neuroblastoma. Eur. J. Cancer 44, 2634-2639.

Perfumo, C., Parodi, S., Mazzocco, K. Defferrari, R., Inga, A., Scarra, G. B., et al. (2009). MDM2 SNP309 genotype influences survival of metastatic but not of localized neuroblastoma. Pediatr. Blood Cancer 53, 576-583.

Piccinin, S., Tonin, E., Sessa, S., Demontis, S., Rossi, S., Pecciarini, L., et al. (2012). A "twist box" code of p53 inactivation: twist box:p53 interaction promotes p53 degradation. Cancer Cell 22, 404-415.

Qin, J. J., Nag, S., Voruganti, S. Wang, W., and Zhang, R. (2012). Natural Product MDM2 Inhibitors: anticancer Activity and Mechanisms of Action. Curr. Med. Chem. PMID:22830335. [Epub ahead of print].

Raschella, G., Negroni, A., Giubilei, C. Romeo, A., Ferrari, S., Castello, M. A., et al. (1991). Transcription of Nmyc and proliferation-related genes is linked in human neuroblastoma. Cancer Lett. 56, 45-51.

Raver-Shapira, N., Marciano, E., Meiri, E., Spector, Y., Rosenfeld, N., Moskovits, N., et al. (2007). Transcriptional activation of miR-34a contributes to p53-mediated apoptosis. Mol. Cell 26, 731-743.

Reisman, D., Elkind, N. B., Roy, B., Beamon, J., and Rotter, V. (1993). c-Myc trans-activates the p53 promoter through a required downstream CACGTG motif. Cell Growth Differ. 4, 57-65.

Revet, I., Huizenga, G., Koster, J., Volckmann, R., Van Sluis, P., Versteeg, R., et al. (2010). MSX1 induces the Wnt pathway antagonist genes DKK1, DKK2, DKK3, and SFRP1 in neuroblastoma cells, but does not block Wnt3 and Wnt5A signalling to DVL3. Cancer Lett. 289, 195-207.

Rico-Bautista, E., Yang, C. C., Lu, L., Roth, G. P., and Wolf, D. A. (2010). Chemical genetics approach to restoring p27Kip1 reveals novel compounds with antiproliferative activity in prostate cancer cells. BMC Biol. 8, 153. doi:10.1186/1741-70078-153

Riley, T., Sontag, E., Chen, P., and Levine, A. (2008). Transcriptional control of human p53-regulated genes. Nat. Rev. Mol. Cell Biol. 9, 402-412.

Robertson, K. D., and Jones, P. A (1998). The human ARF cell cycle regulatory gene promoter is a $\mathrm{CpG}$ island which can be silenced by DNA methylation and down-regulated by wild-type p53. Mol. Cell. Biol. 18, 6457-6473.
Roman-Gomez, J., Jimenez-Velasco, A., Agirre, X., Castillejo, J. A., Navarro, G., Barrios, M., et al. (2004). Transcriptional silencing of the Dickkopfs-3 (Dkk-3) gene by CpG hypermethylation in acute lymphoblastic leukaemia. Br. J. Cancer 91, 707-713.

Rose, A. E., Wang, G., Hanniford, D., Monni, S., Tu, T., Shapiro, R. L., et al. (2011). Clinical relevance of SKP2 alterations in metastatic melanoma. Pigment Cell Melanoma Res. 24, 197-206.

Roy, B., Beamon, J., Balint, E., and Reisman, D. (1994). Transactivation of the human p53 tumor suppressor gene by c-Myc/Max contributes to elevated mutant p53 expression in some tumors. Mol. Cell. Biol. 14, 7805-7815.

Roy, S., Kaur, M., Agarwal, C., Tecklenburg, M., Sclafani, R. A., and Agarwal, R. (2007). p21 and p27 induction by silibinin is essential for its cell cycle arrest effect in prostate carcinoma cells. Mol. Cancer Ther. 6, 2696-2707.

Sachdeva, M., Zhu, S., Wu, F., Wu, H., Walia, V., Kumar, S., et al. (2009). p53 represses c-Myc through induction of the tumor suppressor miR145. Proc. Natl. Acad. Sci. U.S.A. 106, 3207-3212.

Saigusa, K., Hashimoto, N., Tsuda, H., Yokoi, S., Maruno, M., Yoshimine, T., et al. (2005). Overexpressed Skp2 within $5 \mathrm{p}$ amplification detected by array-based comparative genomic hybridization is associated with poor prognosis of glioblastomas. Cancer Sci. 96, 676-683.

Sakaguchi, M., Kataoka, K., Abarzua, F., Tanimoto, R., Watanabe, M., Murata, H., et al. (2009). Overexpression of REIC/Dkk-3 in normal fibroblasts suppresses tumor growth via induction of interleukin-7. J. Biol. Chem. 284, 14236-14244.

Santos, F. P., Kantarjian, H., GarciaManero, G., Issa, J. P., and Ravandi, F. (2010). Decitabine in the treatment of myelodysplastic syndromes. Expert Rev Anticancer Ther 10, 9-22.

Sarmento, L. M., Huang, H., Limon, A., Gordon, W., Fernandes, J., Tavares, M. J., et al. (2005). Notch1 modulates timing of G1-S progression by inducing SKP2 transcription and p27 Kip1 degradation. J. Exp. Med. 202, 157-168.

Schneider, G., Saur, D., Siveke, J. T., Fritsch, R., Greten, F. R., and Schmid, R. M. (2006). IKKalpha controls p52/RelB at the skp2 gene promoter to regulate $\mathrm{G1}$ - to $\mathrm{S}$-phase progression. EMBO J. 25, 3801-3812. 
Schuler, S., Diersch, S., Hamacher, R., Schmid, R. M., Saur, D., and Schneider, G. (2011). SKP2 confers resistance of pancreatic cancer cells towards TRAIL-induced apoptosis. Int. J. Oncol. 38, 219-225.

Schulman, B. A., Carrano, A. C., Jeffrey, P. D., Bowen, Z., Kinnucan, E. R., Finnin, M. S., et al. (2000). Insights into SCF ubiquitin ligases from the structure of the Skp1-Skp2 complex. Nature 408, 381-386.

Schulte, J. H., Horn, S., Otto, T., Samans, B., Heukamp, L. C., Eilers, U. C., et al. (2008). MYCN regulates oncogenic MicroRNAs in neuroblastoma. Int. J. Cancer 122, 699-704.

Schwab, M. (2000). "MYCN amplification in neuroblastoma," in $\mathrm{Neu}$ roblastoma, Eds G. M. Brodeur, T. Sawada, Y. Tsuchida, and P. A. Voûte (Amsterdam: Elsevier Science B.V.), 75-83.

Seoane, J., Le, H. V., and Massague, J. (2002). Myc suppression of the p21(Cip1) Cdk inhibitor influences the outcome of the p53 response to DNA damage. Nature 419, 729-734.

Shangary, S., Ding, K., Qiu, S., Nikolovska-Coleska, Z., Bauer, J. A., Liu, M., et al. (2008). Reactivation of p53 by a specific MDM2 antagonist (MI-43) leads to p21-mediated cell cycle arrest and selective cell death in colon cancer. Mol. Cancer Ther. 7, 1533-1542.

Shapira, M., Kakiashvili, E., Rosenberg, T., and Hershko, D. D. (2006). The mTOR inhibitor rapamycin downregulates the expression of the ubiquitin ligase subunit Skp2 in breast cancer cells. Breast Cancer Res. 8, R46.

Shibahara, T., Onishi, T., Franco, O. E., Arima, K., and Sugimura, Y. (2005). Down-regulation of Skp2 is correlated with p27-associated cell cycle arrest induced by phenylacetate in human prostate cancer cells. Anticancer Res. 25, 1881-1888.

Shim, E. H., Johnson, L., Noh, H. L., Kim, Y. J., Sun, H., Zeiss, C., et al. (2003). Expression of the F-box protein SKP2 induces hyperplasia, dysplasia, and low-grade carcinoma in the mouse prostate. Cancer Res. 63, 1583-1588.

Shimada, H., Ambros, I. M., Dehner, L. P., Hata, J., Joshi, V. V., and Roald, B. (1999). Terminology and morphologic criteria of neuroblastic tumors: recommendations by the International Neuroblastoma Pathology Committee. Cancer 86, 349-363.

Shimada, H., Stram, D. O., Chatten, J., Joshi, V. V., Hachitanda, Y., Brodeur, G. M., et al. (1995). Identification of subsets of neuroblastomas by combined histopathologic and N-myc analysis. J. Natl. Cancer Inst. 87, 1470-1476.

Shimono, A., Okuda, T., and Kondoh, H. (1999). N-myc-dependent repression of ndrl, a gene identified by direct subtraction of whole mouse embryo cDNAs between wild type and N-myc mutant. Mech. Dev. 83, 39-52.

Shiota, M., Izumi, H., Onitsuka, T., Miyamoto, N., Kashiwagi, E., Kidani, A., et al. (2008). Twist and p53 reciprocally regulate target genes via direct interaction. Oncogene 27, 5543-5553

Sidell, N., and Koeffler, H. P. (1988). Modulation of $\mathrm{Mr} 53,000$ protein with induction of differentiation of human neuroblastoma cells. Cancer Res. 48, 2226-2230.

Signoretti, S., Di Marcotullio, L., Richardson, A., Ramaswamy, S. Isaac, B., Rue, M., et al. (2002). Oncogenic role of the ubiquitin ligase subunit Skp2 in human breast cancer. J. Clin. Invest. 110, 633-641.

Skowyra, D., Craig, K. L., Tyers, M., Elledge, S. J., and Harper, J. W. (1997). F-box proteins are receptors that recruit phosphorylated substrates to the SCF ubiquitin-ligase complex. Cell 91, 209-219.

Slack, A., Chen, Z., Tonelli, R., Pule, M., Hunt, L., Pession, A., et al. (2005). The p53 regulatory gene MDM2 is a direct transcriptional target of MYCN in neuroblastoma. Proc. Natl. Acad. Sci. U.S.A. 102, 731-736.

Slack, A. D., Chen, Z., Ludwig, A. D., Hicks, J., and Shohet, J. M. (2007). MYCN-directed centrosome amplification requires MDM2-mediated suppression of p53 activity in neuroblastoma cells. Cancer Res. 67, 2448-2455.

Smart, P., Lane, E. B., Lane, D. P., Midgley, C., Vojtesek, B., and Lain, S. (1999). Effects on normal fibroblasts and neuroblastoma cells of the activation of the $\mathrm{p} 53$ response by the nuclear export inhibitor leptomycin B. Oncogene 18, 7378-7386.

Smith, M. A., Maris, J. M., Gorlick, R., Kolb, E. A., Lock, R., Carol, H., et al. (2012). Initial testing of the investigational NEDD8-activating enzyme inhibitor MLN4924 by the pediatric preclinical testing program. Pediatr. Blood Cancer 59, 246-253.

Song, H., Hollstein, M., and Xu, Y. (2007). p53 gain-of-function cancer mutants induce genetic instability by inactivating ATM. Nat. Cell Biol. 9, 573-580.

Song, M. S., Song, S. J., Kim, S. J., Nakayama, K., Nakayama, K. I., and Lim, D. S. (2008). Skp2 regulates the antiproliferative function of the tumor suppressor RASSF1A via ubiquitin-mediated degradation at the G1-S transition. Oncogene 27, 3176-3185.

Soucy, T. A., Smith, P. G., Milhollen, M. A., Berger, A. J., Gavin, J. M., Adhikari, S., et al. (2009). An inhibitor of NEDD8-activating enzyme as a new approach to treat cancer. Nature 458, 732-736.

Soussi, T., Dehouche, K., and Beroud, C. (2000). p53 website and analysis of p53 gene mutations in human cancer: forging a link between epidemiology and carcinogenesis. Hum. Mutat. 15, 105-113.

Speidel, D., Helmbold, H., and Deppert, W. (2006). Dissection of transcriptional and non-transcriptional p53 activities in the response to genotoxic stress. Oncogene 25, 940-953.

Spitz, R., Oberthuer, A., Zapatka, M., Brors, B., Hero, B., Ernestus, K., et al. (2006). Oligonucleotide array-based comparative genomic hybridization (aCGH) of 90 neuroblastomas reveals aberration patterns closely associated with relapse pattern and outcome. Genes Chromosomes Cancer 45, 1130-1142.

Spruck, C., Strohmaier, H., Watson, M. Smith, A. P., Ryan, A., Krek, T. W., et al. (2001). A CDK-independent function of mammalian Cks1: targeting of $\mathrm{SCF}(\mathrm{Skp} 2)$ to the $\mathrm{CDK}$ inhibitor p27Kip1. Mol. Cell 7, 639-650.

Staller, P., Peukert, K., Kiermaier, A., Seoane, J., Lukas, J., Karsunky, H., et al. (2001). Repression of p15INK4b expression by Myc through association with Miz-1. Nat. Cell Biol. 3 , 392-399.

Stasinopoulos, I. A., Mironchik, Y., Raman, A., Wildes, F., Winnard, P. Jr., and Raman, V. (2005). HOXA5-twist interaction alters $\mathrm{p} 53$ homeostasis in breast cancer cells. J. Biol. Chem. 280 , 2294-2299.

Stein, S., Thomas, E. K., Herzog, B., Westfall, M. D., Rocheleau, J. V., Jackson, R. S. II, et al. (2004). NDRG1 is necessary for p53dependent apoptosis. J. Biol. Chem. 279, 48930-48940.

Stommel, J. M., Marchenko, N. D., Jimenez, G. S., Moll, U. M., Hope, T. J., and Wahl, G. M. (1999). A leucinerich nuclear export signal in the p53 tetramerization domain: regulation of subcellular localization and p53 activity by NES masking. EMBO $J$. $18,1660-1672$.

Stott, F. J., Bates, S., James, M. C., Mcconnell, B. B., Starborg, M.,
Brookes, S., et al. (1998). The alternative product from the human CDKN2A locus, p14(ARF), participates in a regulatory feedback loop with p53 and MDM2. EMBO J. 17, 5001-5014.

Su, W. T., Alaminos, M., Mora, J., Cheung, N. K., La Quaglia, M. P., and Gerald, W. L. (2004). Positional gene expression analysis identifies $12 \mathrm{q}$ overexpression and amplification in a subset of neuroblastomas. Cancer Genet. Cytogenet. 154, 131-137.

Sugihara, E., Kanai, M., Saito, S., Nitta, T., Toyoshima, H., Nakayama, K., et al. (2006). Suppression of centrosome amplification after DNA damage depends on p27 accumulation. Cancer Res. 66, 4020-4029.

Sugiyama, H., Arita, M., Min, Z., Zhong, X., Iwasaki, I., Hirano, K., et al. (2003). A novel dysfunctional p53 mutation in the human neuroblastoma cell line TGW. Tohoku J. Exp. Med. 201, 229-237.

Sutterluty, H., Chatelain, E., Marti, A., Wirbelauer, C., Senften, M., Muller, U., et al. (1999). p45SKP2 promotes p27Kipl degradation and induces $S$ phase in quiescent cells. Nat. Cell Biol. 1, 207-214.

Swarbrick, A., Woods, S. L., Shaw, A., Balakrishnan, A., Phua, Y., Nguyen, A., et al. (2010). miR$380-5 \mathrm{p}$ represses p53 to control cellular survival and is associated with poor outcome in MYCNamplified neuroblastoma. Nat. Med. 16, 1134-1140.

Tanimoto, R., Abarzua, F., Sakaguchi, M., Takaishi, M., Nasu, Y., Kumon, H., et al. (2007). REIC/Dkk-3 as a potential gene therapeutic agent against human testicular cancer. Int. J. Mol. Med. 19, 363-368.

Tao, W., and Levine, A. J. (1999a). Nucleocytoplasmic shuttling of oncoprotein $\mathrm{Hdm} 2$ is required for Hdm2-mediated degradation of p53. Proc. Natl. Acad. Sci. U.S.A. 96, 3077-3080.

Tao, W., and Levine, A. J. (1999b). P19(ARF) stabilizes p53 by blocking nucleo-cytoplasmic shuttling of Mdm2. Proc. Natl. Acad. Sci. U.S.A. 96, 6937-6941.

Tarasov, V., Jung, P., Verdoodt, B., Lodygin, D., Epanchintsev, A., Menssen A., et al. (2007). Differential regulation of microRNAs by 553 revealed by massively parallel sequencing: miR-34a is a p53 target that induces apoptosis and G1-arrest. Cell Cycle 6, 1586-1593.

Tedesco, D., Lukas, J., and Reed, S. I. (2002). The pRb-related protein $\mathrm{p} 130$ is regulated by 
phosphorylation-dependent proteolysis via the protein-ubiquitin ligase SCF(Skp2). Genes Dev. 16, 2946-2957.

Teitz, T., Wei, T., Liu, D., Valentine, V., Valentine, M., Grenet, J., et al. (2002). Caspase- 9 and Apaf- 1 are expressed and functionally active in human neuroblastoma tumor cell lines with 1 p36 LOH and amplified MYCN. Oncogene 21, 1848-1858.

Than, S. S., Kataoka, K., Sakaguchi, M., Murata, H., Abarzua, F., Taketa, C., et al. (2011). Intraperitoneal administration of an adenovirus vector carrying REIC/Dkk-3 suppresses peritoneal dissemination of scirrhous gastric carcinoma. Oncol. Rep. 25, 989-995.

Thompson, P. M., Gotoh, T., Kok, M., White, P. S., and Brodeur, G. M. (2003). CHD5, a new member of the chromodomain gene family, is preferentially expressed in the nervous system. Oncogene 22, 1002-1011.

Thompson, P. M., Maris, J. M., Hogarty, M. D., Seeger, R. C., Reynolds, C. P., Brodeur, G. M., et al. (2001). Homozygous deletion of CDKN2A (p16INK4a/p14ARF) but not within $1 \mathrm{p} 36$ or at other tumor suppressor loci in neuroblastoma. Cancer Res. 61, 679-686.

Tivnan, A., Orr, W. S., Gubala, V., Nooney, R., Williams, D. E., Mcdonagh, C., et al. (2012). Inhibition of neuroblastoma tumor growth by targeted delivery of microRNA-34a using antidisialoganglioside GD2 coated nanoparticles. PLoS ONE 7, e38129. doi:10.1371/journal.pone.0038129

Totary-Jain, H., Sanoudou, D., Dautriche, C. N., Schneller, H., Zambrana, L., and Marks, A. R. (2012). Rapamycin resistance is linked to defective regulation of Skp2. Cancer Res. 72, 1836-1843.

Tsuji, T., Miyazaki, M., Sakaguchi, M., Inoue, Y., and Namba, M. (2000). A REIC gene shows down-regulation in human immortalized cells and human tumor-derived cell lines. Biochem. Biophys. Res. Commun. 268, 20-24.

Tsuji, T., Nozaki, I., Miyazaki, M., Sakaguchi, M., Pu, H., Hamazaki, Y., et al. (2001). Antiproliferative activity of REIC/Dkk-3 and its significant down-regulation in non-small-cell lung carcinomas. Biochem. Biophys. Res. Commun. 289, 257-263.

Tsvetkov, L. M., Yeh, K. H., Lee, S. J., Sun, H., and Zhang, H. (1999). p27(Kip1) ubiquitination and degradation is regulated by the SCF(Skp2) complex through phosphorylated Thr187 in p27. Curr. Biol. 9, 661-664.
Tweddle, D. A., Malcolm, A. J., Bown, N., Pearson, A. D., and Lunec, J. (2001a). Evidence for the development of p53 mutations after cytotoxic therapy in a neuroblastoma cell line. Cancer Res. 61, 8-13.

Tweddle, D. A., Malcolm, A. J., Cole, M., Pearson, A. D., and Lunec, J. (2001b). p53 cellular localization and function in neuroblastoma: evidence for defective $\mathrm{G}(1)$ arrest despite WAF1 induction in MYCN-amplified cells. Am. J. Pathol. 158, 2067-2077.

Tweddle, D. A., Pearson, A. D., Haber, M., Norris, M. D., Xue, C., Flemming, C., et al. (2003). The p53 pathway and its inactivation in neuroblastoma. Cancer Lett. 197, 93-98.

Uddin, S., Ahmed, M., Bavi, P., El-Sayed, R., Al-Sanea, N., Abduljabbar, A., et al. (2008). Bortezomib (Velcade) induces p27Kipl expression through S-phase kinase protein 2 degradation in colorectal cancer. Cancer Res. 68, 3379-3388.

Uddin, S., Ahmed, M., Hussain, A. R., Jehan, Z., Al-Dayel, F., Munkarah, A., et al. (2009). Bortezomib-mediated expression of p27Kipl through Sphase kinase protein 2 degradation in epithelial ovarian cancer. Lab. Invest. 89, 1115-1127.

Ueno, K., Hirata, H., Majid, S., Chen, Y., Zaman, M. S., Tabatabai, Z. L., et al. (2011). Wnt antagonist DICKKOPF-3 (Dkk-3) induces apoptosis in human renal cell carcinoma. Mol. Carcinog. 50, 449-457.

Valentiner, U., Haane, C., Nehmann, N., and Schumacher, U. (2009). Effects of bortezomib on human neuroblastoma cells in vitro and in a metastatic xenograft model. Anticancer Res. 29, 1219-1225.

Valsesia-Wittmann, S., Magdeleine, M., Dupasquier, S., Garin, E., Jallas, A. C., Combaret, V., et al. (2004). Oncogenic cooperation between $\mathrm{H}$-Twist and N-Myc overrides failsafe programs in cancer cells. Cancer Cell 6, 625-630.

van Leeuwen, I. M. (2012). Cyclotherapy: opening a therapeutic window in cancer treatment. Oncotarget 3, 596-600.

Van Maerken, T., Ferdinande, L., Taildeman, J., Lambertz, I., Yigit, N., Vercruysse, L., et al. (2009a). Antitumor activity of the selective MDM2 antagonist nutlin-3 against chemoresistant neuroblastoma with wild-type p53. J. Natl. Cancer Inst. 101, 1562-1574.

Van Maerken, T., Vandesompele, J., Rihani, A., De Paepe, A., and Speleman, F. (2009b). Escape from p53-mediated tumor surveillance in neuroblastoma: switching off the p14(ARF)-MDM2-p53 axis. Cell Death Differ. 16, 1563-1572.

Van Maerken, T., Rihani, A., Dreidax, D., De Clercq, S., Yigit, N., Marine, J. C., et al. (2011). Functional analysis of the p53 pathway in neuroblastoma cells using the small-molecule MDM2 antagonist nutlin-3. Mol. Cancer Ther. 10, 983-993.

Van Maerken, T., Speleman, F., Vermeulen, J., Lambertz, I., De Clercq, S., De Smet, E., et al. (2006). Smallmolecule MDM2 antagonists as a new therapy concept for neuroblastoma. Cancer Res. 66, 9646-9655.

Vassilev, L. T. (2004). Small-molecule antagonists of p53-MDM2 binding: research tools and potential therapeutics. Cell Cycle 3, 419-421.

Vassilev, L. T., Vu, B. T., Graves, B., Carvajal, D., Podlaski, F., Filipovic, Z., et al. (2004). In vivo activation of the p53 pathway by small-molecule antagonists of MDM2. Science 303 , 844-848.

Veeck, J., Bektas, N., Hartmann, A., Kristiansen, G., Heindrichs, U., Knuchel, R., et al. (2008). Wnt signalling in human breast cancer: expression of the putative Wnt inhibitor Dickkopf-3 (DKK3) is frequently suppressed by promoter hypermethylation in mammary tumours. Breast Cancer Res. 10, R82.

Veeck, J., and Dahl, E. (2012). Targeting the Wnt pathway in cancer: the emerging role of Dickkopf-3. Biochim. Biophys. Acta 1825, 18-28.

Veeck, J., Wild, P. J., Fuchs, T., Schuffler, P. J., Hartmann, A., Knuchel, R., et al. (2009). Prognostic relevance of Wnt-inhibitory factor1 (WIF1) and Dickkopf-3 (DKK3) promoter methylation in human breast cancer. BMC Cancer 9, 217. doi:10.1186/1471-2407-9-217

Verissimo, C. S., Molenaar, J. J., Fitzsimons, C. P., and Vreugdenhil, E. (2011). Neuroblastoma therapy: what is in the pipeline? Endocr. Relat. Cancer 18, R213-R231.

Vogan, K., Bernstein, M., Leclerc, J. M., Brisson, L., Brossard, J., Brodeur, G. M., et al. (1993). Absence of p53 gene mutations in primary neuroblastomas. Cancer Res. 53, 5269-5273.

von der Lehr, N., Johansson, S., Wu, S., Bahram, F., Castell, A., Cetinkaya, C., et al. (2003). The F-box protein Skp2 participates in c-Myc proteosomal degradation and acts as a cofactor for c-Myc-regulated transcription. $\mathrm{Mol}$. Cell 11, 1189-1200.

Vousden, K. H., and Lu, X. (2002). Live or let die: the cell's response to p53. Nat. Rev. Cancer 2, 594-604.

Wade, M., and Wahl, G. M. (2009). Targeting Mdm2 and Mdmx in cancer therapy: better living through medicinal chemistry? Mol. Cancer Res. 7, $1-11$.

Wagner, L. M., and Danks, M. K. (2009). New therapeutic targets for the treatment of high-risk neuroblastoma. J. Cell. Biochem. 107, 46-57.

Wang, B., Xiao, Z., Ko, H. L., and Ren, E. C. (2010a). The p53 response element and transcriptional repression. Cell Cycle 9, 870-879.

Wang, H., Bauzon, F., Ji, P., Xu, X., Sun, D., Locker, J., et al. (2010b). Skp2 is required for survival of aberrantly proliferating Rb1-deficient cells and for tumorigenesis in $\mathrm{Rbl} \pm$ mice. Nat. Genet. 42, 83-88.

Wang, S., Raven, J. F., and Koromilas, A. E. (2010c). STAT1 represses Skp2 gene transcription to promote p27Kip1 stabilization in Rastransformed cells. Mol. Cancer Res. 8, 798-805.

Wang, I. C., Chen, Y. J., Hughes, D., Petrovic, V., Major, M. L., Park, H. J., et al. (2005). Forkhead box M1 regulates the transcriptional network of genes essential for mitotic progression and genes encoding the SCF (Skp2-Cks1) ubiquitin ligase. Mol. Cell. Biol. 25, 10875-10894.

Wang, W., Zhu, W., Xu, X. Y., Nie, X. C., Yang, X., Xing, Y. N., et al. (2012a). The clinicopathological significance of REIC expression in colorectal carcinomas. Histol. Histopathol. 27, 735-743.

Wang, X. C., Tian, L. L., Tian, J., and Jiang, X. Y. (2012b). Overexpression of SKP2 promotes the radiation resistance of esophageal squamous cell carcinoma. Radiat. Res. 177, 52-58.

Wang, Z., Fukushima, H., Inuzuka, H., Wan, L., Liu, P., Gao, D., et al. (2012c). Skp2 is a promising therapeutic target in breast cancer. Front. Oncol. 1:57. doi:10.3389/fonc.2011.00057

Wang, X. C., Wu, Y. P., Ye, B., Lin, D. C., Feng, Y. B., Zhang, Z. Q., et al. (2009). Suppression of anoikis by SKP2 amplification and overexpression promotes metastasis of esophageal squamous cell carcinoma. Mol. Cancer Res. 7, 12-22.

Wanzel, M., Herold, S., and Eilers, M. (2003). Transcriptional repression by Myc. Trends Cell Biol. 13, 146-150.

Weber, J. D., Taylor, L. J., Roussel, M. F., Sherr, C. J., and Bar-Sagi, D. (1999). Nucleolar Arf sequesters Mdm2 and activates p53. Nat. Cell Biol. 1, 20-26.

Wei, J. S., Song, Y. K., Durinck, S., Chen, Q. R., Cheuk, A. T., Tsang, P., et al. (2008). The MYCN oncogene is a 
direct target of miR-34a. Oncogene 27, 5204-5213.

Wei, W., Ayad, N. G., Wan, Y., Zhang, G. J., Kirschner, M. W., and Kaelin, W. G. Jr. (2004). Degradation of the SCF component Skp2 in cellcycle phase G1 by the anaphasepromoting complex. Nature 428, 194-198.

Weiss, W. A., Aldape, K., Mohapatra, G., Feuerstein, B. G., and Bishop, J. M. (1997). Targeted expression of MYCN causes neuroblastoma in transgenic mice. EMBO J. 16, 2985-2995.

Welch, C., Chen, Y., and Stallings, R. L. (2007). MicroRNA-34a functions as a potential tumor suppressor by inducing apoptosis in neuroblastoma cells. Oncogene 26, 5017-5022.

Westermann, F., Henrich, K. O., Wei, J. S., Lutz, W., Fischer, M., Konig, R., et al. (2007). High Skp2 expression characterizes high-risk neuroblastomas independent of MYCN status. Clin. Cancer Res. 13, 4695-4703.

Westermann, F., Muth, D., Benner, A., Bauer, T., Henrich, K. O., Oberthur, A., et al. (2008). Distinct transcriptional MYCN/c-MYC activities are associated with spontaneous regression or malignant progression in neuroblastomas. Genome Biol. 9, R150.

Wirbelauer, C., Sutterluty, H., Blondel, M., Gstaiger, M., Peter, M., Reymond, F., et al. (2000). The F-box protein Skp2 is a ubiquitylation target of a Cull-based core ubiquitin ligase complex: evidence for a role of Cull in the suppression of Skp2 expression in quiescent fibroblasts. EMBO J. 19, 5362-5375.

Wolf, M., Korja, M., Karhu, R., Edgren, H., Kilpinen, S., Ojala, K., et al. (2010). Array-based gene expression, CGH and tissue data defines a $12 \mathrm{q} 24$ gain in neuroblastic tumors with prognostic implication. BMC Cancer 10, 181. doi:10.1186/14712407-10-181

Woo, C. W., Tan, F., Cassano, H., Lee, J., Lee, K. C., and Thiele, C. J. (2008). Use of RNA interference to elucidate the effect of MYCN on cell cycle in neuroblastoma. Pediatr. Blood Cancer 50, 208-212.

Wu, C. Y., Hung, J. J., and Wu, K. J. (2012a). Linkage between Twist1 and Bmil: molecular mechanism of cancer metastasis/stemness and clinical implications. Clin. Exp. Pharmacol. Physiol. 39, 668-673.
Wu, J., Lee, S. W., Zhang, X., Han, F., Kwan, S. Y., Yuan, X., et al. (2012b). Foxo3a transcription factor is a negative regulator of $\mathrm{Skp} 2$ and Skp2 SCF complex. Oncogene. doi: 10.1038/onc.2012.26

Wu, J., Smith, L. T., Plass, C., and Huang, T. H. (2006). ChIP-chip comes of age for genome-wide functional analysis. Cancer Res. 66, 6899-6902.

Xiao, J., Yin, S., Li, Y., Xie, S., Nie, D., Ma, L., et al. (2009). SKP2 siRNA inhibits the degradation of P27kip1 and down-regulates the expression of MRP in HL-60/A cells. Acta Biochim. Biophys. Sin. (Shanghai) 41, 699-708.

Xiong, S., Pant, V., Suh, Y. A., Van Pelt, C. S., Wang, Y., Valentin-Vega, Y. A., et al. (2010). Spontaneous tumorigenesis in mice overexpressing the p53negative regulator Mdm4. Cancer Res. 70, 7148-7154.

$\mathrm{Xu}, \mathrm{Y}$. (2008). Induction of genetic instability by gain-of-function p53 cancer mutants. Oncogene 27, 3501-3507.

Xue, C., Haber, M., Flemming, C., Marshall, G. M., Lock, R. B., Mackenzie, K. L., et al. (2007). p53 determines multidrug sensitivity of childhood neuroblastoma. Cancer Res. 67, 10351-10360.

Yamakuchi, M., Lotterman, C. D., Bao, C., Hruban, R. H., Karim, B., Mendell, J. T., et al. (2010). P53induced microRNA-107 inhibits HIF-1 and tumor angiogenesis. Proc. Natl. Acad. Sci. U.S.A. 107, 6334-6339.

Yang, B., Du, Z., Gao, Y. T., Lou, C., Zhang, S. G., Bai, T., et al. (2010). Methylation of Dickkopf-3 as a prognostic factor in cirrhosis-related hepatocellular carcinoma. World J. Gastroenterol. 16, 755-763.

Yang, Z. R., Dong, W. G., Lei, X. F., Liu, M., and Liu, Q. S. (2012). Overexpression of Dickkopf-3 induces apoptosis through mitochondrial pathway in human colon cancer. World J. Gastroenterol. 18, 1590-1601.

Yeh, K. H., Kondo, T., Zheng, J., Tsvetkov, L. M., Blair, J., and Zhang, H. (2001). The F-box protein SKP2 binds to the phosphorylated threonine 380 in cyclin $\mathrm{E}$ and regulates ubiquitindependent degradation of cyclin E. Biochem. Biophys. Res. Commun. 281, 884-890.

Yokoi, S., Yasui, K., Iizasa, T., Takahashi, T., Fujisawa, T., and Inazawa,
J. (2003). Down-regulation of SKP2 induces apoptosis in lungcancer cells. Cancer Sci. 94 344-349.

Yokoi, S., Yasui, K., Mori, M., Iizasa, T., Fujisawa, T., and Inazawa, J. (2004). Amplification and overexpression of SKP2 are associated with metastasis of non-small-cell lung cancers to lymph nodes. Am. J. Pathol. 165 175-180.

Yu, J., Tao, Q., Cheng, Y. Y., Lee, K. Y., Ng, S. S., Cheung, K. F., et al. (2009). Promoter methylation of the Wnt/betacatenin signaling antagonist Dkk3 is associated with poor survival in gastric cancer. Cancer 115, 49-60.

Yu, Z. K., Gervais, J. L., and Zhang, H. (1998). Human CUL-1 associates with the SKP1/SKP2 complex and regulates $\mathrm{p} 21(\mathrm{CIP} 1 / \mathrm{WAF} 1)$ and cyclin D proteins. Proc. Natl. Acad. Sci. U.S.A. 95, 11324-11329.

Yuan, Y., Liao, Y. M., Hsueh, C. T., and Mirshahidi, H. R. (2011). Novel targeted therapeutics: inhibitors of MDM2, ALK and PARP. J. Hematol. Oncol. 4, 16.

Yue, W., Sun, Q., Dacic, S., Landreneau, R. J., Siegfried, J. M., Yu, J., et al. (2008). Downregulation of Dkk3 activates beta-catenin/TCF-4 signaling in lung cancer. Carcinogenesis 29 84-92.

Yung, Y., Walker, J. L., Roberts, J. M., and Assoian, R. K. (2007). A Skp2 autoinduction loop and restriction point control. J. Cell Biol. 178, 741-747.

Zeller, K. I., Jegga, A. G., Aronow, B. J., O'Donnell, K. A., and Dang, C. V. (2003). An integrated database of genes responsive to the Myc oncogenic transcription factor: identification of direct genomic targets. Genome Biol. 4, R69.

Zhang, H., Kobayashi, R., Galaktionov, K., and Beach, D. (1995). p19Skp1 and $455 \mathrm{Sp} 2$ are essential elements of the cyclin A-CDK2 S phase kinase. Cell 82, 915-925.

Zhang, J., Chen, S., Zhang, W., Zhang, J., Liu, X., Shi, H., et al. (2008). Human differentiation-related gene NDRG1 is a Myc downstream-regulated gene that is repressed by Myc on the core promoter region. Gene 417, 5-12.

Zhang, J., Li, F., Liu, X., Shen, L., Liu, J., Su, J., et al. (2006). The repression of human differentiationrelated gene NDRG2 expression by Myc via Miz-1-dependent interaction with the NDRG2 core promoter. J. Biol. Chem. 281, 39159-39168.

Zhang, L., Li, K., Lv, Z., Xiao, X., and Zheng, J. (2009). The effect on cell growth by Wntl RNAi in human neuroblastoma SH-SY5Y cell line. Pediatr. Surg. Int. 25, 1065-1071.

Zhang, L., and Wang, C. (2006). F-box protein Skp2: a novel transcriptional target of E2F. Oncogene 25, 2615-2627.

Zhang, Y., Xiong, Y., and Yarbrough, W. G. (1998). ARF promotes MDM2 degradation and stabilizes p53: ARFINK4a locus deletion impairs both the $\mathrm{Rb}$ and $\mathrm{p} 53$ tumor suppression pathways. Cell 92, 725-734.

Zheng, N., Schulman, B. A., Song, L., Miller, J. J., Jeffrey, P. D., Wang, P., et al. (2002). Structure of the CullRbx1-Skp1-F boxSkp2 SCF ubiquitin ligase complex. Nature 416, 703-709.

Zindy, F., Eischen, C. M., Randle, D. H., Kamijo, T., Cleveland, J. L., Sherr, C. J., et al. (1998). Myc signaling via the ARF tumor suppressor regulates p53-dependent apoptosis and immortalization. Genes Dev. 12, 2424-2433.

Zuo, T., Liu, R., Zhang, H., Chang, X., Liu, Y., Wang, L., et al. (2007). FOXP3 is a novel transcriptional repressor for the breast cancer oncogene SKP2. J. Clin. Invest. 117, 3765-3773.

Conflict of Interest Statement: The authors declare that the research was conducted in the absence of any commercial or financial relationships that could be construed as a potential conflict of interest.

Received: 30 August 2012; accepted: 01 November 2012; published online: 28 November 2012.

Citation: Chen L and Tweddle DA (2012) p53, SKP2, and DKK3 as MYCN target genes and their potential therapeutic significance. Front. Oncol. 2:173. doi: 10.3389/fonc. 2012.00173

This article was submitted to Frontiers in Cancer Molecular Targets and Therapeutics, a specialty of Frontiers in Oncology. Copyright (c) 2012 Chen and Tweddle. This is an open-access article distributed under the terms of the Creative Commons Attribution License, which permits use, distribution and reproduction in other forums, provided the original authors and source are credited and subject to any copyright notices concerning any third-party graphics etc. 